\title{
Disclaimer:
}

This report was prepared as an account of work sponsored by an agency of the United States Government. Neither the United States Government nor any agency thereof, nor any of their employees, makes any warranty, express or implied, or assumes any legal liability or responsibility for the accuracy, completeness, or usefulness of any information, apparatus, product, or process disclosed, or represents that its use would not infringe privately owned rights. Reference herein to any specific commercial product, process, or service by trade name, trademark, manufacturer, or otherwise does not necessarily constitute or imply its endorsement, recommendation, or favoring by the United States Government or any agency thereof. The views and opinions of authors expressed herein do not necessarily state or reflect those of the United States Government or any agency thereof.

\section{Title: Geo-Engineering Modeling through INternet Informatics (GEMINI)}

Cooperative Agreement No.:

Contractor Name and Address:

Date of Report:

Award Date:

DOE Cost of Project:

Principal Investigators:

Project Manager:

Reporting Period:
$D E-F C 26-00 B C 15310$

The University of Kansas Center for Research Inc.

January 16, 2003

September 25, 2000

\$ 877,271 (Budget Period 10/01/00 - 09/30/03)

John H. Doveton

W. Lynn Watney

Daniel J. Ferguson, NPTO Tulsa, Oklahoma

Year 2 Annual Report, October 1, 2001-September 30, 2002

Kansas Geological Survey Staff Involved with GEMINI Project:

W. Lynn Watney, PI, petroleum geology

John H. Doveton, Co-PI, Log Petrophysics

John R. Victorine, Lead Programmer

Geoffrey C. Bohling, Co-PI, Mathematical Geologist \& Programmer

Saibal Bhattacharya, Co-PI, Petroleum Engineer

Alan P. Byrnes, Rock Petrophysicist

Timothy R. Carr, Co-PI, Petroleum Geologist

Martin K. Dubois, Petroleum Geologist

Glen Gagnon, Programmer

Willard J. Guy, Log Petrophysicist

Kurt Look, Co-PI, Systems Programmer

Mike Magnuson, Analyst for Rock Petrophysics Lab

Melissa Moore, Data Manager

Ricardo Olea, Mathematical Geologist

Jayprakash Pakalapadi, Programmer

Ken Stalder, Web programmer, geologist

Participating Companies and corresponding staff members:

Mr. Henry DeWitt, Anadarko Petroleum Corporation, 17001 Northchase, Houston, TX 77060

Mr. Richard P. Dixon, (MC 3.414), Post Office Box 3092, BP, Houston, TX

Mr. Philip Van De Verg, Phillips Petroleum Company, 249B Geoscience Building, Bartlesville, OK 74004

Mr. Mark Shreve, Mull Drilling Company, Inc., 221 N. Main, Suite 300, Wichita, KS 67202

Mr. Scott Robinson, Murfin Drilling Company, Inc., 250 N. Water, Suite 300, Wichita, KS 67202

Mr. Louis Goldstein, Pioneer Resources Company, 5205 N. O'Connor Blvd., Suite 1400, Irving, TX 75039-3746 


\section{Table of Contents}

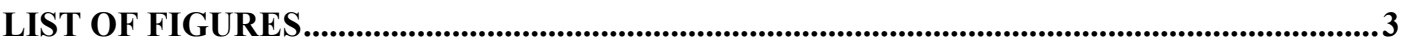

INTRODUCTION ........................................................................................................... 7

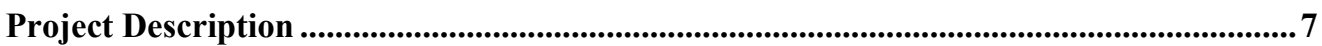

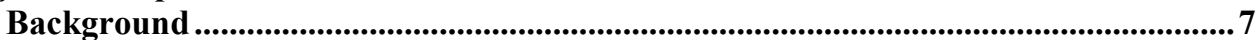

Work Performed ........................................................................................................... 7

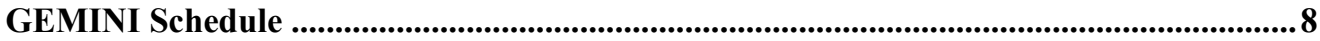

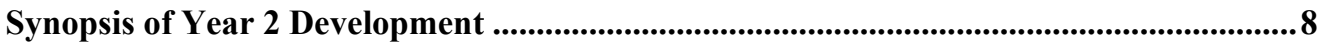

TASK 1. DESIGN PROJECT INTERFACE ....................................................................19

Subtask 1.2. Implement a phased development strategy and schedule ......................19

1.2.1. User/Project Module Development ............................................................19

1.2.2. Project Workflow ................................................................................................. 21

TASK 2. RESERVOIR CHARACTERIZATION..................................................................21

Subtask 2.1. Parameter Definition ........................................................................21

2.1.1. Well Profile Module.........................................................................................21

Subtask 2.2. Petrophysical Modeling .........................................................................224

2.2.1. PfEFFER Log Analysis Module ....................................................................24

2.2.2. GEMINI Rock Catalog .....................................................................29

Subtask 2.3. Geomodel Development ...............................................................................33

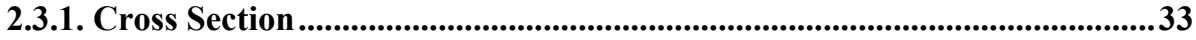

2.3.2. KHAN (Kansas Hydrocarbon Association Navigator .................................36

TASK 3. GEO-ENGINEERING MODELING...................................................................... 38

Subtask 3.1. Volumetrics Module..........................................................................38

3.1.1. Production Bubble Maps ................................................................................ 42

Subtask 3.2. Material Balance Module ......................................................................... 43

Subtask 3.3. Parameterization for Reservoir Simulation ..............................................43

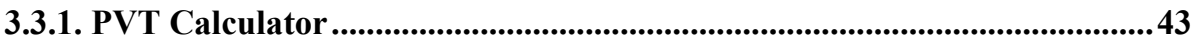

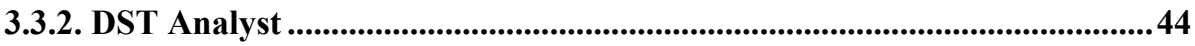

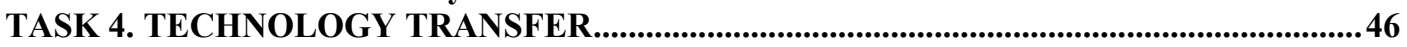

Subtask 4.1. Project Application and Testing ............................................................. 46

4.1.1. Industry Partners Affiliated with GEMINI .........................................46

4.1.2. Exploration Application of GEMINI ..........................................................46

4.1.3. Technology Transfer Opportunities.........................................................51

Subtask 4.2. Concepts and Tutorial ...............................................................52

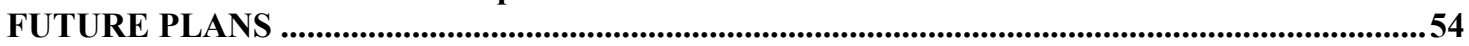

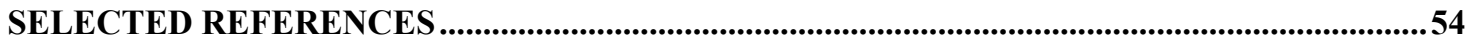




\section{LIST OF FIGURES}

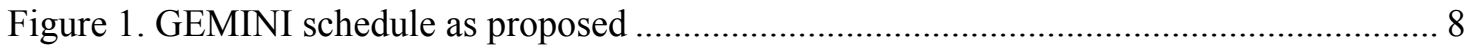

Figure 2. Reservoir characterization and modeling incorporates observations

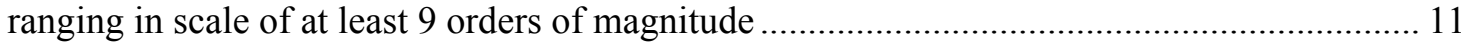

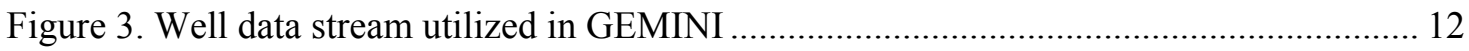

Figure 4. Dialog for DST analyst including worksheet that can be used to manually enter time pressure data

Figure 5. The basic software framework for GEMINI software and data exchange between the server, database, and user/client....

Figure 6. Modular software development in GEMINI showing grouping of modules by well level and field level, and rock and fluid catalogs and calculators

Figure 7. Applet dialog for user to choose particular module. Modules are organized by well level analyses, field level analyses, and catalogs and calculators. Blue color indicates completed module, green represents nearly completed for release, and red indicates work in progress

Figure 8. Opening browser dialog. User clicks on $<$ Log on to GEMINI $>$ button to begin a session. Browser can be used to negotiate GEMINI or examine reports and developments in GEMINI

Figure 9. Map interface showing wells in Stanton County that reside on the Oracle database at the Kansas Geological. Interface is used to select wells to include in a project on Arroyo Field in Stanton County. Map shows wells highlighted from Arroyo Field. Other fields can also be filtered using this dialog by clicking on the field in the upper right box. Wells can be further filtered based on other database information including whether they have LAS files, core data, core images, and DST data. The lower dialog is another option to view the wells in tabular form where Arroyo Field wells are highlighted. Wells can be selected or deleted into a project as needed

Figure 10. Prototype LAS upload dialog used to add digital LAS wireline logs to a project from the user's computer. Procedure also permits setting the well file as confidential for up to two years from the completion date of the well that is consistent with the rules of the Kansas Corporation Commission. The users provide information that is in the header of the $\log$..

Figure 11. Dialog showing project for Arroyo Field demonstration. The users who share the project are listed along with the list of wells included in the project. The user can add or remove wells and enter petrophysics and multi-well analyses from this dialog....

Figure 12. Dialog used in Well Profile to select depth interval, depth scale, curve type and tracks, formation tops database, core data to display, and quick look log analysis (saturation parameters such as Sw using PfEFFER). Once complete, user then sets plot limits which include scales in tracks and color of curves 
Figure 13. Screen capture of dialog showing Well Profile including core data plotted as small circles and location of core images along right margin

Figure 14. When mouse is clicked in an active log window, a pop-up windows appears that is used to add formation tops, set intervals for PfEFFER (log analysis), and establish perforated and DST interval.....

Figure 15. Annotated plot of LAS digital log from Kendrick 22-1 showing three sand lobes $(\mathrm{a}, \mathrm{b}, \mathrm{c})$ in the Lower Morrow Sandstone from Arroyo Field. Log display includes perforated interval (small connected red circles on left side of the depth track). The logging track on right side (track 4) is a quick-look water saturation. Log can be printed to scale through web browser. Labels of log types and scales from GEMINI are not shown in this example

Figure 16. Pickett crossplot with contours of water saturation in blue and bulk water volume shown in red. Points are color coded by depth as shown on legend. Clusters of points are noted labeled $a, b$, and c, corresponding to three stacked sandstone reservoirs shown on $\log$ in Figure 9

Figure 17. Well information and well parameter dialogs including key information about well and reservoir. Dialog also provides entry point to various activities in the log analysis module. Upcoming option will be to download reservoir parameters to a file to use in other applications.

Figure 18. Pickett crossplots for each of five layers (on previous page) comprising a Lower Morrow sandstone reservoir in Huber \#28-1 Lauman well. Depth plot of logs from reservoir interval shown at bottom of figure

Figure 19. Several dialogs shown were created during development of a lithology solution using the rhomaa-umaa option in PfEFFER. Both a triangular composition plot and a depth-plot of compositions are generated. The user can interact with the solution to tailor results to the particular lithofacies.

Figure 20. Zonation of a reservoir by depth-constrained cluster analysis, an activity available in PfEFFER log analysis. User defines logs curves to use in the cluster analysis and the number of zones to calculate for the dendrogram as shown along right margin of the depth plot. User selects the number of zones to block for the selected log curves......

Figure 21. Upper dialog from Rock Catalog Module shows a cross plot between the porosity and permeability for two lithologies. It is clear in this comparison that the packgrainstone fabric is more permeable than the mud-wackestone lithofacies. The lower dialog shows a core image.

Figure 22. Table rock catalog data table

Figure 23. Example construction of a cross-plot in Rock Catalog 
Figure 24. JPEG version of a structural cross section generated in the Cross Section Module showing correlation lines between formation tops read by GEMINI from the database and color-filled layers of five layers that subdivide the sandstone. User has full control of the $\log$ curves, $\log$ annotations, scales, colors, and datums. In this illustration, the index map and larger sized labels were added to highlight features of cross section.

Figure 25. JPEG version of northwest-southeast stratigraphic cross section generated using the Cross Section Module of GEMINI. The section has been further annotated with arrows to show location of stratigraphic datum above the sandstone, index map of cross section, and title and description information

Figure 26. Cross-section dialog window showing portion of a southwest to northeast cross with a stratigraphic datum above the Lower Morrow sandstone. Arrows are added to emphasize the stratigraphic datum and an inset map showing cross section location in the context of other wells in the project.

Figure 27. Electrofacies probability plot alongside well logs used in making the classification.

Figure 28. Selected dialogs generated in Volumetrics: A) list of well data with reservoir parameters used in volumetric calculations; B) gridding parameters for zone 9 (note users sets grid spacing); C) volumetric calculation of mobile oil in zone 9 using irreducible oil saturation of 0.3; and map above -- colored volumetric grid cells for zone 9 showing original-oil- in-place, triangles added to show wells that are perforated in zone 9.

Figure 29. Base map identifying wells in project with well symbol as explained in legend beneath the map.

Figure 30. Parameter maps for Zone 5 in the Lower Morrow Sandstone in Arroyo Field, Kansas. Values derived from PfEFFER log analysis. Net pay uses cut-offs for water saturation, porosity, bulk volume water, and shale fraction. Average values of porosity and water saturation are derived from the effective pay. Grid size and interpolation functions are selected by the user. Colors table also selected by the user.

Figure 31. Set of maps from Arroyo Field showing original-oil-in-place (OOIP) for four of five layers. Grid cell size is 1000 feet. Darker, hotter colors reflect greater oil in place. Triangles indicated wells completed in particular layer/zone. Note well location in zone 3 is an opportunity for recompletion, if it can be further assessed that adjoining layers are not communicating with this interval.

Figure 32. Example of a bubble map of same project area as preceeding maps showing cumulative lease production.

Figure 33. Example dialogs from the PVT Module.

Figure 34. Selected dialogs from prototype DST Module showing those that help the user choose a particular test to analyze, examine table of pressure data and resulting Horner Plot, and obtain calculations of $\mathrm{Pi}, \mathrm{M}$, and flow rate. Time and pressure data can be typed into the spreadsheet by the user, if the DST is not in digital form. 
Figure 35. LAS dataset used in Haskell County to test use of GEMINI in an exploratory concept, defining prospective pay over large stratigraphic interval, subregional area, and using moderate sized LAS well database. Bypassed and underproduced pay are believed to be abundant in the stratigraphic interval examined.

Figure 36. Example log profile of a well from the Haskell County database showing 800 $\mathrm{ft}$ stratigraphic interval that is the target of the exploratory example. BVW and porosity are plotted together in track 4 as a quick look technique to spot log shows. Specifically, low BVW relative to porosity is inferred as a "log show", delimited in this example by the blue arrows.

Figure 37. Dialog windows from PfEFFER log analysis showing reservoir cut-off parameters and Pickett crossplot of the total interval covering $855 \mathrm{ft}$ of Middle and Upper Pennsylvanian cyclic carbonates.

Figure 38. Depth-filtered Pickett crossplots examining potential pay zones.

Figure 39. Pickett crossplot for entire 855-foot interval in new well exhibiting points with low Sw, relatively low BVW, and high porosity that may represent hydrocarbon pay. KHAN software would be used to automate the process of isolating these potential pays in this well and the other 100 LAS files in the project. Alternatively, the user can progress through the depth filtering and manually isolate potential pay zones.

Figure 40. Structural wireline log cross section highlighting 800+ ft thick Middle and Upper Pennsylvanian interval in Haskell County, Kansas. Base map in lower middle showing project area, 100 wells included in the project, and cross section index. Stratigraphic Interval consists of cyclic carbonate-dominated intervals. Plans are to automate pay detection based on KHAN module utilizing LAS files used to construct this or all 100 wells included in this project.

Figure 41. Example of interactive concepts web page used to understand background of GEMINI Modules. Web pages are indexed and linked back to modules for quick reference by user activating Help while using the program.

Figure 42. Page from Tutorial/Step-by-Step showing how to add colors to layers in construction of a cross section. 


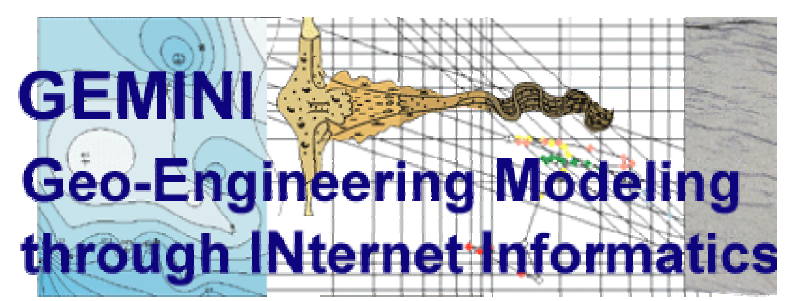

1. INTRODUCTION

\section{Project Description}

\section{Background}

Utilization of improved recovery technologies could add significantly to the U.S. energy supply. In reservoir management, consistent, quantitative characterization and modeling of reservoirs are essential to make decisions on application of the most appropriate technology. Implementing this type of modeling is often not practical because of limitation of software, staff, and expertise. GEMINI (Geo-Engineering Modeling through Internet Informatics) will harness existing expertise and resources of the Kansas Geological Survey to provide efficient, interactive access to data and software modeling tools when and wherever it is needed. GEMINI will integrate extensive petroleum and petrophysical databases associated with the DOE-funded Northern Mid-Continent Digital Petroleum Atlas (DPA) (http://crude2.kgs.ukans.edu/DPA/dpaHome.html). GEMINI is being built on experience gained in software development provided through the DOEfunded PfEFFER (Petrofacies Evaluation of Formations for Engineering Reservoirs) software (http://crude2.kgs.ukans.edu/PRS/software/pfeffer1.html. GEMINI will resolve reservoir parameters that control well performance; characterize subtle reservoir properties important in understanding and modeling hydrocarbon pore volume and fluid flow; expedite recognition of bypassed, subtle, and complex oil and gas reservoirs at regional and local scale; differentiate commingled reservoirs; build integrated geologic and engineering model based on real-time, iterative solutions to evaluate reservoir management options for improved recovery; provide practical tools to assist the geoscientist, engineer, and petroleum operator in making their tasks more efficient and effective; enable evaluations to be made at different scales, ranging from individual well, through lease, field, to play and region (scalable information infrastructure); and provide training and technology transfer to elevate capabilities of the client.

\section{Work Performed}

The program, for development and methodologies, is a 3-year interdisciplinary effort to develop an interactive, integrated Internet Website named GEMINI (GeoEngineering Modeling through Internet Informatics) that will build real-time geo- 
engineering reservoir models for the Internet using the latest technology in Web applications. The client would be able to retrieve databases, upload information, and run software interactively using the intelligent interfaces that will efficiently assemble a project based on the definition of a three-dimensional data volume. Analytical software operating on the assembled data and results will be delivered to the client through the web pages. System informatics, consisting of the network, software, data, and tutorial components, will permit the client to develop any number of projects. Analytical components of GEMINI include assembling fluid and rock parameters, basic and enhanced wireline log interpretation, spatial analysis and visualization, volumetrics, material balance, and specific parameterization and formatting of these results suited for input into reservoir simulation software. A tutorial module will instruct clients on theory, application of analytical tools, and operation of GEMINI. Participating major and independent companies will provide information and expertise to provide feedback during the development process

\section{GEMINI Schedule}

The schedule for the GEMINI Project as proposed is divided into five tasks as described in Figure 1.

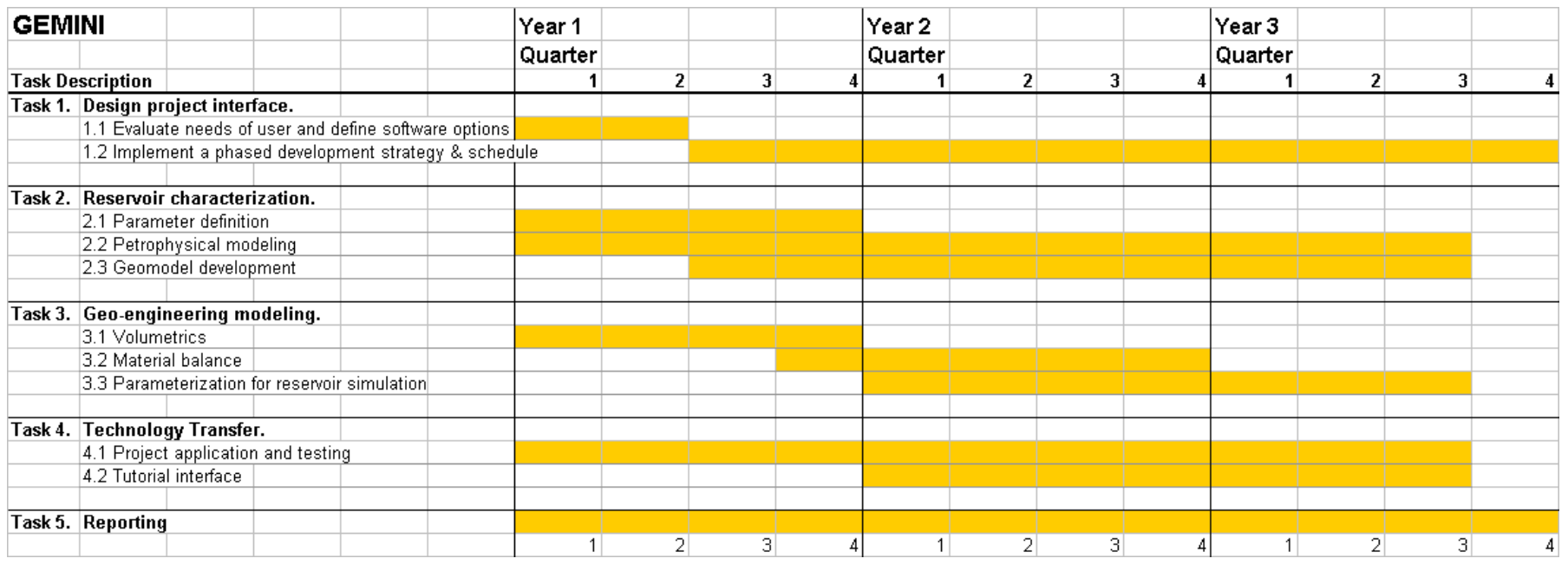

Figure 1. GEMINI schedule as proposed.

\section{Synopsis of Year 2 Development}

GEMINI (Geo-Engineering Modeling through INternet Informatics) is a public domain, interactive, integrated Internet web application that provides a suite of userfriendly geologic and engineering software, calculators, and utility programs designed to facilitate real-time geologic and engineering petroleum reservoir modeling. Digital data 
obtained from the Kansas Geological Survey and the user are assembled "on the fly". Compilation of data, calculations, and models are maintained as a project on the Internet server where reports and data files can be downloaded at anytime and location with an Internet connection. Projects and data uploaded into the project are password protected.

GEMINI is being developed by the Kansas Geological Survey (KGS) (http://www.kgs.ukans.edu/Gemini/index.html), over a 3-year period between September 2000- September 2003, funded provided by the U.S. Department of Energy (Contract No. DE-FG26-00BC15310). Six companies are providing data and expertise to test and evaluate the software including: Anadarko Production Corporation, BP-Amoco, ConocoPhillips, Lario Petroleum, Mull Drilling Company, Murfin Drilling Company, and Pioneer Resources.

Current prototype modules in GEMINI perform many functions useful in everyday petroleum reservoir characterization and modeling including software to view, annotate, and analyze digital well logs. GEMINI provides an integrated solution of effective pay utilizing core, well log, and test data. Software tools are available to construct cross sections and maps, to analyze DST tests, to assemble reservoir parameters, to compare reservoir models with production bubble maps, and to perform volumetric and material balance calculations.

Geo-engineering modeling as used in GEMINI is a process comprised of integrated log, core, and well test analyses followed by iteratively solving volumetric and material balance calculations (Bhattacharya et al., 1999). Calculators and catalogs are provided to obtain reservoir and fluid parameters needed in modeling. The goals of GEMINI are to: 1) provide real-time, interactive analyses of the petroleum reservoir, 2) quantitatively model reservoir heterogeneity, 3 ) estimate recoverable hydrocarbons, 4) target locations in the reservoir best suited for further development, 5) provide reliable quantitative information for more informed reservoir management, 6) obtain reservoir and fluid parameters for subsequent reservoir fluid flow simulation, and 7) screen wells for subtle, overlooked or bypassed pay from both exploration and development perspective. Answers in GEMINI are delivered to the user interactively via the Internet where application tools and data reside in projects developed on the Internet. The objective is to rapidly establish a project, assemble information, and develop simple geoengineering models to determine appropriate methods and technologies to improve oil and gas recovery. As an exploration application, GEMINI can be used to process and statistically model large amounts of digital log data to target prospective reservoirs suited for further evaluation. Small independent operators are the key clients identified for this technology, providing tools that are similar to those used by large independents and major oil companies.

The reservoir model is closely calibrated to the reservoir's petrofacies defined as a combination of lithofacies and pore type with characteristic and constrained variations in petrophysical properties. Evaluation of the type and distribution of pores and related fluid saturation is increasingly an essential task to reevaluate mature oil and gas fields where the objective is to develop underproduced and bypassed reserves. Smaller and often 
subtle pays remain due to reservoir complexities that caused them to be overlooked initially. A relational rock catalog in GEMINI provides a means to perform analyze core data and integrate results with wireline log analysis to establish correlations between rock petrofacies and petrophysical response and improve accuracy of hydrocarbon volume, affecting the economic decisions based on these results.

Limited volumes of reservoir are typically sought in redevelopment of mature oil and gas fields. Thus, extensive or complex quantitative modeling of the reservoir is impractical and uneconomic (Bhattacharya et al., 1999; Watney et al. 1999; Doveton et al 2000). Simple, petrophysically-based models are best suited for small reservoir systems and are believed to be quite adequate for reservoir management, particularly when petrophysical models, volumetric analysis and material balance calculations are integrated and accessed interactively.

Activities in development of fields and exploration plays can both benefit from application of simple, efficient approaches to geologic and engineering modeling. Data assembly and software tools are provided in GEMINI, tailored to help small oil and gas operators and consultants. The ultimate goal of the project is to maintain a viable petroleum economy and infrastructure in mature oil and gas producing areas.

Targeted users are companies and consultants who seek to develop remaining oil and gas reserves in mature oil and gas provinces like Kansas. Cost-effective, efficient, and reliable means are essential to rapidly assemble and analyze well, lease, field, and even reservoir play information. Integrated information handling and software tools are used to resolve, correlate, and map reservoir pay. Help and tutorial functions assist the user in operation of GEMINI. A new feature in development for 2003 WorkFlow. This coupled with report generator will facilitate progressive collaborative solutions that can be revised as new data and ideas are realized.

GEMINI is being developed to address opportunities to facilitate quantitative reservoir evaluation in smaller, mature oil and gas fields in the domestic U.S. (Table 1 and 2). 


\section{Table 1. Operational opportunities in reservoir modeling:}

- Leverage company data through integration with large well and spatial information that is in the public domain

- Provide suite of user-friendly integrated software tools that are linked to the data to provide rapid analysis and modeling

- Create password protected, on-line projects where data are assembled, software is applied, and results maintained

- Facilitate collaboration between team members wherever they are located

- Overcome time, data, and software issues to go from using no model at all in making decisions about improving oil and gas recovery to development of simple, quantitative models to improve the success in decision making

- Provide for iterative solutions utilizing petrophysical reservoir modeling, volumetrics, and material balance

\section{Table 2. Fundamental issues in reservoir characterization addressed by GEMINI:}

- Reservoir characterization is data intensive and multi-scaled problem

- Definition, correlation, and distribution of properties to create a reservoir model ideally involve a combined geologic and engineering effort

- Constraint and validation of geologic and engineering models, e.g., volumetric assessment, requires an iterative petrophysical solution

- Reservoir mapping and modeling require efficient access to a host of reservoir data in order to maximize time and target opportunities

Reservoir characterization and modeling requires assimilation of at wide range of observations into a coherent quantitative view that is consistent with the data assembled and accurate (Figure 2). Anything less will fail to provide reliable outcomes and negate the time and expense put into modeling. An optimum approach in modeling is to also make the effort consistent with the size of the reservoir and economic outcome.

\section{RESERVOIR ANALYSIS TOOLS PORE TO RESERVOIR}

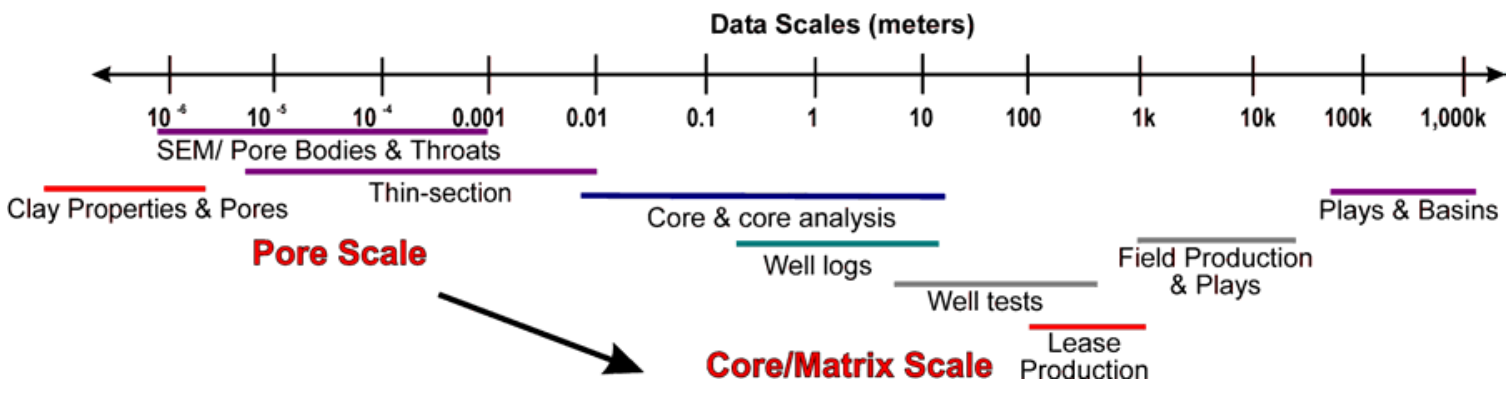

Figure 2. Reservoir characterization and modeling incorporates observations ranging in scale of at least 9 orders of magnitude. 
The project interface has changed over the year reflecting new modules and enhancements made to them. The flow has also been modified to make negotiation of GEMINI increasingly user-friendly directed toward compiling well data and running software modules in the context of wells that are part of a defined project. Access to projects is password-protected. A user might establish a project for analysis, becoming the project owner, and, in turn, share it as read-only or permit full read and write capability. The data, analyses, and results that are maintained in a GEMINI project can be updated or retrieved and downloaded as electronic reports, images and charts, and electronic data files, the later permitting further analysis using other software.

Well data are assembled by GEMINI through dialog and map interfaces that, in turn, access networked computer servers at the Kansas Geological Survey where the data is stored. Data types assembled in GEMINI are typical suite that is available online or residing with the user (Figure 3). LAS (log ASCII standard) log files can now be uploaded for use in a project. Drillstem test (DST) analyses can be entered into the well database by typing in the information in a dialog (Figure 4). The user-friendly procedure to upload LAS data allows the user to specify confidentiality of the data for up to two years, a policy consistent with KCC regulations. The user also has the option to pass the file to a digital well log database for Kansas containing in excess of 5,000 wells. LAS files can be searched at (http://www.kgs.ku.edu/Magellan/Logs/index.html).

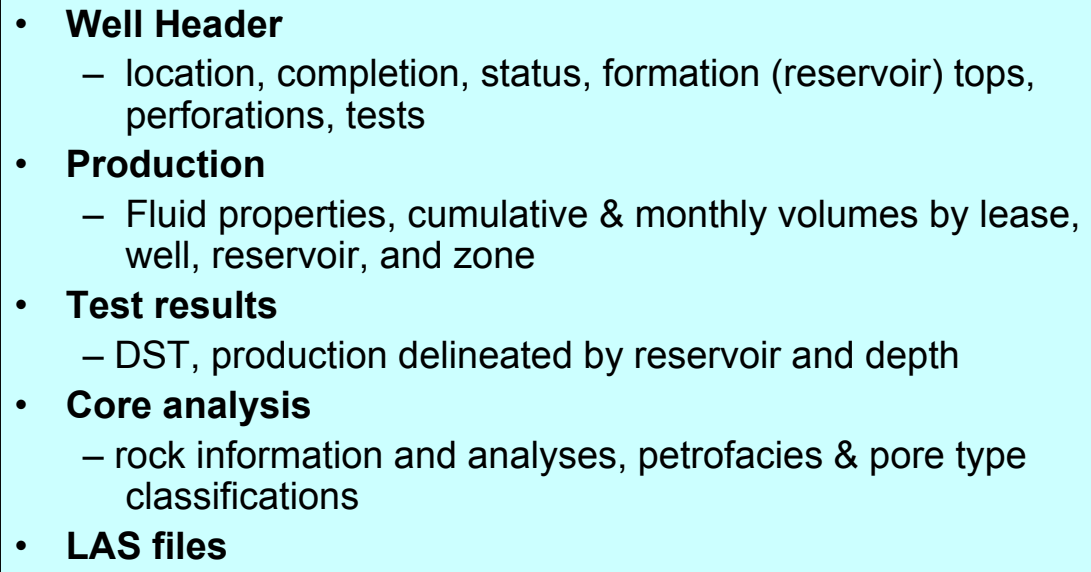

Figure 3. Well data stream utilized in GEMINI. 


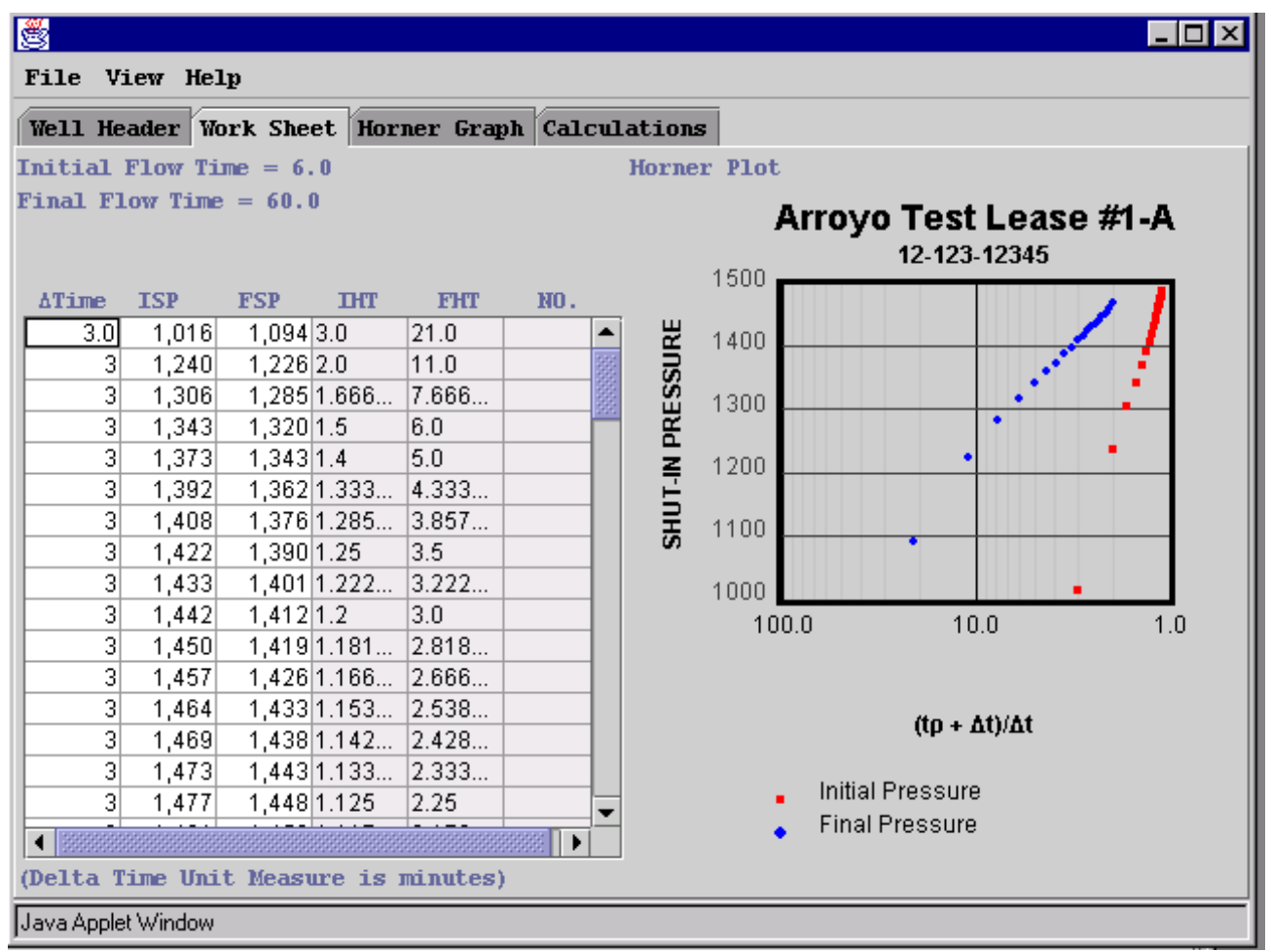

Figure 4. Dialog for DST analyst including worksheet that can be used to manually enter time pressure data.

Gemini has an application web site where the software is launched (http://www.kgs.ukans.edu/Gemini/index.html). Java applets using Swing (enhanced graphical user interface) are to used to display information. Java Servlets act as a bridge between the Client and the Server to access data and files (Figure 5). Each module in GEMINI is a stand-alone application that reduces the size of file transferred to the user and consequently the download time (Figure 6). Browser software is used to save and print output the output. Efforts continue to be made to increase the efficiencies and speed of the software.

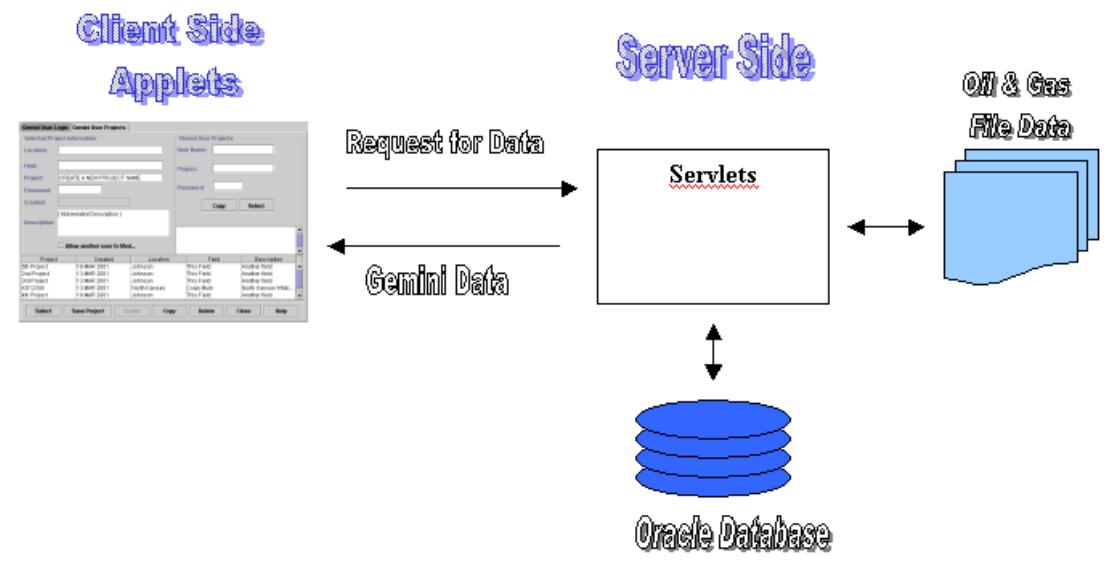

Figure. 5. The basic software framework for GEMINI software and data exchange between the server, database, and user/client. 


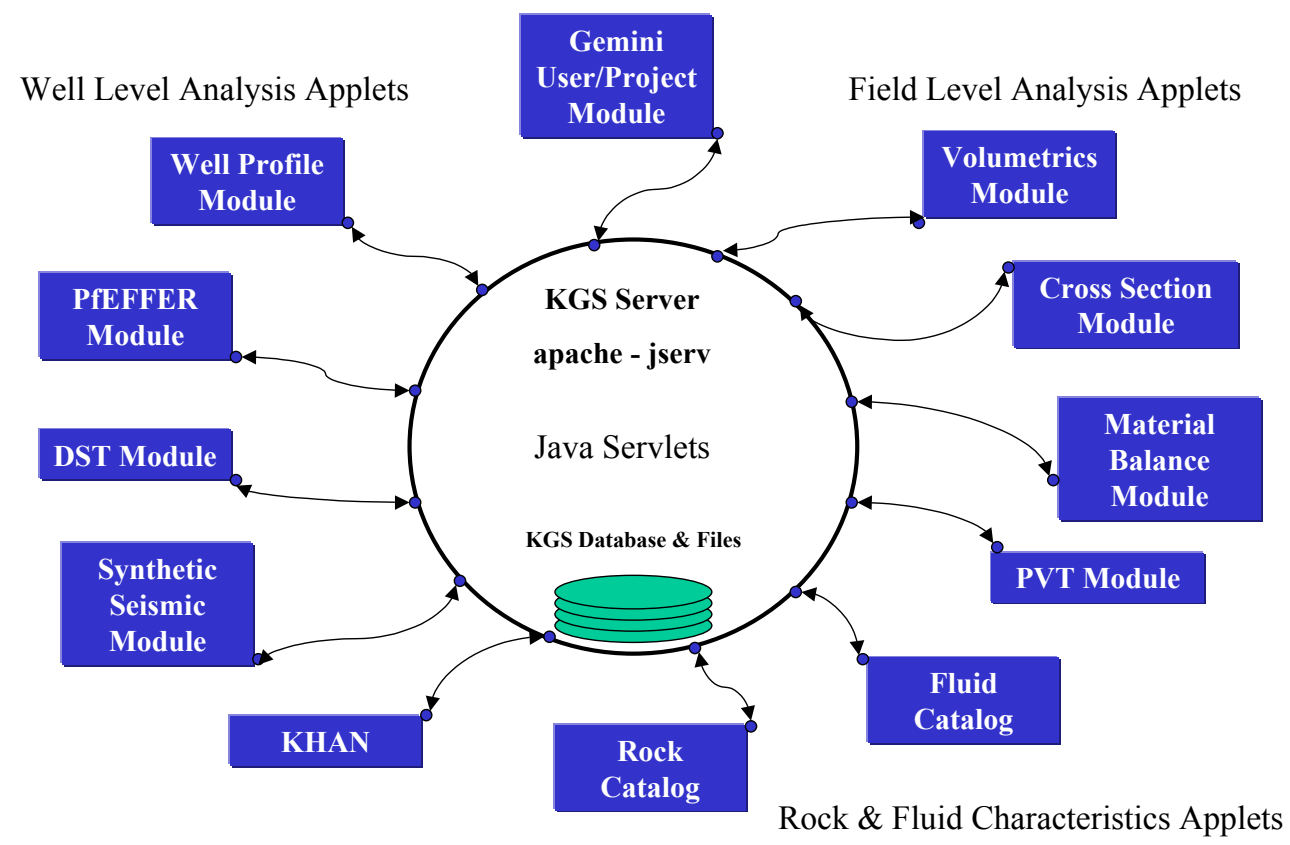

Figure 6. Modular software development in GEMINI showing grouping of modules by well level and field level, and rock and fluid catalogs and calculators

GEMINI Version 2.6 issued October 3, 2002 on the $2^{\text {nd }}$ anniversary of the project contains 502 Java Source Files, Applets, Servlets, Plot Classes, Math Model Classes, Java Swing Frames, Panels and Table Classes. The total number of lines of code is 157,209. In the course of development, the primary interface has evolved and been refined. The latest interface includes icons for all modules, catalogs, and calculators that are color-coded by status (Figure 7). 


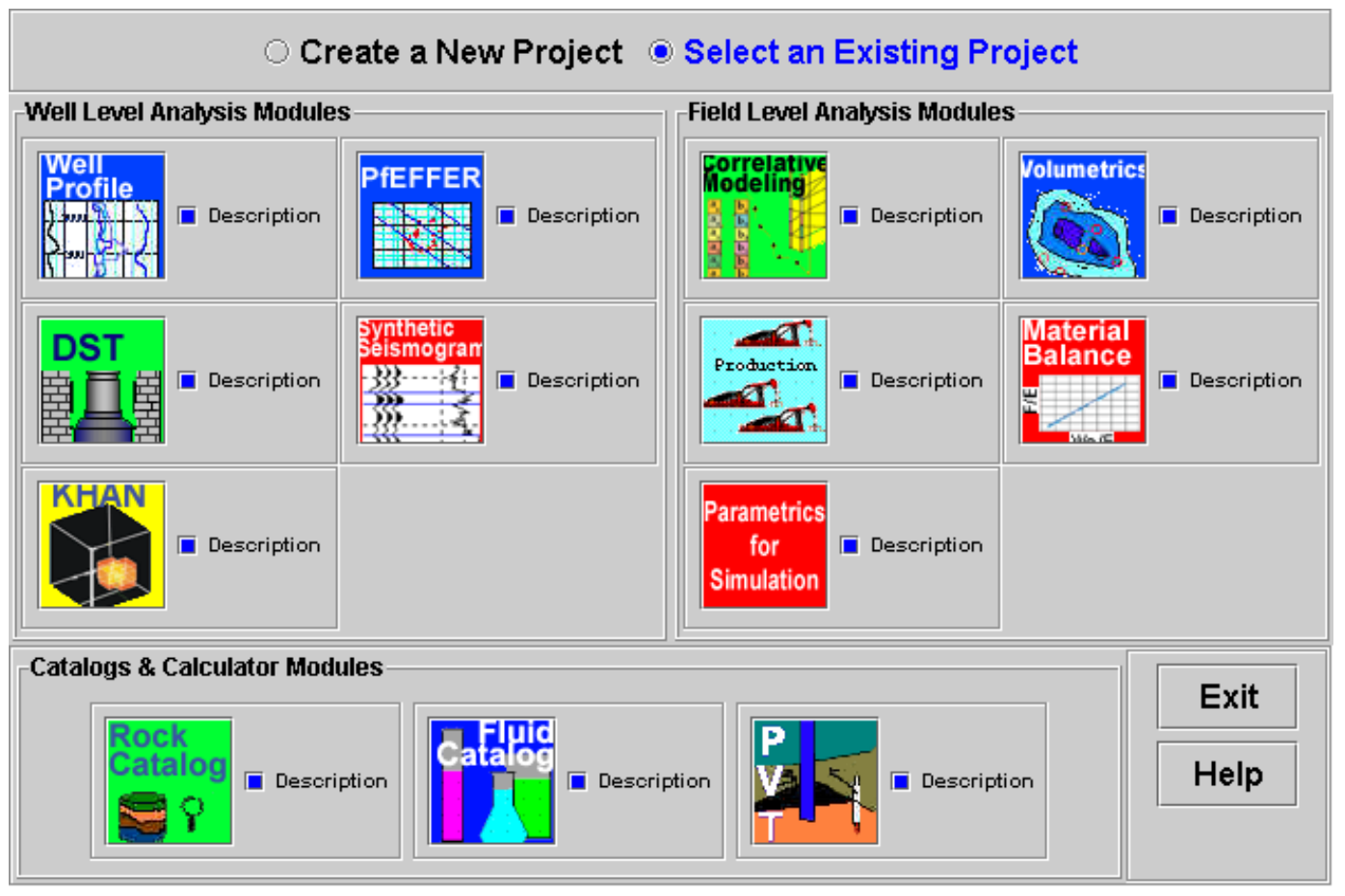

Figure 7. Applet dialog for user to choose particular module. Modules are organized by well level analyses, field level analyses, and catalogs and calculators. Blue color indicates completed module, green represents nearly completed for release, and red indicates work in progress.

The GEMINI website at http://www.kgs.ukans.edu/Gemini/index.html provides the entry point for users. This GEMINI prototype currently requires a Java 2 plug-in installed on the client's computer. The plug-in is obtained free from the Sun Microsystems website (http://java.sun.com/products/plugin/) as provided in a link in the GEMINI opening page.

Software modules in GEMINI are grouped into three categories: geological, engineering, and utilities (Figure 7). Current operational geological modules include: Well Profile, PfEFFER log analysis, and Cross Section. The completed engineering module is Volumetrics. This module includes assembly and mapping of reservoir parameters. The catalogs and calculators that are now available include Fluid and Rock catalogs and PVT calculator.

A new feature in Year 2 is the web browser that accompanies the Java applet windows that is used to guide the user through GEMINI (Figure 8). The browser pages also provide updates on reports, personnel, links, and access to more comprehensive help. An activity button is also present which the user activates to enter GEMINI. Task 1, Design of project interface, now follows. 


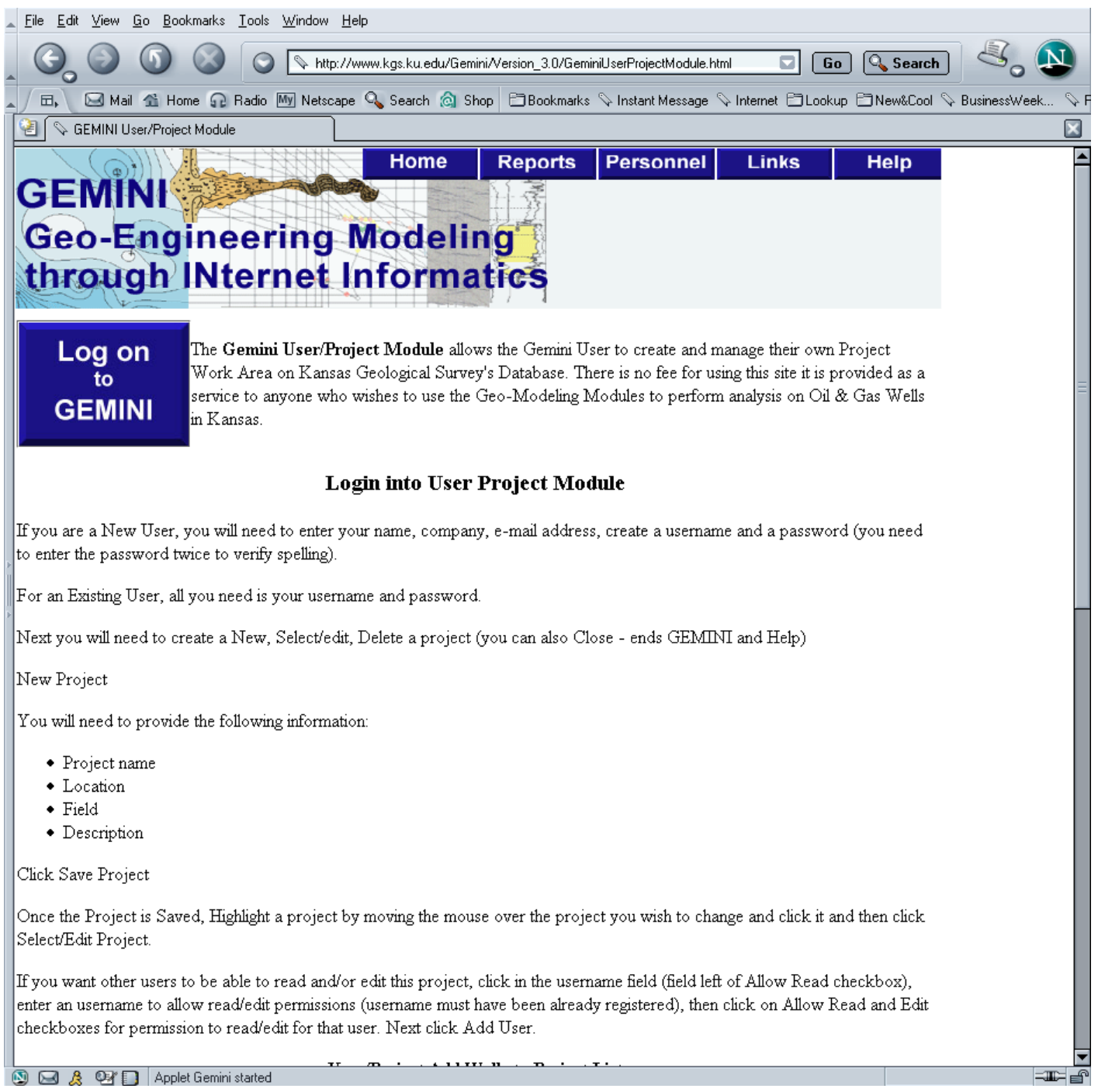

Figure 8. Opening browser dialog. User clicks on <Log on to GEMINI> button to begin a session. Browser can be used to negotiate GEMINI or examine reports and developments in GEMINI.

\section{Programming Considerations}

The first year of GEMINI Project focused on the design of the Application Web Site. A prototype of the GEMINI Application Web Site was created using Java Applets for the client side and Java Servlets for the server side. The first year was used to illustrate how GEMINI was going to work. Procedures for development of the modules were prepared. A detailed schedule was also prepared outlining the remaining tasks for the remaining 2 years of the contract.

Prototypes developed in the first year were converted in Year 2 to completed modules. The Volumetric and Rock Catalog Modules required a total redesign, including dialogs and functionality. Another full-time Java Programmer was hired to insure the completion of all the modules promised in the original contract. 
Releases of GEMINI in 2002. In moving from the prototype phase to the development phase, scripts were written to better build and release the GEMINI Modules. As each module was completed, a complete build and create was made of a new Version directory on the KGS Server with the following code:

○ GEMINI Modules

- HTML Files for each Module

- Applet JAR Files

○ Documentation Directory

- All the GEMINI Source Code

- Documentation Web Pages for each completed Module - These web pages consists of screen captures of the GEMINI Module dialogs with brief explanation of the different classes the module calls. The web pages have links to the Java Source Code as well as other web pages to illustrate other dialogs. This method provides a way to keep the source code in a common place for all developers and managers to have access to it.

- All Scripts used to build GEMINI Modules and Servlets

- The SQL Scripts to create the GEMINI Database Tables.

Version 2.0 - 29 January 2002

User/Project Module - This module allows the Gemini User to create and maintain their own workspace on the Kansas Geological Survey's database.

Kansas Well Location Module - This module allows the Gemini User the ability to select a well from a list of wells that are presently in the Kansas Geological Survey's database.

Upload LAS File Module - This module allows the Gemini User to upload any LAS Files and include that file within their project area. The Gemini User is then able to plot their LAS file with the Well Profile Module

\section{Version 2.2 - 7 March 2002}

New Gemini Application Web Page - Added links to all the modules developed for the GEMINI Project. The New Gemini Application Web Page will assist the Gemini User in navigating the Tools that are available to them in order to perform Well and Field Level Analysis on Oil and Gas Wells in Kansas.

PVT Calculator Module - Oil, Gas and Water Fluid Calculator.

Fluid Catalog Module - Search for brine analyses in Kansas, link to the DPA Web Site.

Version 2.2a - 19 March 2002

Login for Hugoton Tops Data -Well Profile Module now requires the user to log into the Hugoton Project area before access to the Tops.

Version 2.3 - 2 May 2002

PfEFFER Module - Completed the PfEFFER Module for Beta Testing. The PfEFFER Module is focused on interpreting and analyzing reservoir pore type, permeability trends, and variations in mineral composition. PfEFFER provides procedures for optimal estimation of bulk volume water and water saturation (including irreducible values) to better evaluate potential production, reservoir 
quality, and heterogeneity. Also capillary pressure data can be incorporated to further calibrate well log data with pore size or to assess depth to the free water level.

Version 2.4 - 25 June 2002

Volumetric Module - Completed the Volumetric Module for Beta Testing. An important application of the reservoir geomodel is the initial evaluation of reserves and the estimation of the volume of recoverable hydrocarbons. Volumetric-study offers an opportunity to evaluate the total production potential of the reservoir based on the petrophysical properties defined at each well.

Version 2.5 - 13 August 2002

DST Module (Prototype) - The drill stem test (DST) module is being developed to be able to access and process digital drill stem test data to compute permeability knowing the thickness of the zone being tested, obtain the reservoir pressure through a Horner Plot, and display fluid recoveries for use as an indication of initial production rates. Over 1000 digital DST files currently reside in the Kansas Geological Survey's Oracle database, information that was donated by Triolobite Testing.

Cross-Section Module (Prototype) - The Cross Section Module combines color image and conventional log curves that can be annotated. Correlation lines are also drawn. Wells are selected from a context-sensitive map.

Version 2.6 - 1 October 2002

Final Build \& Release in preparation for the Year End Review of GEMINI. Version 3.0 - 9 December 2002

Rock Catalog Module - The fundamental paradigm of the geologist, as it is in this digital rock catalog, is that rocks of similar lithology and basic properties exhibit similar petrophysical properties. In contrast to earlier rock catalogs, our digital version is presented in relational context, not limited to categorical data as previous attempts. GEMINI's rock catalog is project specific and relational in that type sample properties are shown within the context of other samples of similar type or within context of all samples for study. In other words, a sample can be compared to others to determine correlations and permit use of data models, e.g., permeability vs. porosity.

Volumetrics Module - Added the capability to download the contents of the Gridding and Volumetric Tables to a File that can be saved on the Users PC. Cross-Section - The Cross Section Module will combine color image and conventional log curves that can be annotated. Correlation lines are also drawn. Wells are selected from a context-sensitive map. 


\section{TASK 1. DESIGN PROJECT INTERFACE}

\section{Subtask 1.2. Implement a phased development strategy and schedule}

\subsubsection{User/Project Module Development}

User/Project is a utility module that establishes a project and assigned a user and password. This primary user is able to add or delete users who have permission to view or edit a project. A user can have multiple projects. The primary user is the manager of projects as they are developed. Interactive dialogs and maps are used to negotiate the public-domain database, select wells, and upload associated well information (Figure 9).

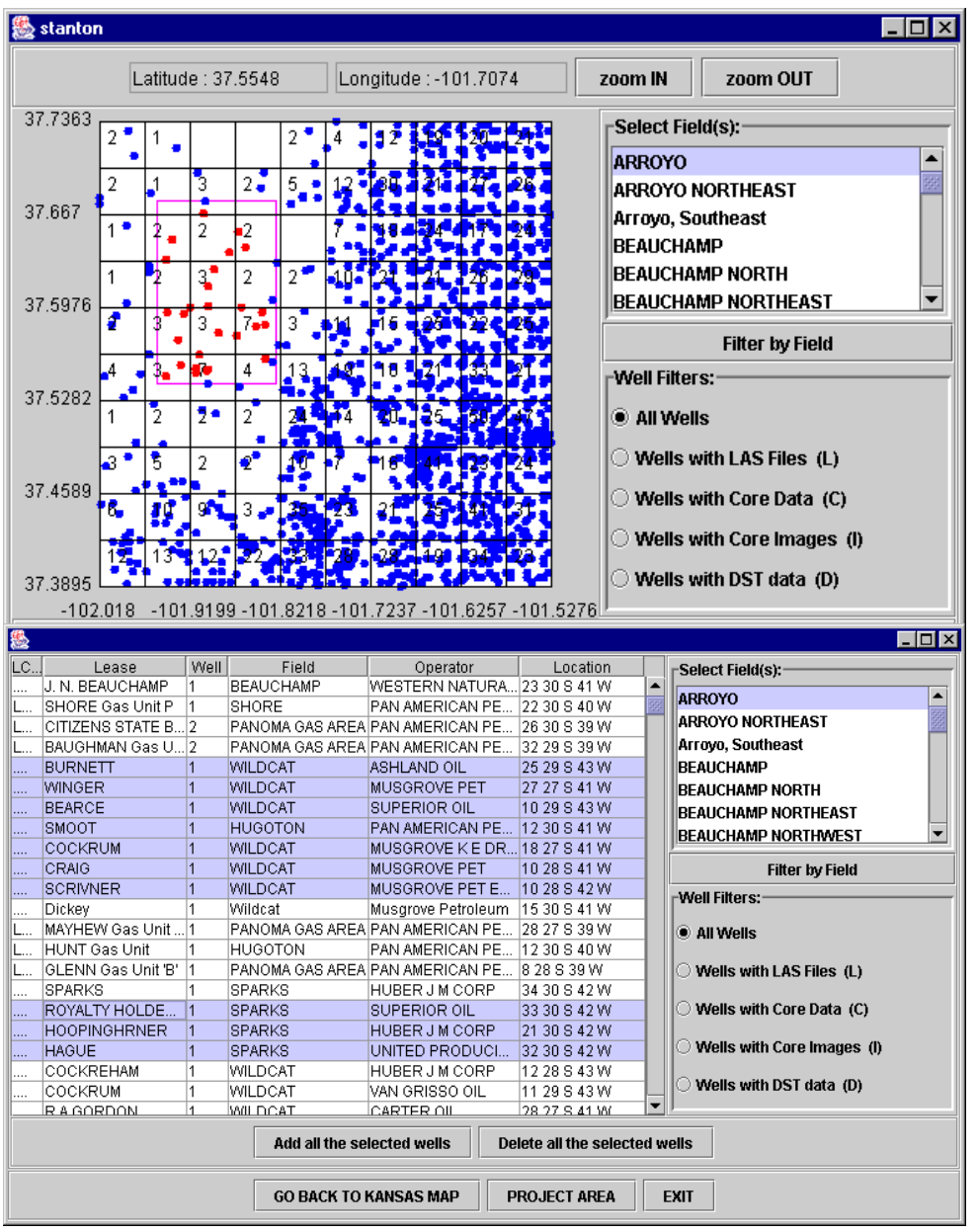

Figure 9. Map interface showing wells in Stanton County that reside on the Oracle database at the Kansas Geological. Interface is used to select wells to include in a project on Arroyo Field in Stanton County. Map shows wells highlighted from Arroyo Field. Other fields can also be filtered using this dialog by clicking on the field in the upper right box. Wells can be further filtered based on other database information including whether they have LAS files, core data, core images, and DST data. The lower dialog is another option to view the wells in tabular form where Arroyo Field wells are highlighted. Wells can be selected or deleted into a project as needed.

User can upload LAS log files via user-friendly dialogs (Figure 10). The user is also able to request confidentiality for these records that is consistent with the rules of the Kansas Corporation Commission (http://www.kcc.state.ks.us/conservation/ conservation.htm). The LAS upload first brings the file into the database. Once, the file 
structure is confirmed with a LAS validation program, the file is released for use in GEMINI. An electronic "flag" is attached to the file that will "release" it when the confidentiality period expires. This procedure ensures use of the digital log by the client during the confidentiality period, accessible only via password used in the project.

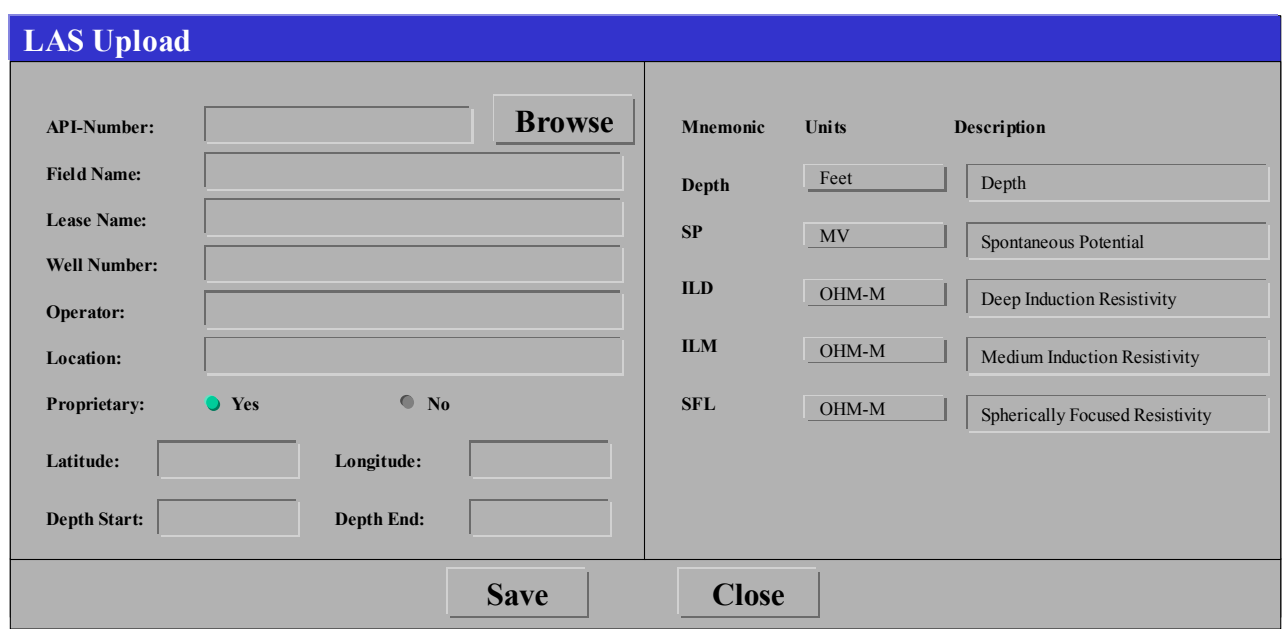

Figure 10. Prototype LAS upload dialog used to add digital LAS wireline logs to a project from the user's computer. Procedure also permits setting the well file as confidential for up to two years from the completion date of the well that is consistent with the rules of the Kansas Corporation Commission. The users provide information that is in the header of the log.

The user adds wells from the User/Project dialog (Figure 11). The user is able to manage the data and access modules from this entry point.

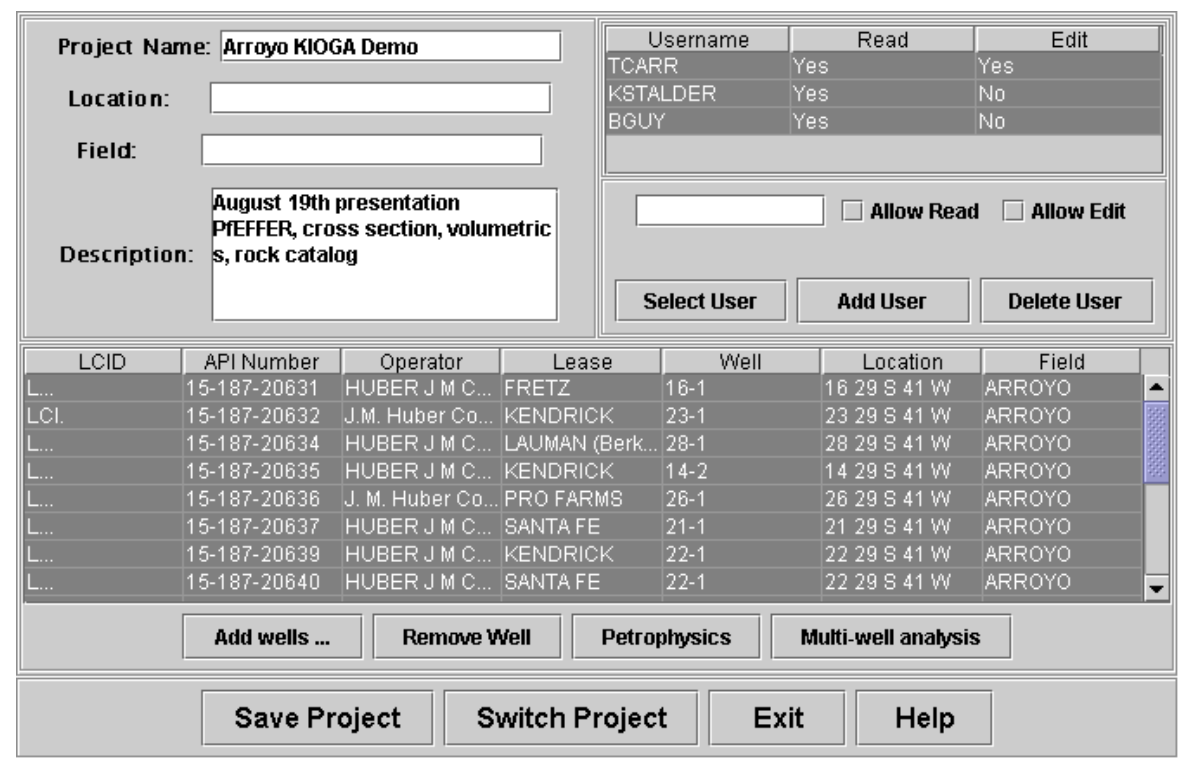

Figure 11. Dialog showing project for Arroyo Field demonstration. The users who share the project are listed along with the list of wells included in the project. The user can add or remove wells and enter petrophysics and multi-well analyses from this dialog. 


\subsubsection{Project Workflow}

Project Workflow is a new interface for GEMINI that is currently in the conceptual stage, but will be implemented in Year 3. The new interface will recommend a list of modules to negotiate in order to obtain particular results, e.g., net pay, hydrocarbon volume, etc., established by the user. As the modules are negotiated in a project, GEMINI will also track this progress and record, for example, the wells used, activities completed, and parameters obtained. The user can rapidly determine the status and evaluation specifics at some later time. A collaborator also can easily and efficiently review progress and build on results. Thus, the current interface will continue to be improved in Year 3.

\section{TASK 2. RESERVOIR CHARACTERIZATION}

\section{Subtask 2.1. Parameter Definition}

\subsubsection{Well Profile Module}

The Well Profile module is used to view LAS (Log ASCII Standard) wireline log files and interactively annotate logs with formation tops, pay/flow units for log analysis, perforations, and DST intervals; print logs to scale, or export image files to other applications. The primary well profile dialog is used to select the depth interval, the vertical scale, the log curves and tracks, curve colors and scale, core data to be included, and computation of quick-look log analysis, e.g., water saturation (Figure 12). The result is a screen image of the logs such as in Figure 13 or a jpeg file that can saved to the user's computer and printed to scale. The onscreen version of the well log can be interactively used to select new formation tops in addition to those incoroporated from the database and to define intervals of the reservoir that may proxy as flow units and used in the log analysis. Also, the user can set the drill stem and perforation intervals to be shown later in cross section displays (Figure 14). This module continued to be improved in Year 2. This annotated or marked log developed in Well Profile is saved for use in other modules, in particular, log analysis and cross section. These marked logs can be modified as needed, as the reservoir model is refined. As described above, digital logs can be uploaded into a project as they are obtained by the user and viewed, marked, and shared with other users who are collaborating. Another Well Profile displaying log curves from the Kendrick 22-1 well in Arroyo Field is shown in Figure 15. In this example, three distinctive sandstone layers are identified. A Pickett crossplot of this reservoir interval is shown in Figure 16. 


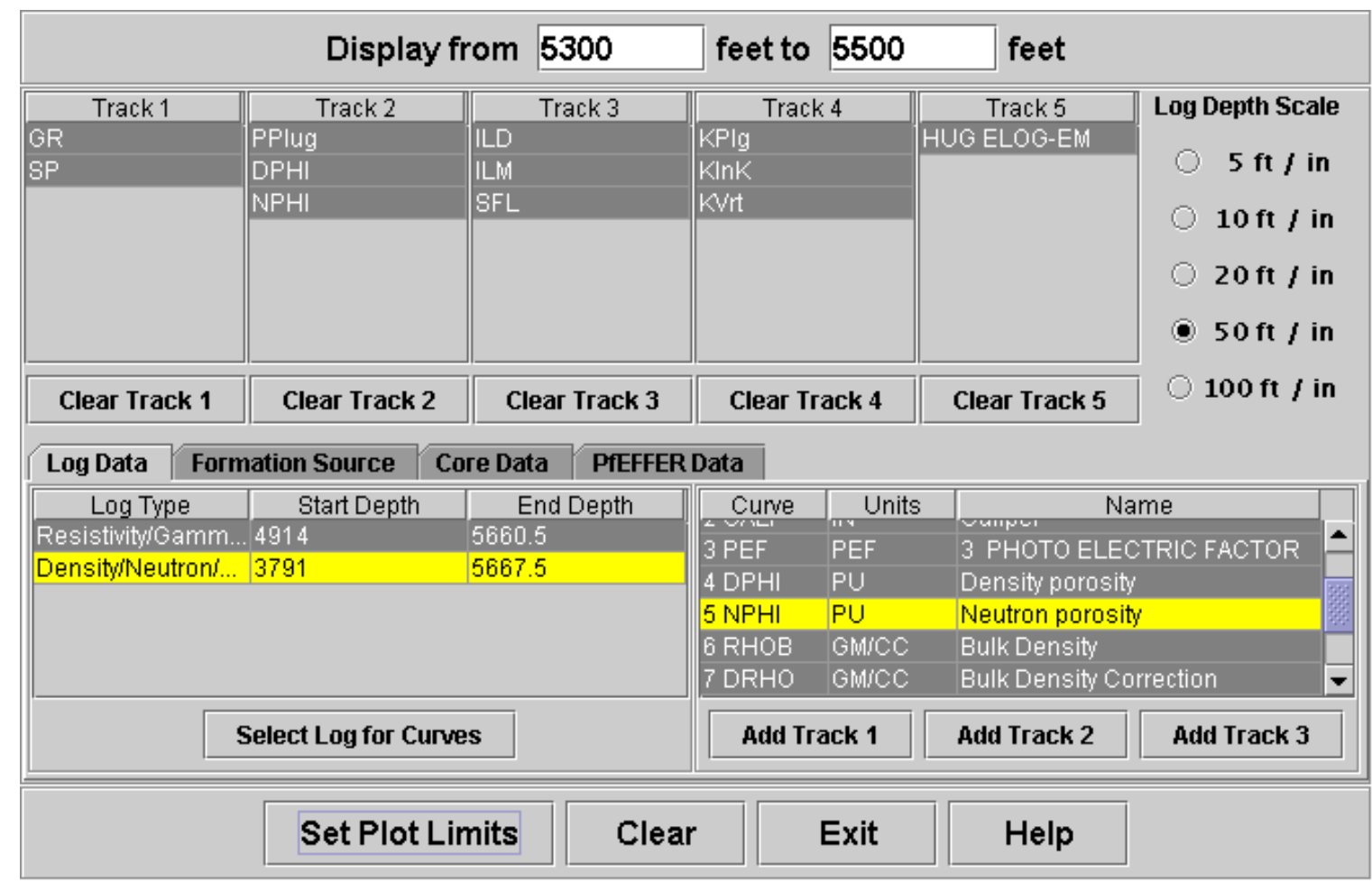

Figure 12. Dialog used in Well Profile to select depth interval, depth scale, curve type and tracks, formation tops database, core data to display, and quick look log analysis (saturation parameters such as Sw using PfEFFER). Once complete user then set plot limits which include scales in tracks and color of curves.

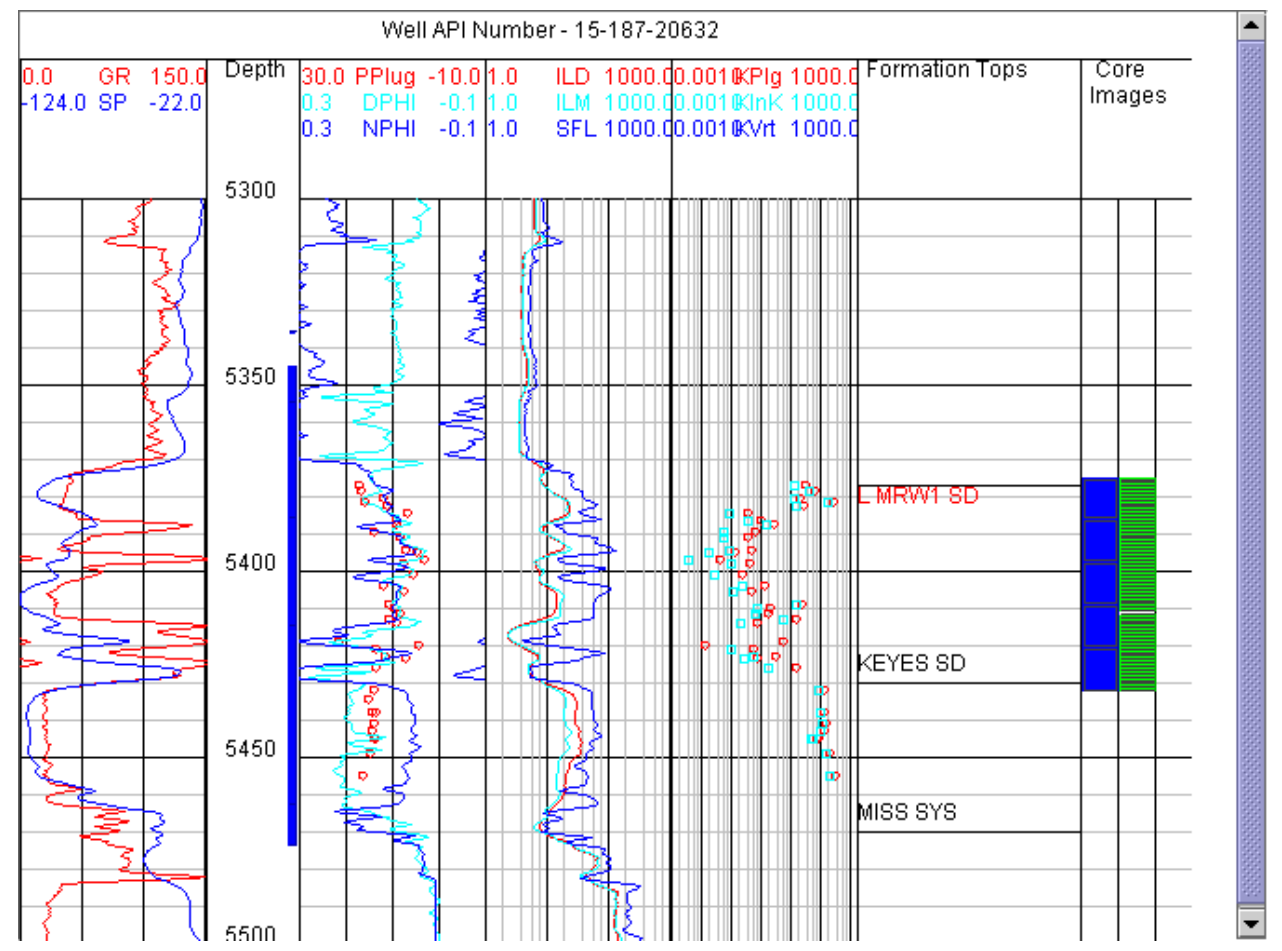

Figure 13. Screen capture of dialog showing Well Profile including core data plotted as small Circles and location of core images along right margin. 


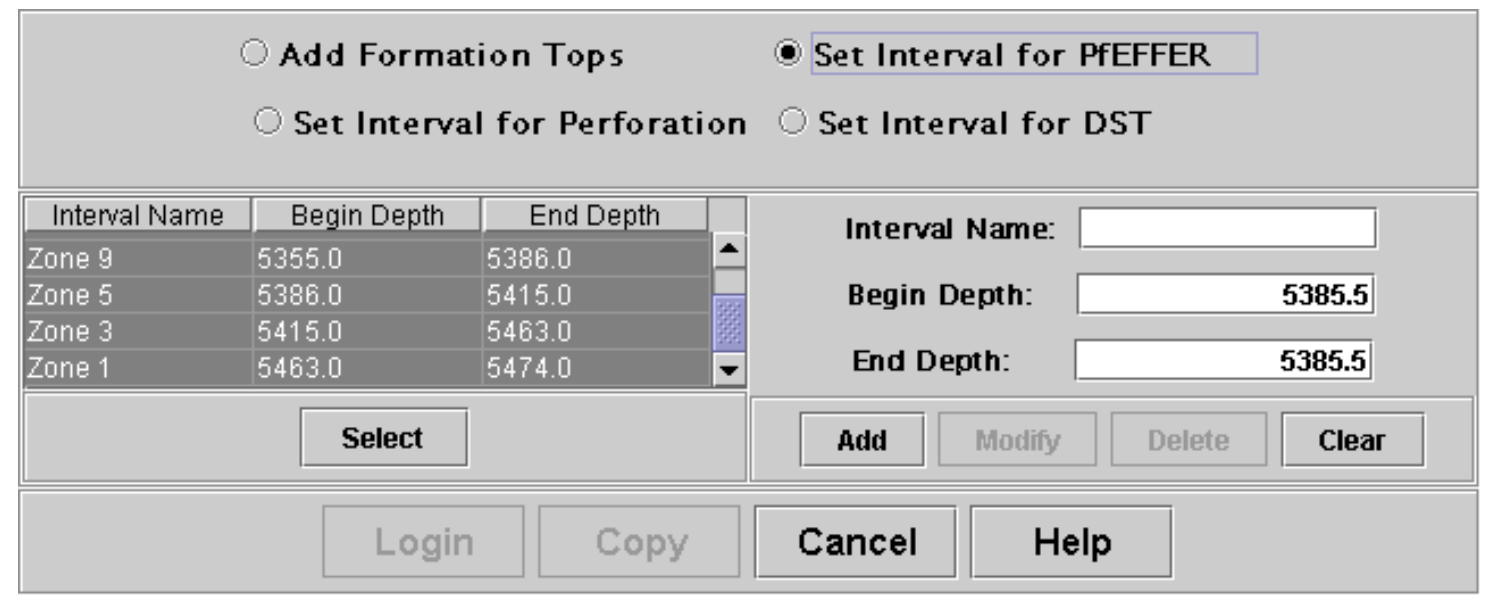

Figure 14. When mouse is clicked in an active log window, a pop-up windows appears that Is used to add formation tops, set intervals for PfEFFER (log analysis), and establish perforated and DST intervals.

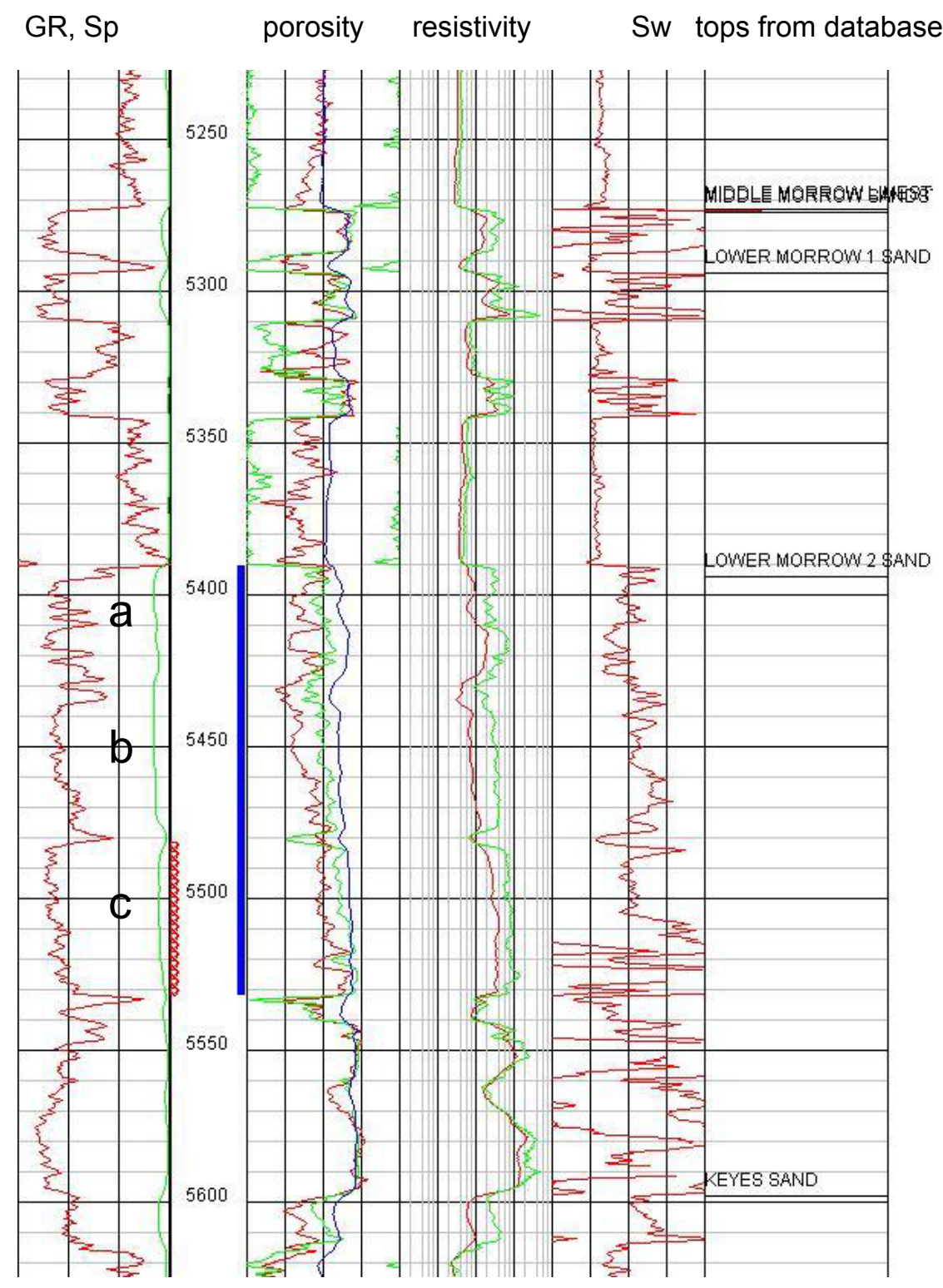

Figure 15. Annotated plot of LAS digital log from Kendrick 22-1 showing three sand lobes $(a, b, c)$ in the Lower Morrow Sandstone from Arroyo Field. Log display includes perforated interval (small connected red circles on left side of the depth track). The logging track on right side (track 4) is a quick-look water saturation. Log can be printed to scale through web browser. Labels of log types and scales from GEMINI are not shown in this example. 


\section{Subtask 2.2. Petrophysical Modeling}

\subsubsection{PfEFFER Log Analysis Module}

PfEFFER log analysis incorporates conventional log analysis to define pay cutoffs using water models and Pickett crossplots annotated with BVW (bulk volume water) and Sw contours (Figure 16). Depth profile was shown in Figure 15. The data points are connected by depth and, in this example, the points are color-coded by depth through the sandstone reservoir. Patterns produced reflect pore type and relative fluid saturations, the later related to the capillarity of the pore and fluid system and the elevation above the hydrocarbon:water contact. Correlating the clusters and patterns of points on the Pickett crossplot with data from core descriptions and analyses is used to establish the reservoir's petrofacies, a distinctive family of the lithofacies and pore type. Clusters of points, often paralleling BVW contours suggests the reservoir is at irreducible water saturation. Also, succession of points that form a linear trend paralleling porosity suggest a transition zone while those that parallel water saturation lines possibly indicate changes in pore type, with smaller pores toward higher values of BVW. Points that lie

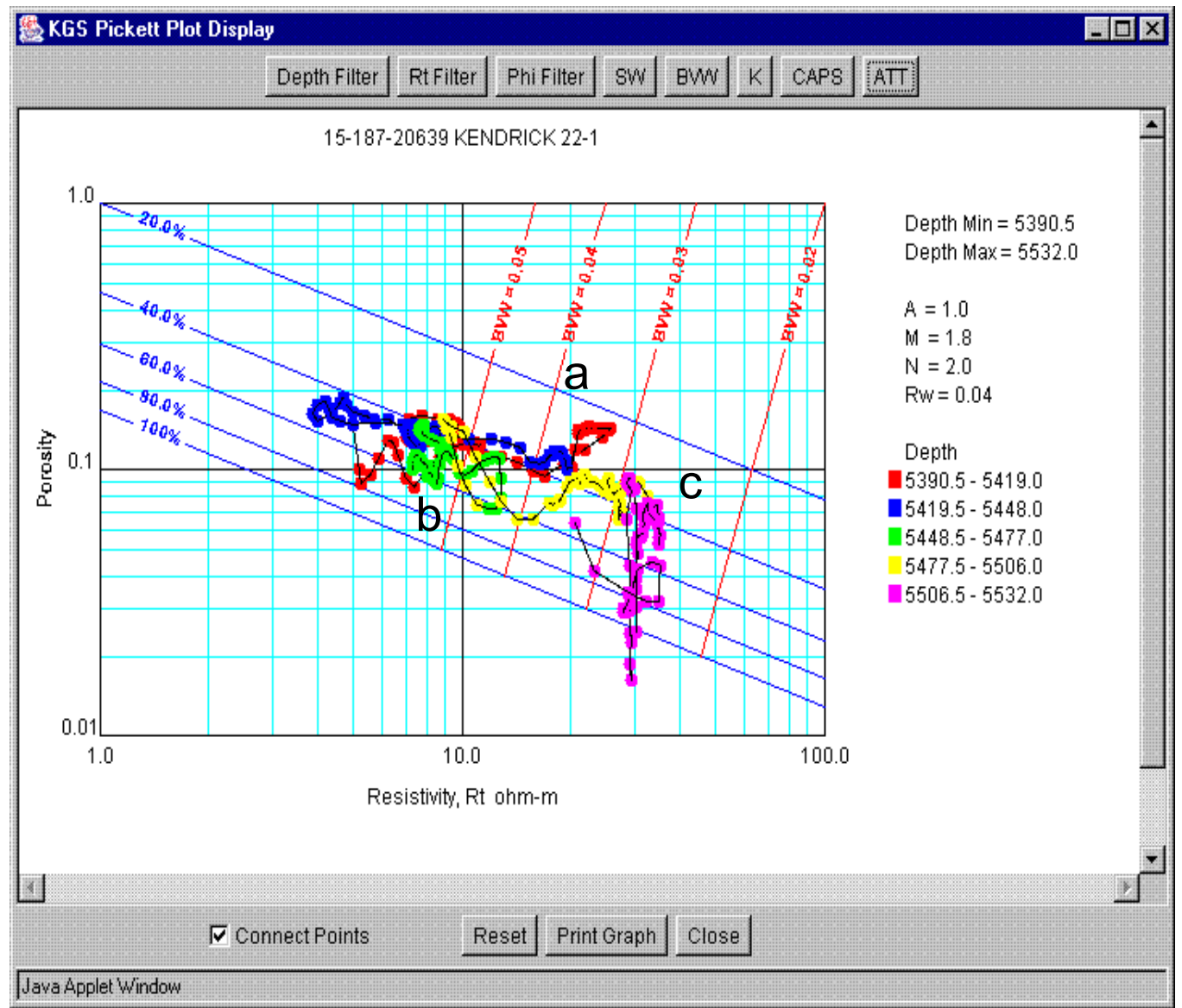

Figure 16. Pickett crossplot with contours of water saturation in blue and bulk water volume shown in red. Points are color coded by depth as shown on legend. Clusters of points are noted labeled a, b, and c, corresponding to three stacked sandstone reservoirs shown on log in Figure 9. 
along the $100 \%$ water saturation line indicate that they are water wet. Principles of petrofacies analysis are described by Doveton et al. (2000). Guy (2002) provides a collection of several hundred Pickett crossplots for Kansas reservoirs. Application of petrofacies analysis is illustrated in Watney et al. (2001).

The petrofacies (lithofacies \& pore type) approach is well suited in helping designate flow units. Separate clusters of points separated by low porosity non reservoir rock are obvious means to help choose reservoir layers. Vertical fluid communication may be suggested by trends of clustered points possibly indicating one transition zone. Uniform spatial patterns of BVW and Sw between wells for a correlated layer can provide evidence for reservoir continuity. Once flow units/layers are defined, well log analysis can be performed and average properties derived for further modeling. PfEFFER $\log$ analysis calculates average values for the parameters. The PfEFFER module also provides a summary of parameters in a single dialog that can be used alongside the Pickett crossplot and the well log plot (Figure 17).

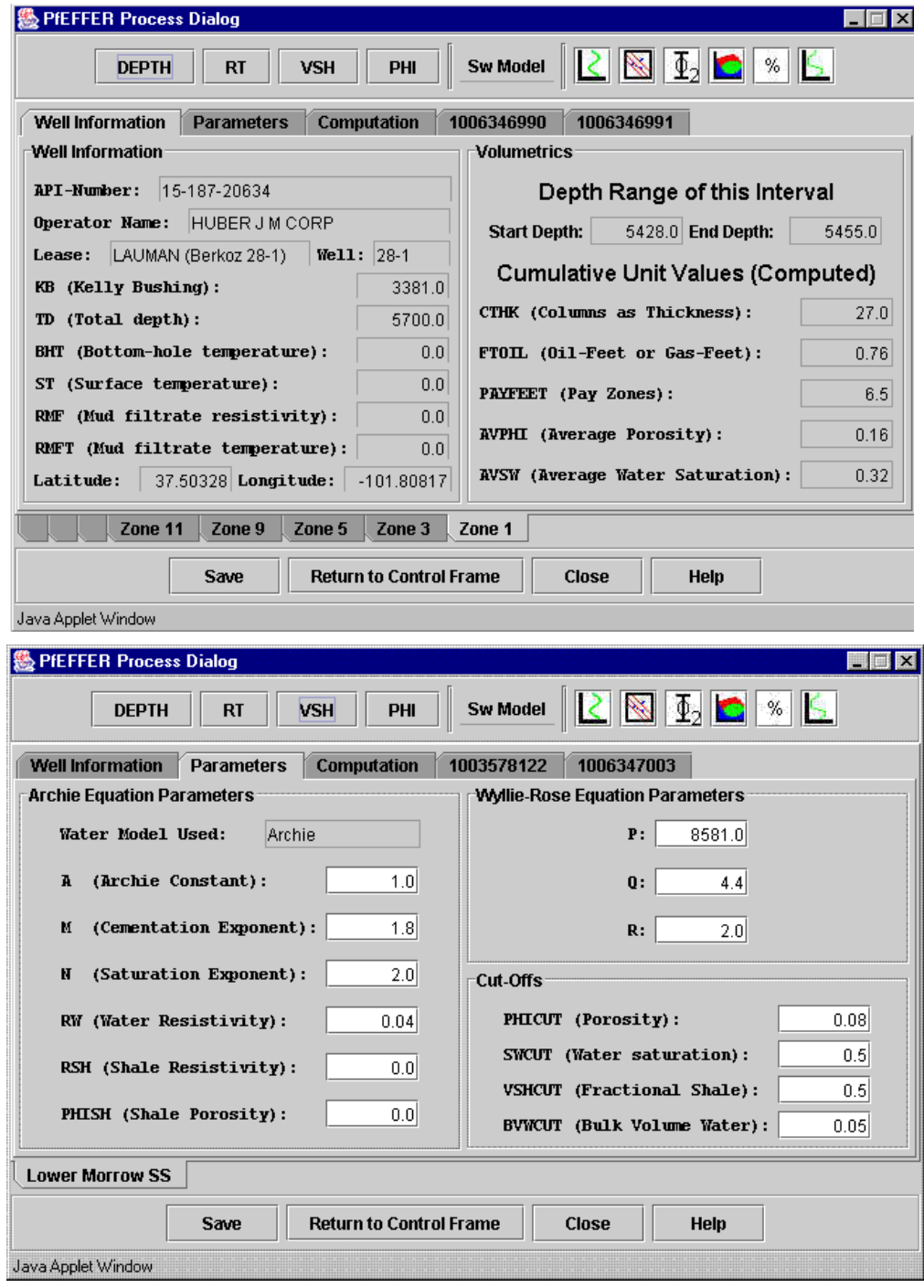

Figure 17. Well information and well parameter dialogs including key information about well and reservoir. Dialog also provides entry point to various activities in the log analysis module. Upcoming option will be to download reservoir parameters to a file to use in other applications. 
Comparison of the petrophysical character of reservoir layers can be accomplished by compilation of Pickett crossplots of each layer (Figure 18). The sandstone reservoir in this example is divided into five layers whose tops are labeled on the right margin of the depth plot in Figure 18. All of the layers in this well lie above the oil:water contact and are near irreducible hydrocarbon saturation, thus the various clustering of points. In turn, the changes in BVW are believed to reflect changes in pore type with the larger pores corresponding to lower values of BVW.
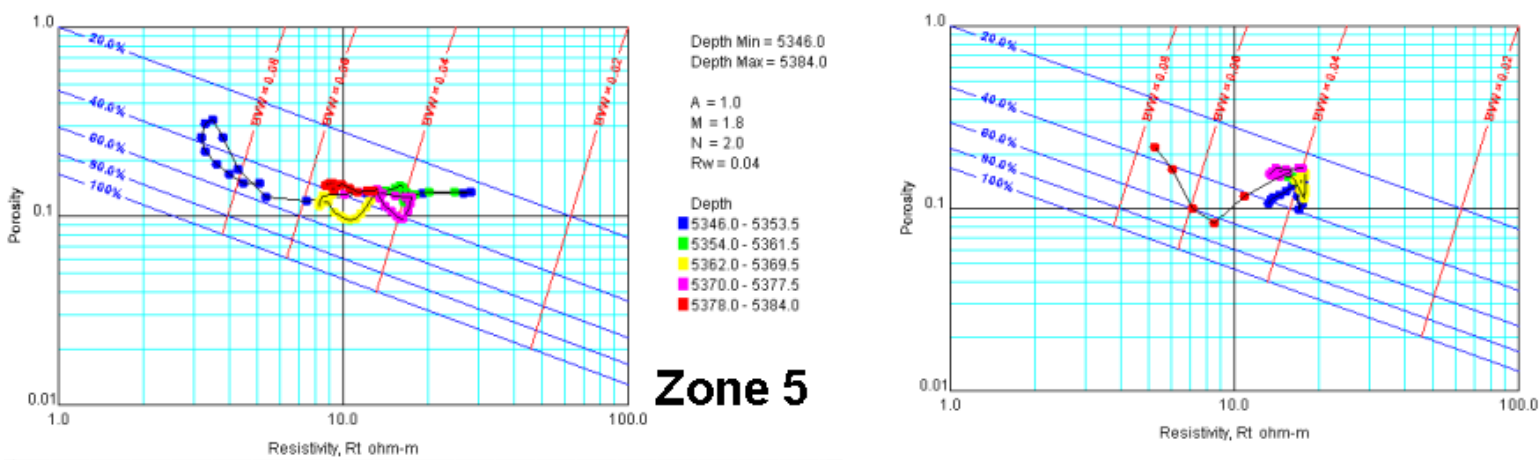

Depth Min $=5304.0$ Depth $\operatorname{Max}=5330$

$A=1.0$

$M=1.8$

$N=2.0$
$R w=0.04$

Depth

- $5304.0-5309.5$
$-5310.0-5315.5$

$5316.0-5321.5$

-5322.0-5327.5

I328.0 - 5330.0

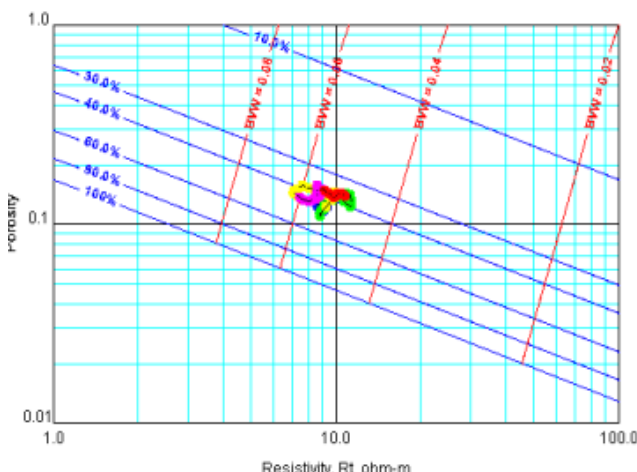

Deptn Min $=5384.0$ Depth Max $=5428.0$

$A=1.0$

$M=1.8$

Rw $=0.04$

Rive

Depth

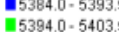

$5394.0 \cdot 5403.5$
$\quad 5404.0 \cdot 5413.5$

$\begin{array}{r}5404.0-5413.5 \\ -5414.0-5423.5 \\ \hline\end{array}$

- $5424.0-5428.0$

\section{Zone 3}

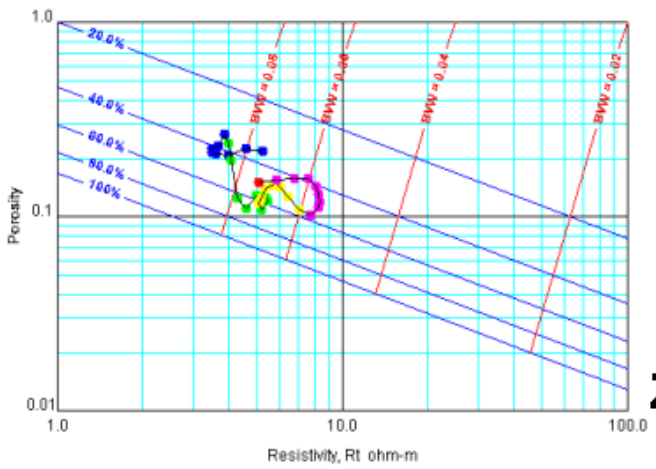

Zone 11

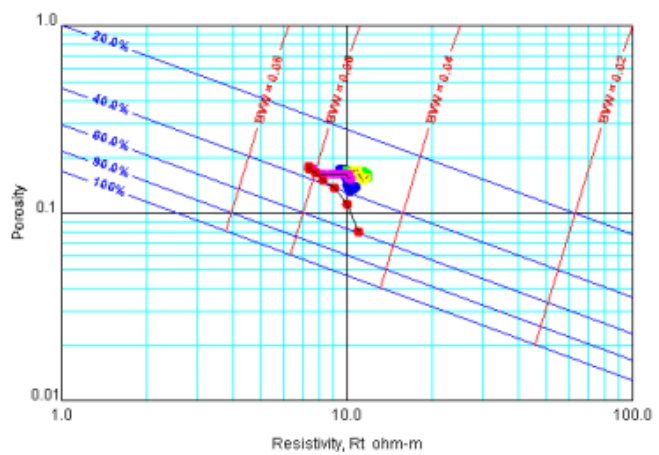

Depth Min $=5428.0$ Depth Max $=5455.0$

$A=1.0$

$M=1.8$
$N=20$

$R w=0.04$ Gas

- $5428.0-5433.5$

$5434.0 \cdot 5439.5$
$5440.0-5445.5$$\quad \mathbf{E D}$

$5446.0-5451.5$

Zone 1

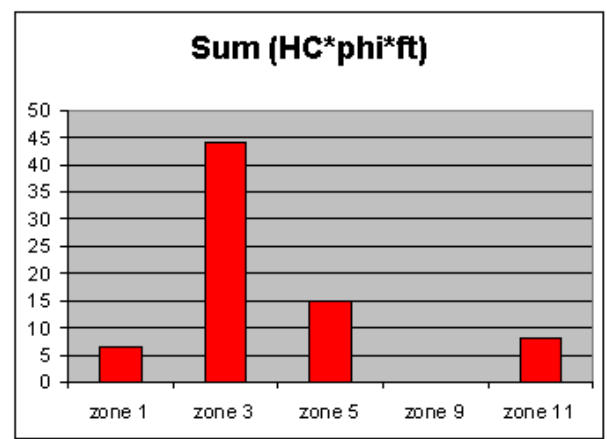

Depth Min $=5330.0$ Depth $\operatorname{Max}=5346.0$

$A=1.0$

$\mathrm{M}=1.8$
$\mathrm{~N}=2$.

Rw $=0.04$

Depth

$5330.0-5333.5$

$5334.0-5337.5$
$-53380-5341.5$

$5338.0-5341.5$

$5342.0-5345.5$
$5346.0-5345.5$

Zone 9

Resistivity, Rt ohm-m

(continued on next page) 


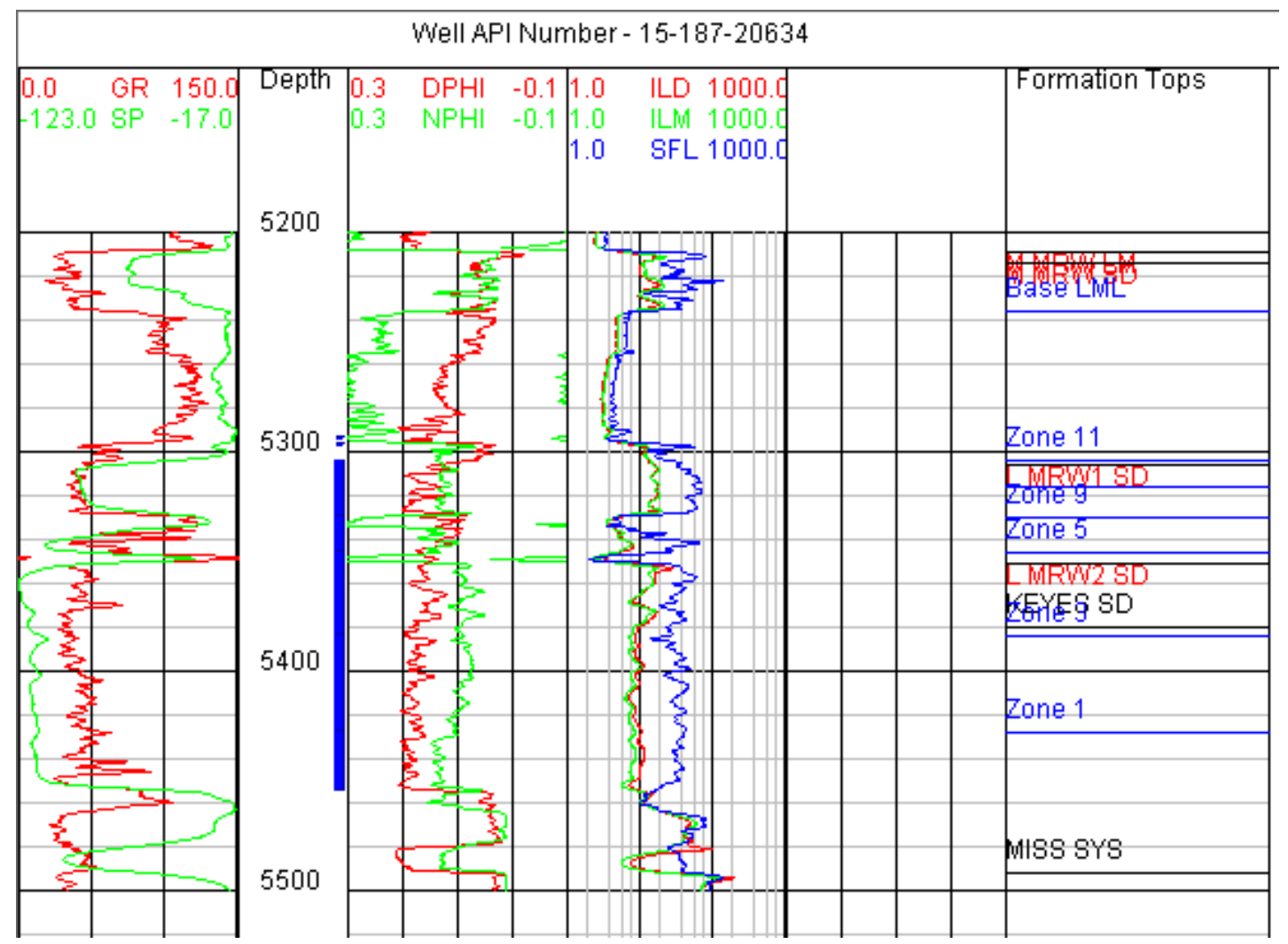

Figure 18. Pickett crossplots for each of five layers (on previous page) comprising a Lower Morrow sandstone reservoir in Huber \#28-1 Lauman well. Depth plot of logs from reservoir interval shown at bottom of figure.

Calculations of porosity and lithology are available options to assist the user in establishing lithofacies, depositional model, and petrofacies (Figure 19). The net result of these software tools is to provide efficient and effective characterization of the reservoir pay in each well of a project to set the stage for the next step, to correlate and map the reservoir through the lease or field. Mapping is discussed in the volumetrics module. 

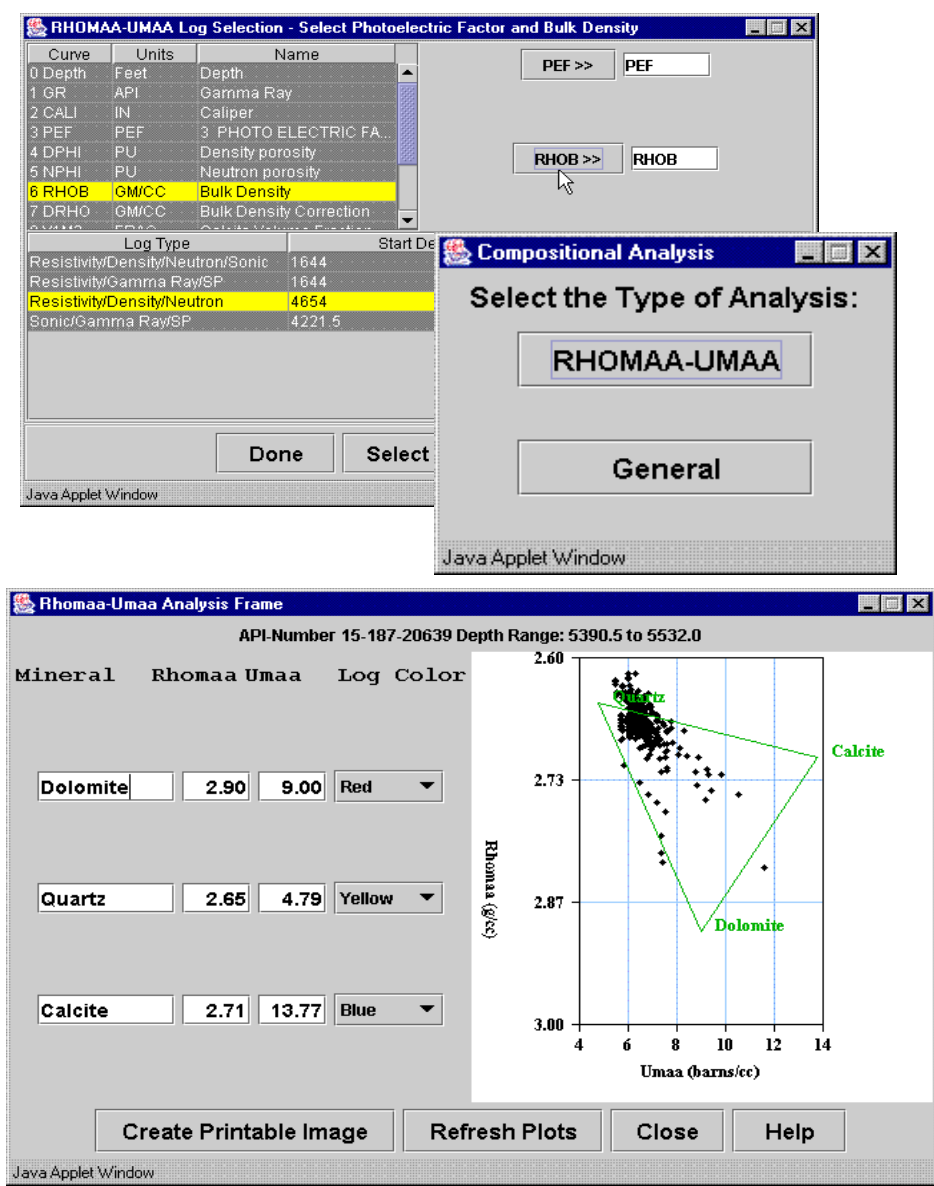

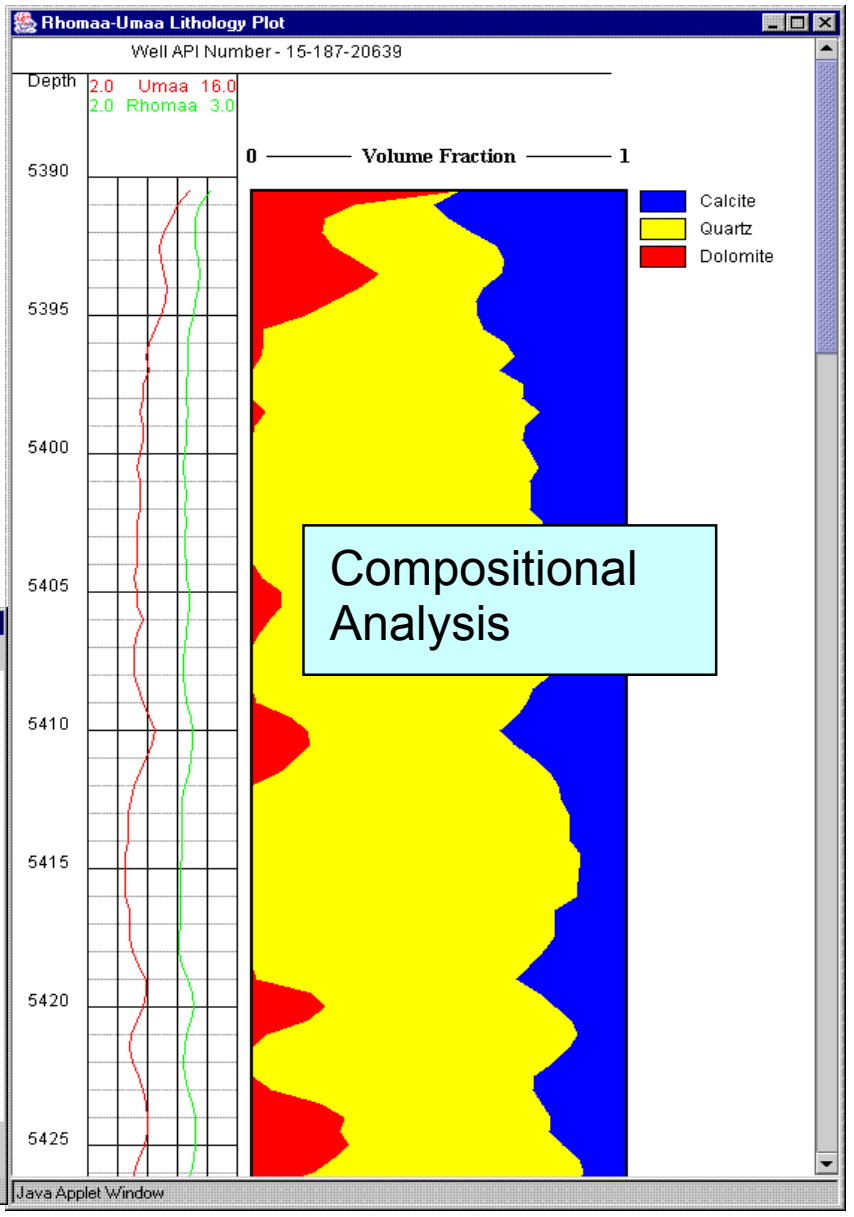

Figure 19. Several dialogs shown were created during development of a lithology solution using the rhomaa-umaa option in PfEFFER. Both a triangular composition plot and a depth-plot of compositions are generated. The user can interact with the solution to tailor results to the particular lithofacies. 
Depth-constrained cluster analysis can be used to subdivide the reservoir into coherent petrophysical units that may also assist in resolving flow units (Figure 19). The delineation of how many layers to use in a reservoir model can be addressed in this activity.

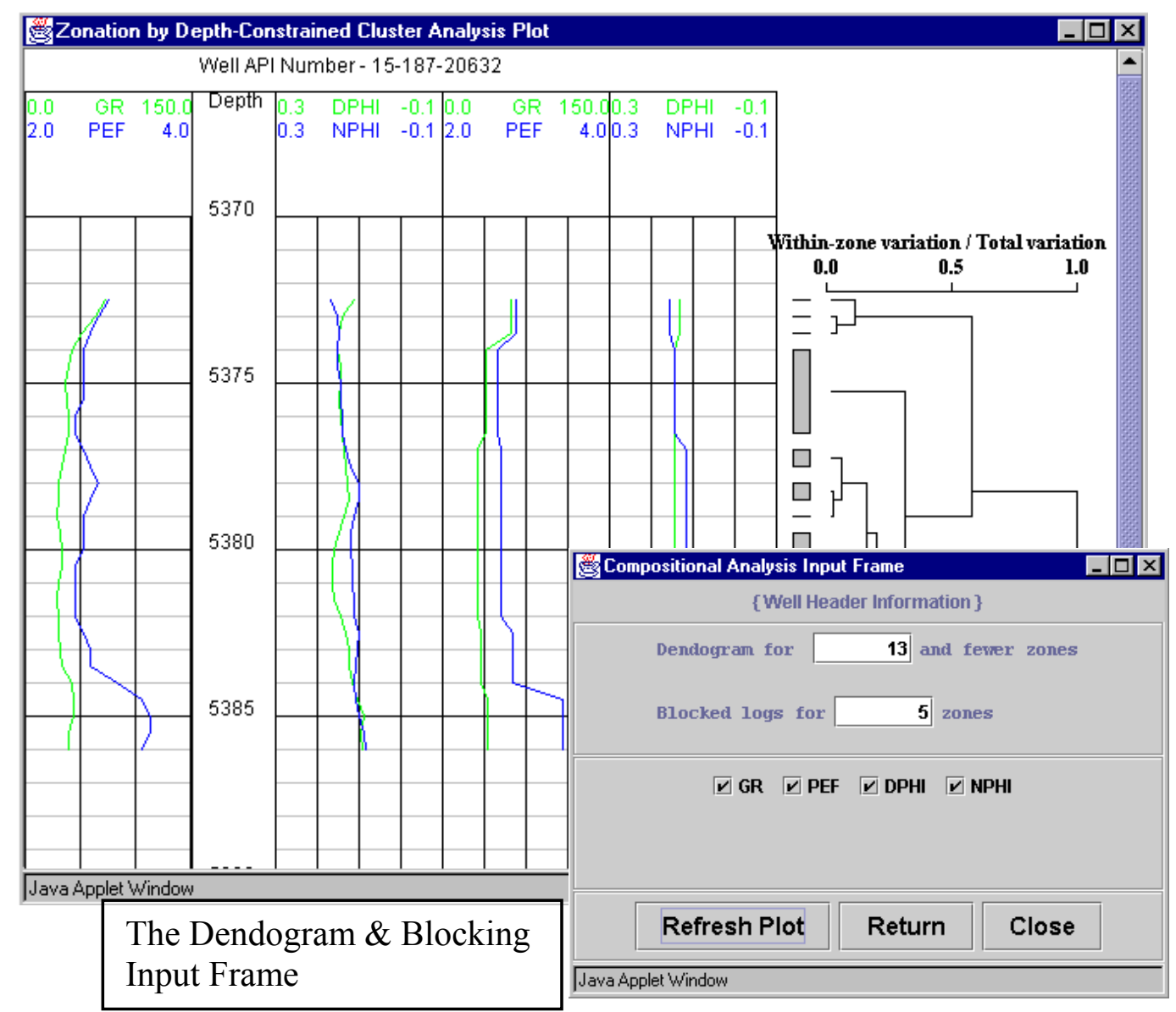

Figure 20. Zonation of a reservoir by depth-constrained cluster analysis, an activity available in PfEFFER log analysis. User defines logs curves to use in the cluster analysis and the number of zones to calculate for the dendrogram as shown along right margin of the depth plot. User selects the number of zones to block for the selected log curves.

\subsubsection{GEMINI Rock Catalog}

GEMINI Rock Catalog provides the basis to calibrate the wireline log analysis. The rock catalog is an extensive software module used to develop correlations between petrophysical variables that comprise common "petrofacies" or classes (Figure 21). The module can also be used to simply look up core analyses available in the database.

Rock Catalog presents a wide range of rock petrophysical data for a range of lithologies, organized on the premise that individual "type" core samples exhibit petrophysical properties that are representative of a class of rocks of similar lithology. Database query tools are available to examine all data for a class of rocks. Class 
definition is user defined (limited only by available fields of data). The petrophysical data are related to wells by depth, location, field, and formation facilitating development of a match with the petrofacies of the reservoir in question. User is able to select information either as categorical or in relational context - relational context is specified by the user. Crossplot, histogram, log, and rock image data are selected by the user for inclusion on an output Rock Catalog "page".

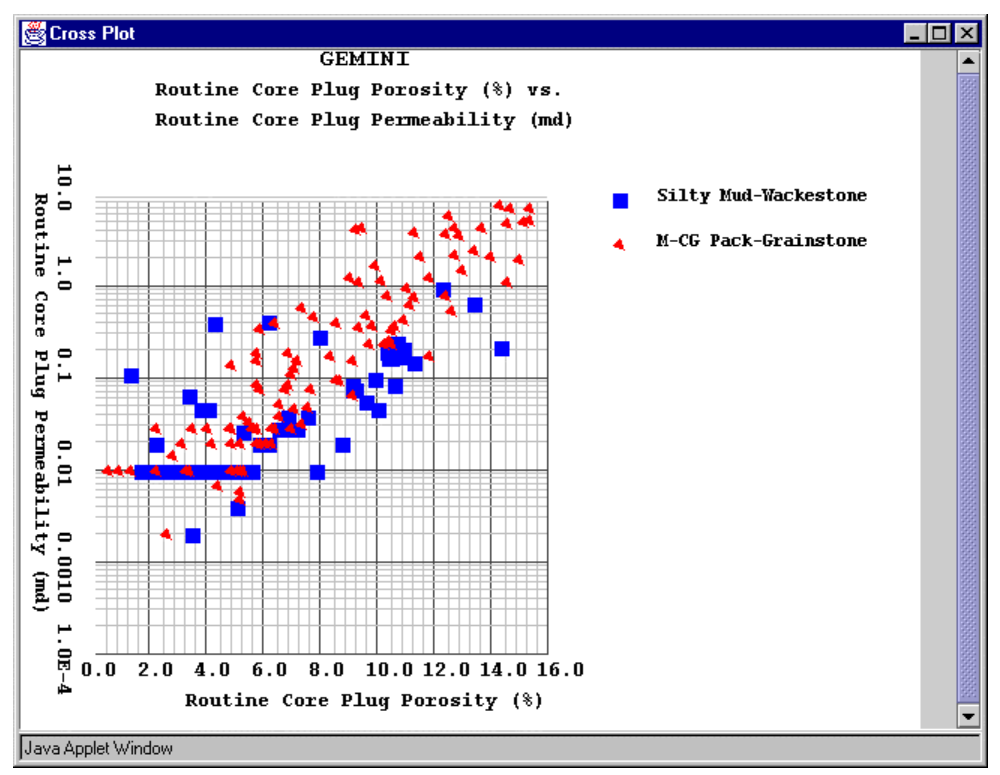

Cross Plot

The database is flexible, can grow continuously, and can be modified. The rock catalog is also versatile and able to integrate with other applications for fully integrated utilization. Core data can be shown by itself or integrated with rock photos. Cores analysis can also be plotted alongside well log data in the Well Profile Module (see Figure 13). The rock catalog module can be accessed separate from a GEMINI project through the KGS website. Basic petrophysical properties available in the current version of Rock Catalog include porosity, permeability, lithology, and grain density. Advanced rock properties including capillary pressure, electrical, and mechanical will be available at some later date.

Figure 21. Upper dialog from Rock Catalog Module shows a cross plot between the porosity and permeability for two lithologies. It is clear in this comparison that the pack-grainstone fabric is more permeable than the mudwackestone lithofacies. The lower dialog shows a core image. 


\begin{tabular}{|c|c|c|}
\hline API_WELL_NUMBER & ARGILLACEOUS_CONTENT_PCT & PERMEABILITY_PLUG_INSTTU_MD \\
\hline COMPLETION_DATE & BEDDING & PERMEABILTYY_PLUG_KLINSITU_MD \\
\hline ELEVATION & CAPILLARY_PRESSURE & PERMEABILTYYPLUG_KLROUTINE_MD \\
\hline FIELD_NAME & CEMENT_POREFILLING_MINERAL & PERMEABILTY_PLUG_ROUTINE_MD \\
\hline INITIAL_PRODUCTION_GAS & COLOR & PERMEABILITY_PLUG_VERT_MD \\
\hline INITAL_PRODUCTION_OIL & CONSOLIDATION_FRACTURING & PERMEABILTY_WHOLE_90_MD \\
\hline INITIAL_PRODUCTION_WATER & DEPOSITIONAL_ENVIRONMENT & PERMEABILTYY_WHOLE_MAX_MD \\
\hline LEASE_NAME & DEPTH_BASE_LITH_FT & PERMEABILITY_WHOLE_VERT_MD \\
\hline OPERATOR_NAME & DEPTH_BOTTOM_CORE_FT & POROSITY_PLUG_800PSI_PCT \\
\hline PERMIT_DATE & DEPTH_TOP_CORE_FT & POROSITY_PLUG_INSITU_PCT \\
\hline RANGE & DEPTH_TOP_LTTH_FT & POROSITY_PLUG_ROUTINE_PCT \\
\hline SECTION & DIGITAL_IMAGE & POROSITY_WHOLE_ROUTINE_PCT \\
\hline SPUD_DATE & FAUNAL_ASSEMBLAGE & PRINCIPAL_PORE_TYPE \\
\hline TOWNSHIP & FORMATION & PROPERTIES_UNDER_STRESS \\
\hline WELL_CLASS & FRACTURES & ROCK_TYPE \\
\hline WELL_NAME & GRAIN_DENSITY_GCC & SATURATION_OIL_PCT \\
\hline ANALYSIS_DATE & GRAIN_SIZE & SATURATION_WATER_PCT \\
\hline ARCHIE_CEMENTATION_AMBIENT & LABORATORY & STRATIGRAPHIC_UNIT \\
\hline ARCHIE_CEMENTATION_INSITU & LITHOFACIES & SUBSIDIARY_PORE_TYPE \\
\hline ARCHIE_SATURATION_AMBIENT & LITHOLOGIC_CLASSIFICATION & THIN_SECTION \\
\hline ARCHIE_SATURATION_INSITU & NMR & WATER_DEPTH \\
\hline
\end{tabular}

Figure 22. Rock Catalog data table.

Figure 23 illustrates the creation of a base dataset that analyzes data for all Council Grove Group samples in the database that are described as having a lithology of nonmarine sandstone (NM Sand) and have routine core plug porosity data. With each selection criteria the total number of samples in the database that have data for all selection criteria is provided to allow evaluation of the size of the population being examined and analyzed. Of a total database of 9694 petrophysical samples in the present database,101 are described as being NM Sand in the Council Grove Group. Of the 101 NM Sand samples, 16 samples have routine core plug porosity data. For quantitative criteria, such as porosity, the range of values present in the database is displayed and is initially defined as the default selection criteria (e.g. 7.5 to $16.7 \%$ in Figure 23 ). If the User wishes to only examine samples within a specific range they can redefine the minimum and maximum values for the selection criteria (e.g. for the existing NM Sand dataset, the User may alternately select to examine only samples with porosity ranging from $10 \%$ to $15 \%$ ). In addition to the BASE dataset, the user can define up to six (6) OVERLAY datasets that will allow definition of subsets of the BASE dataset or completely different datasets, so that comparison between the overlay and base dataset(s) can be performed. 


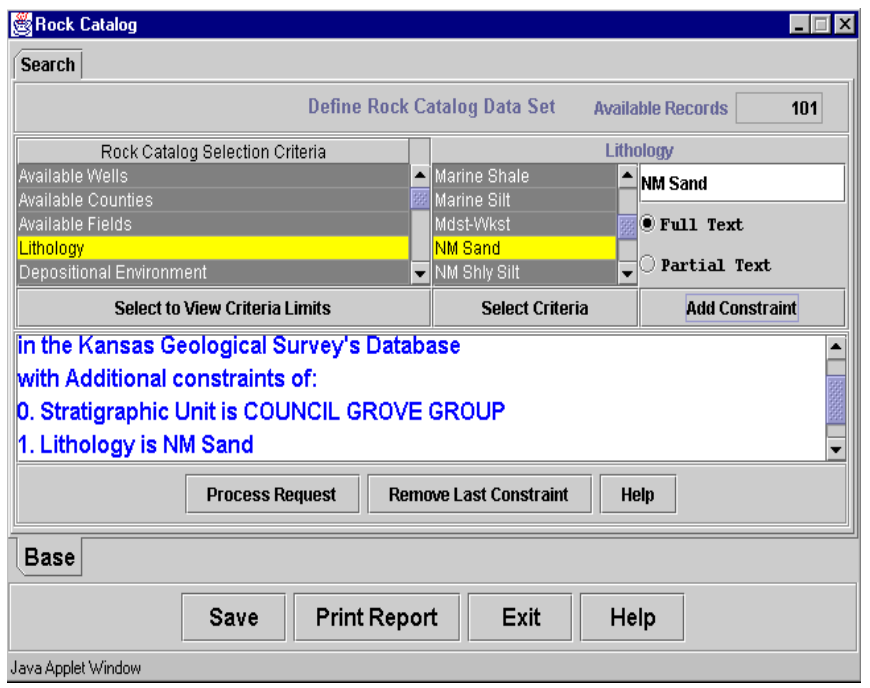

\section{SBock Catalog}

Search Add Overlays Title \& Information Well Profile Cross Plots Histogram Plots Core Images

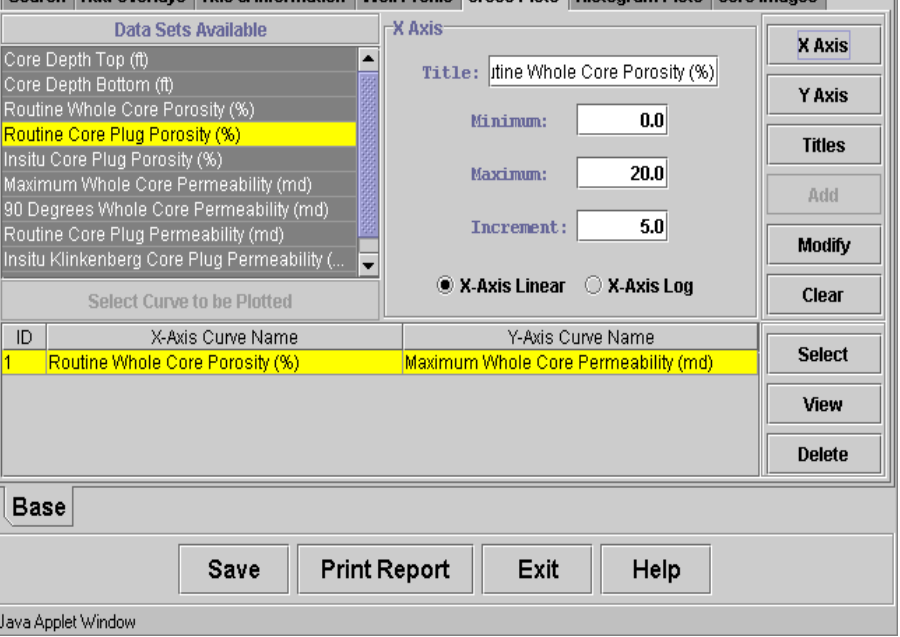

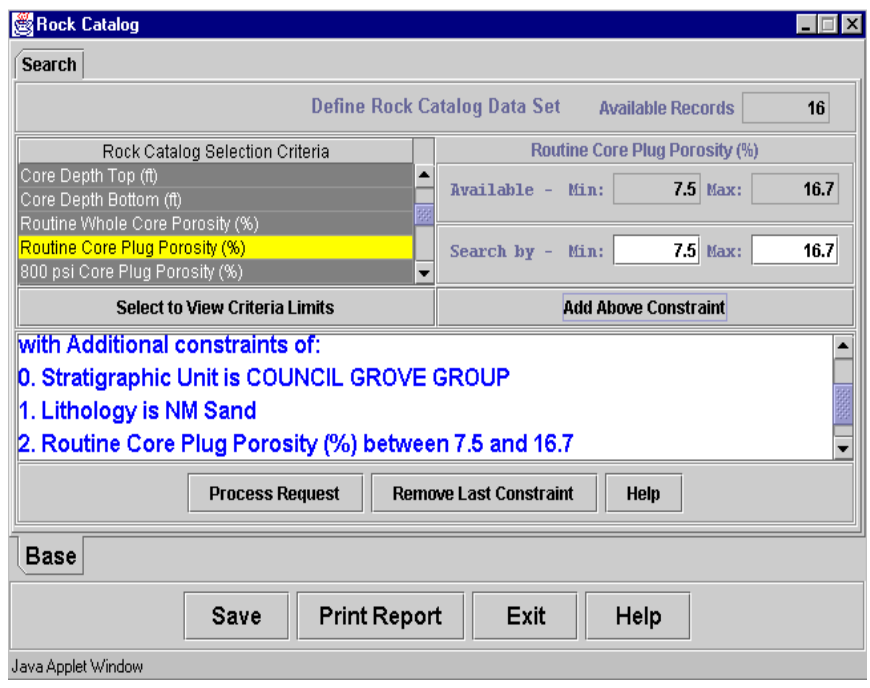

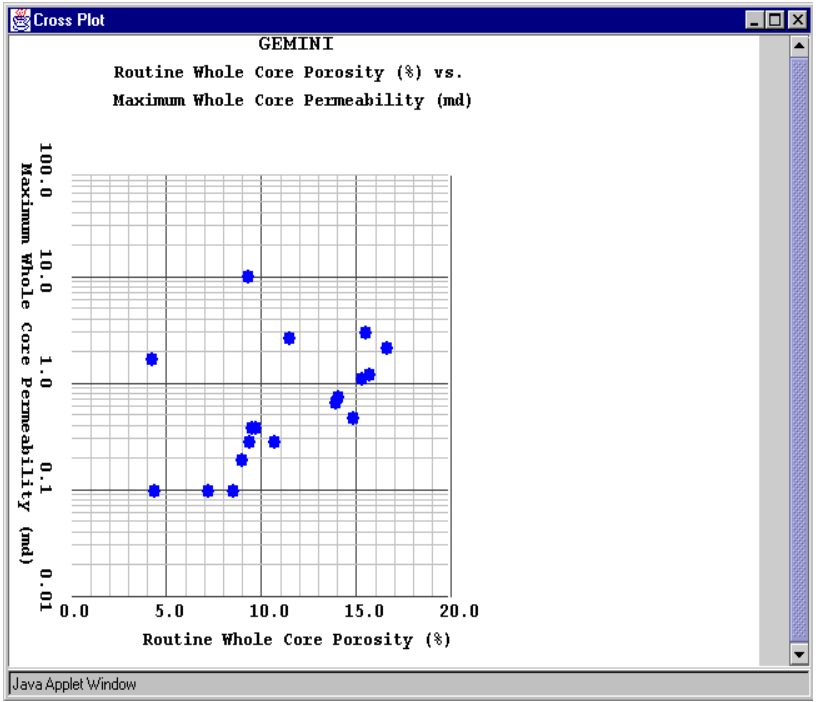

Figure 23. Example construction of a cross-plot in Rock Catalog. 


\section{Subtask 2.3. Geomodel Development}

\subsubsection{Cross Section}

The Cross Section module is used to interactively build an annotated wireline log cross section (Figure 24). Initially, a map interface permits selection of wells from a project to include in the cross section. Up to five wells can be selected at one time, intentionally limited by the processing time and attempt to avoid exceeding the video memory of smaller PC's of users. The interface from the Well Profile Module is used to establish the logging curves and scales. Well logs within the cross section can be annotated with flow units/zones, tops, perforations, and DST intervals. Correlation lines between formation tops are drawn automatically. Layers used in PfEFFER log analysis are also correlated between wells and color coded with color scheme defined by the user. The user can toggle between structural and stratigraphic datums, while the cross section is automatically refreshed to the new datum. Cross sections can be saved as an image files and reopened in a graphics program in order to print the section to a plotter or other device.

When the user returns to the cross section after having saved and closed the application, the software dynamically regenerates the cross section from the data. Modifications to flow units and formation tops made in other modules such as in Well Profile or PfEFFER log analysis are automatically incorporated when rebuilding a cross section.

In Figure 24, a structural log cross section illustrates the distribution of five-layers of a Lower Morrow sandstone in Arroyo Field. The inset map is the cross section index. A low amplitude antiform is developed along the right (southeast) side of the cross section associated with a thicker portion of the sandstone reservoir. This the main producing area of Arroyo Field. Note that the lower three layers of the sandstone are truncated while the upper two extend beyond the cross section.

Simply clicking the radio dial between datums provided in the dialog window of the cross section module leads to refreshing of the screen with the new datum (Figure 25). The user can choose between various stratigraphic datums including formation tops and upper surfaces of the reservoir layers (see Figure 26 for closeup of the radio buttons).

The cross section with a stratigraphic datum above the Lower Morrow sandstone reservoir shown in Figure 25 is more reflective of the depositional conditions of the sandstone, interpreted the infill within an incised valley. The incorporation of formation correlations beneath the sandstone furthermore suggests that the valley was cut along a pre-existing synform. This structural low has been attributed to dissolution of underlying Mississippian evaporites during the formation of the unconformity surface. An insuing valley system occupied of the topographic low as part of a more extensive drainage network. Interestingly, subsequent structural deformation as indicated in Figure 24 led to reversal of the low to a high, the current location of Arroyo Field. 


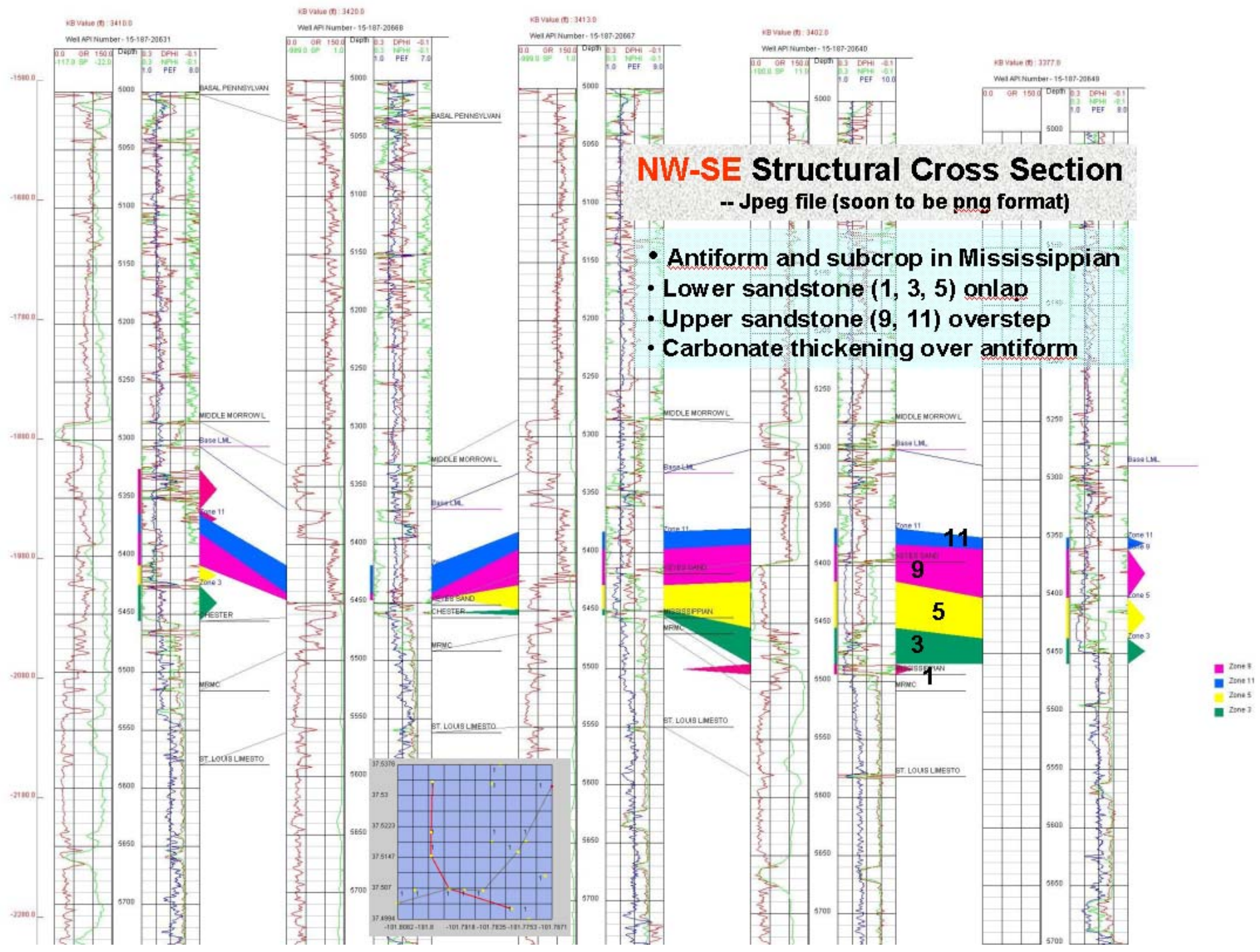

Figure 24. JPEG version of a structural cross section generated in the Cross Section Module showing correlation lines between formation tops read by GEMINI from the database and colorfilled layers of five layers that subdivide the sandstone. User has full control of the log curves, log annotations, scales, colors, and datums. In this illustration, the index map and larger sized labels were added to highlight features of cross section. 


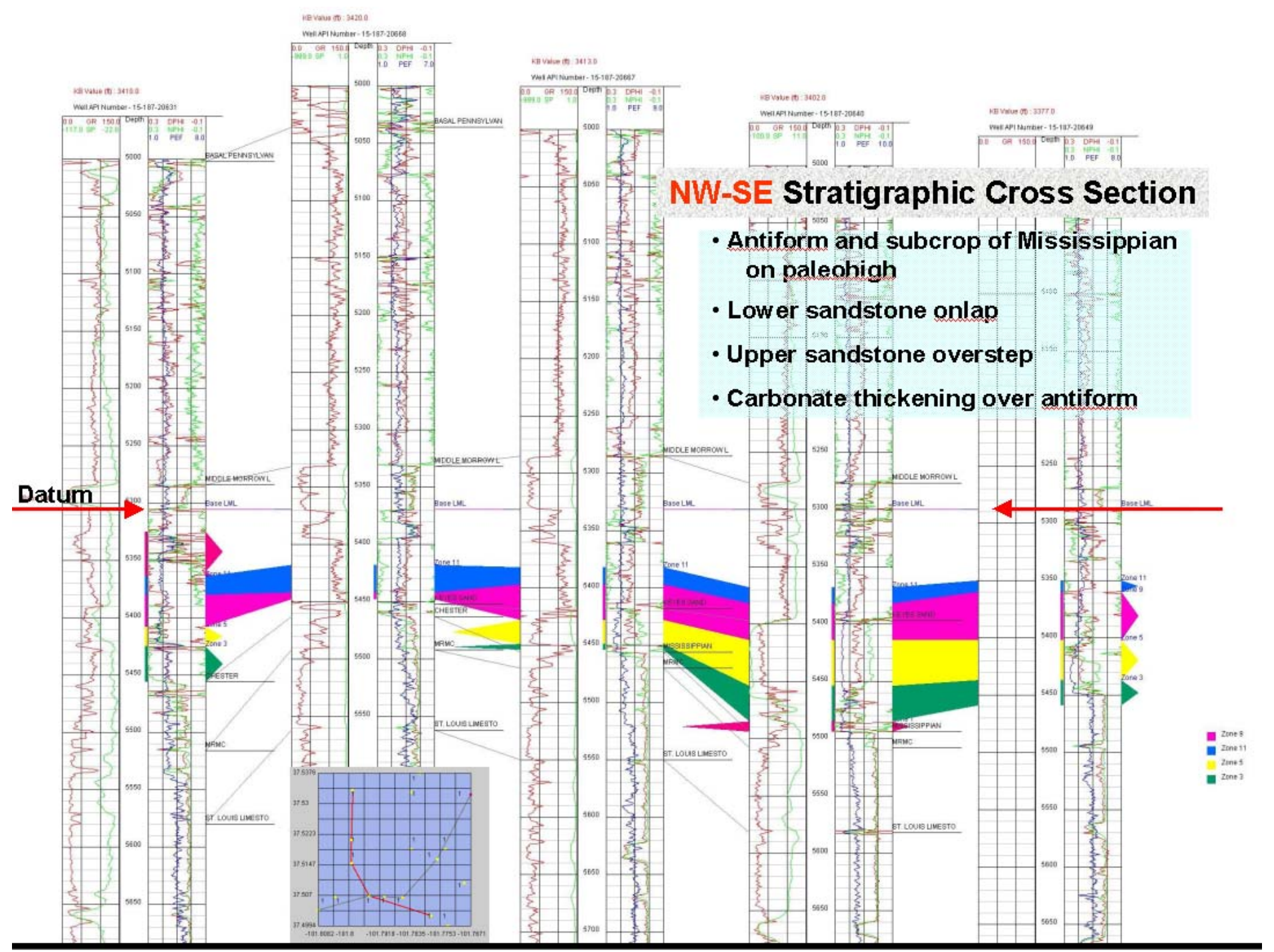

Figure 25. JPEG version of northwest-southeast stratigraphic cross section generated using the Cross Section Module of GEMINI. The section has been further annotated with arrows to show location of stratigraphic datum above the sandstone, index map of cross section, and title and description information.

The scale of the logs shown in the cross section are set by the user using the same Well profile dialog to make the depth plots for a single well. A view of the actual dialog window for the Cross Section Module is shown in Figure 25 showing the familiar 5-layer zonation of the Lower Morrow sandstone. In this stratigraphic cross section the truncation of the sandstone along the right side is interpreted as onlap along the erosional 
edge of an incised valley. The uppermost three layers overstep the valley and extend beyond the cross section. Evidence from core indicates that the upper sandstones are marginal marine while lower sandstones are fluvial and estuarine (Watney et al., 1999). The underlying structural sag indicated by the correlation lines connecting formation tops occurs beneath the thickest sandstone suggesting that a pre-existing flexure was occupied by the incised valley system. Also note that a formation correlation line cross cuts the reservoir layers indicating an inconsistent pick of a formation top.

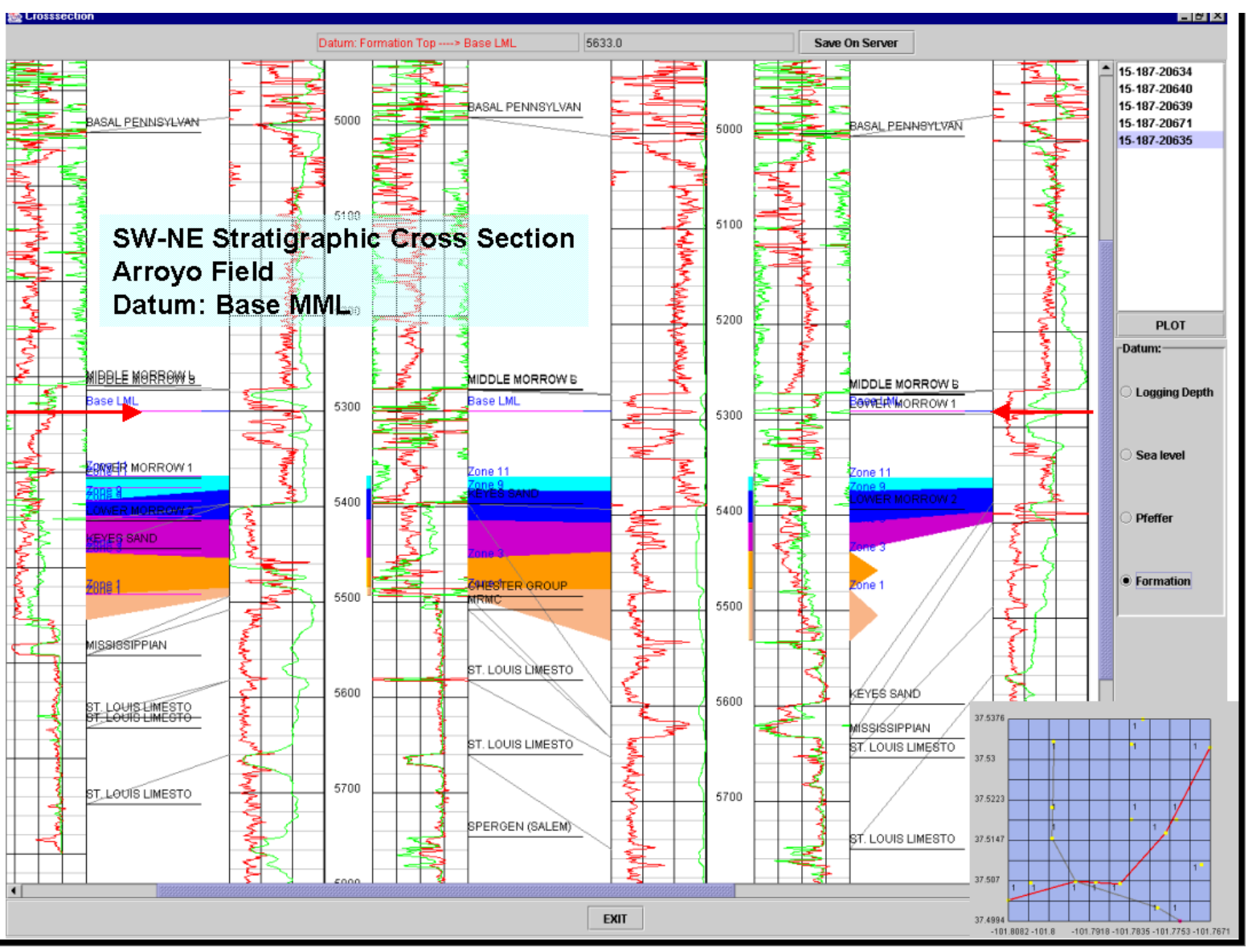

Figure 26. Cross-section dialog window showing portion of a southwest to northeast cross with a stratigraphic datum above the Lower Morrow sandstone. Arrows are added to emphasize the stratigraphic datum and an inset map showing cross section location in the context of other wells in the project.

\subsubsection{KHAN (Kansas Hydrocarbon Association Navigator)}

KHAN is being designed to conduct statistical modeling (continuous variable prediction, discriminant analysis, and clustering) of large databases to derive meaningful patterns including assessing pay in multiple LAS files. The module will accomplish data mining via statistical analysis of databases. The process will be automated and semiautomated, the later to accomplish revealing meaningful patterns in large volumes of data 
in a reasonable amount of time. The predecessor of KHAN is KIPLING demonstrated the ability to predict discrete and continuous variables such as lithofacies and permeability using wireline logs (http://www.kgs.ukans.edu/software/Kipling/Kipling1.html). KHAN fits in the family of applications that include classical and localized regression, smoothing splines and kernel functions, neural networks, and CMAC (Cerebellar Model Arithmetic Computer). Hagens and Doveton (1991) adapted the CMAC algorithm for use in representing a general function of multiple variables and applied the algorithm to mapping of a geological surface. The software developed for this work was a predecessor to the Kipling software. Applications of Kipling to prediction of facies sequences are described in Bohling, Doveton, and Watney (1996) and Bohling, Doveton, and Hoth (1997).

Supervised classification methods include classical discriminant analysis, kernel density estimates, nearest neighbor, neural networks, CMAC, decision trees, and expert systems. Unsupervised classification (clustering) includes a wide variety of clustering techniques. KHAN will incorporate the functionality of both supervised and unsupervised classification.

Currently, the prototype is based on Kipling.xla, an add-in Visual Basic program for Excel. Kipling.xla uses the CMAC algorithm (similar to neural net) and accommodates both continuous variable prediction and supervised classification. The prototype is a stand-alone application and can read data from local files.

The transition probability matrices will be incorporated in categorical prediction and an interface will be written to the database. A flexible, intuitive interface will be written for selecting data volume and variables to analyze. Then KHAN will be integrated with GEMINI where computed results, e.g., zonation from depth constrained cluster analysis in the PfEFFER module of GEMINI can be used as inputs to KHAN. KHAN results will be able to be displayed in well profile, cross section, etc.

A general application for KHAN is to predict "electrofacies", discrete geometric units that ideally are correlatable and correspond to significant, rationale geologic rock bodies. In other words, the petrophysical classification resulting from this "electrofacies" analysis might be based on a "training set" consisting of petrofacies (lithofacies+pore types) or genetic stratigraphic units such as flooding units, condensed sections, and paleosols. Moreover, the user may want to distinguish rock that is hydrocarbon pay. Systematic classification of pay in a field, region, or basin could be used to process new LAS files for hydrocarbon show in a quantitative manner. Systematizing pay at the field level could help develop the reservoirs by helping identify priority areas and intervals.

Dialogs will lead the user through specifying training variables and defining model parameters. Predictions will be made and the model will be matched to the dataset variables. Plots will be generated of the predicted electrofacies probabilities such as that shown in Figure 27. 


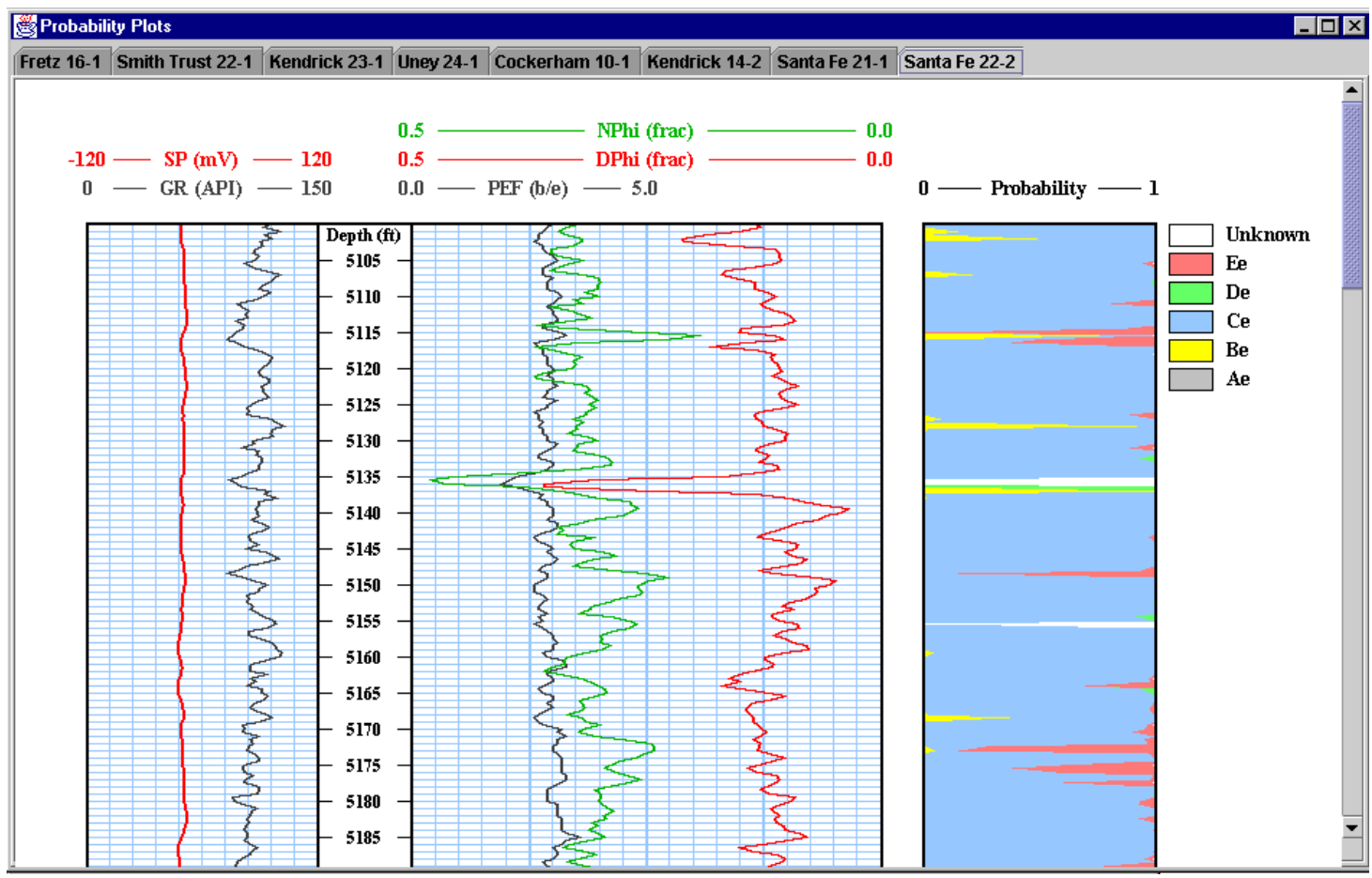

Figure 27. Electrofacies probability plot alongside well logs used in making the classification.

\section{TASK 3. GEO-ENGINEERING MODELING}

\section{Subtask 3.1. Volumetrics Module}

The Volumetrics module creates grids and maps of key variables via userdefined gridding parameters. Original-hydrocarbon-in-place and moveable oil are calculated for each layers/flow units in a given project. Selected dialog windows are included in Figure 28.

\section{Summary of features of the Volumetrics Module:}

- Mapping module runs inside volumetrics

- Input variables and their origin

$\phi, \mathrm{S}_{\mathrm{w}}$, net pay - from PfEFFER analysis

grid cell size provided by user

- $\quad$ Results - maps of: $\phi, \mathrm{S}_{\mathrm{w}}$, net pay, OHIP, Mobile OOIP - $\mathrm{S}_{\text {oir }}$

$\beta$, formation volume factor, is obtained from PVT module 


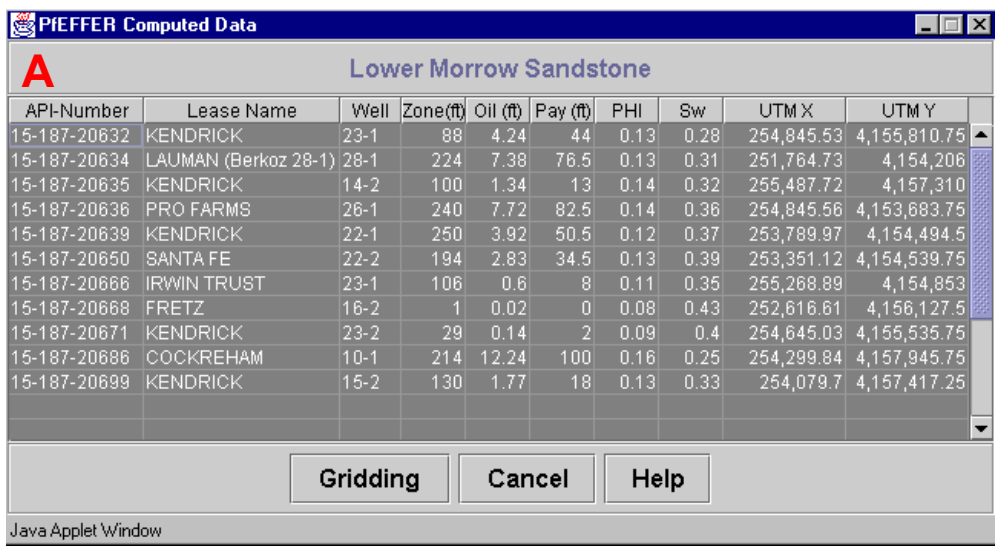

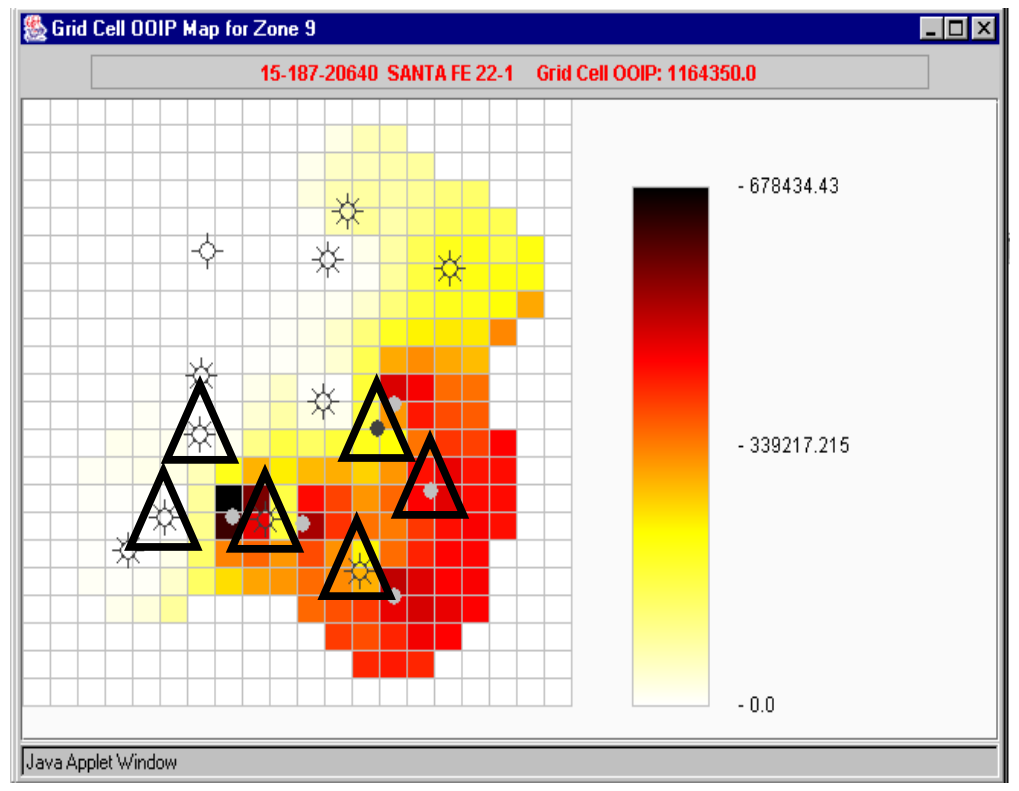

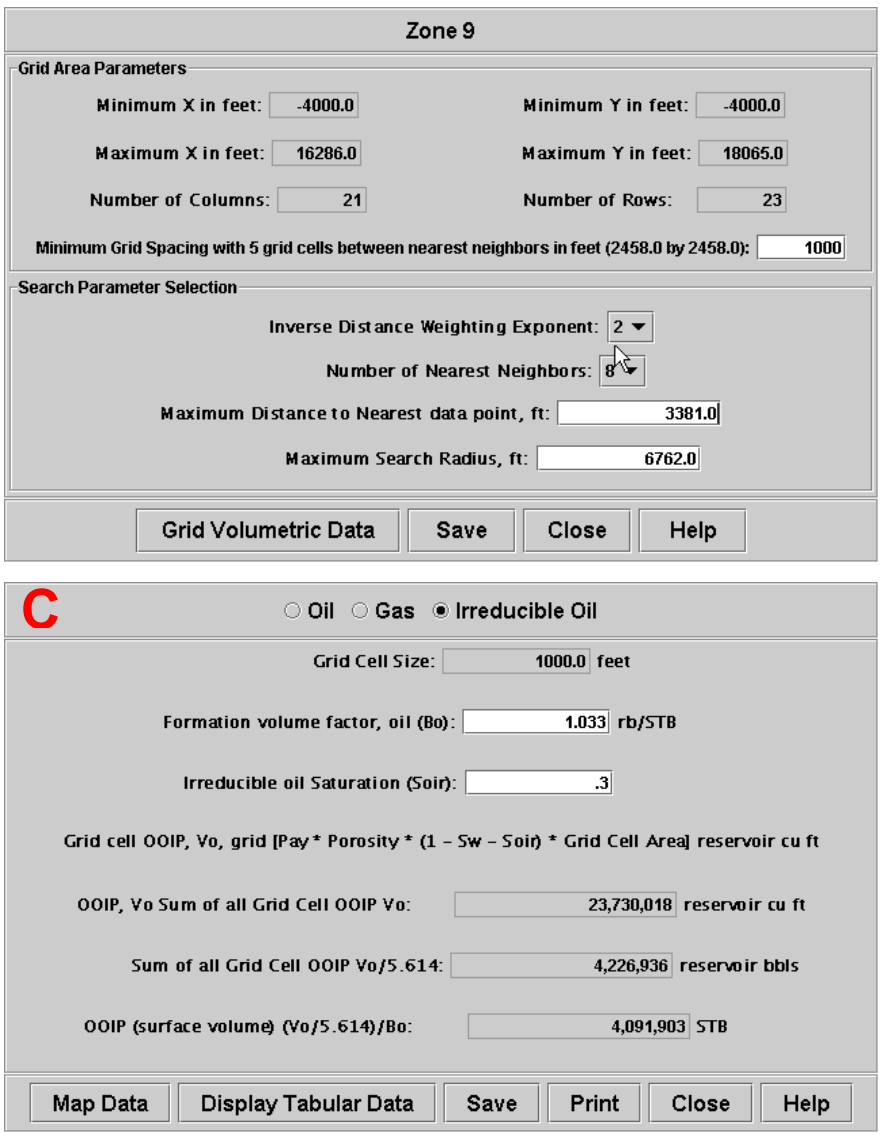

Figure 28. Selected dialogs generated in Volumetrics: A) list of well data with reservoir parameters used in volumetric calculations; B) gridding parameters for zone 9 (note users sets grid spacing); C) volumetric calculation of mobile oil in zone 9 using irreducible oil saturation of 0.3; and map above -- colored volumetric grid cells for zone 9 showing original-oil- in-place, triangles added to show wells that are perforated in zone 9. 


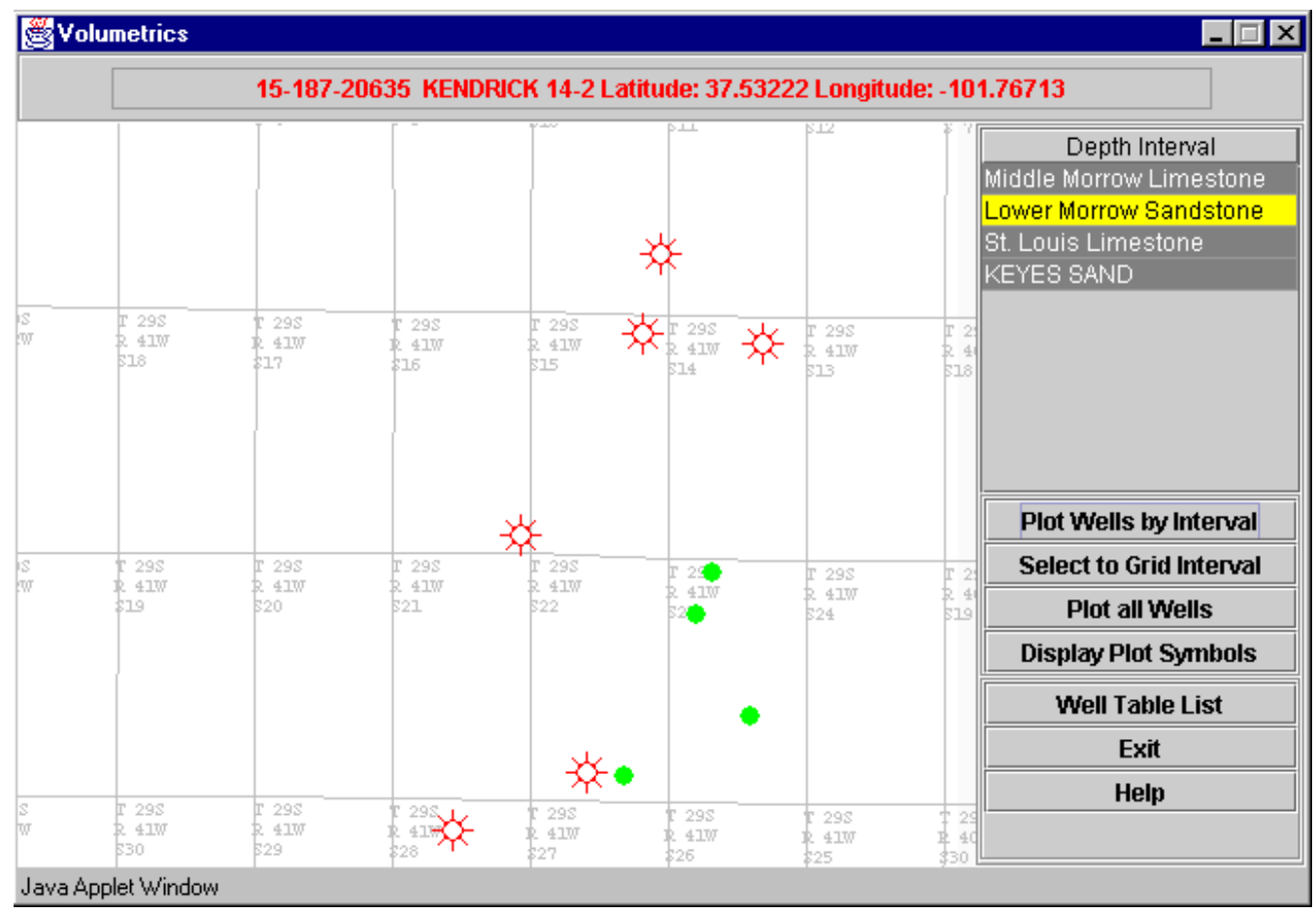

\begin{tabular}{|c|}
\hline Well Plot Symbols \\
\hline WELL SYMBOLS \\
\hline$=($ NONE) Location Only \\
\hline$=(\mathrm{D} \& \mathrm{~A})$ Dry \& Abandon \\
\hline$=(D \& A-O)$ Dry \& Abandon - Oil Show \\
\hline$=(D \& A-G)$ Dry \& Abandon - Gas Show \\
\hline$=(D \& A-O G)$ Dry \& Abandon - Oil \& Gas Show \\
\hline$=\mathrm{Oil}$ \\
\hline$=\mathrm{Gas}$ \\
\hline$=$ Oil \& Gas \\
\hline$=$ (SUS) Suspended \\
\hline$=($ SUS-O) Suspended - Oil \\
\hline$=($ SUS-G) Suspended - Gas \\
\hline$=($ SUS-OG) Suspended - Oil \& Gas \\
\hline$=(S W D)$ Salt-Water-Disposal \\
\hline Java Applet Window \\
\hline
\end{tabular}

Figure 29. Base map identifying wells in project with well symbol as explained in legend beneath the map.

A series of grids and maps of key reservoir parameters are produced in the volumetrics module including average porosity and water saturation, gross thickness, net pay, and hydrocarbon*porosity*feet. Maps can be selected and compiled in a report, downloadable as a JPEG file. A set of maps for zone 5 are shown in Figure 30. A set of maps of original-oil-in-place for four of the five layers in the Lower Morrow sandstone in Arroyo Field are shown in Figure 31. Note that a well location in the OOIP map of Zone 3 is not completed in the zone, yet appears to have appreciable hydrocarbon behind pipe. 

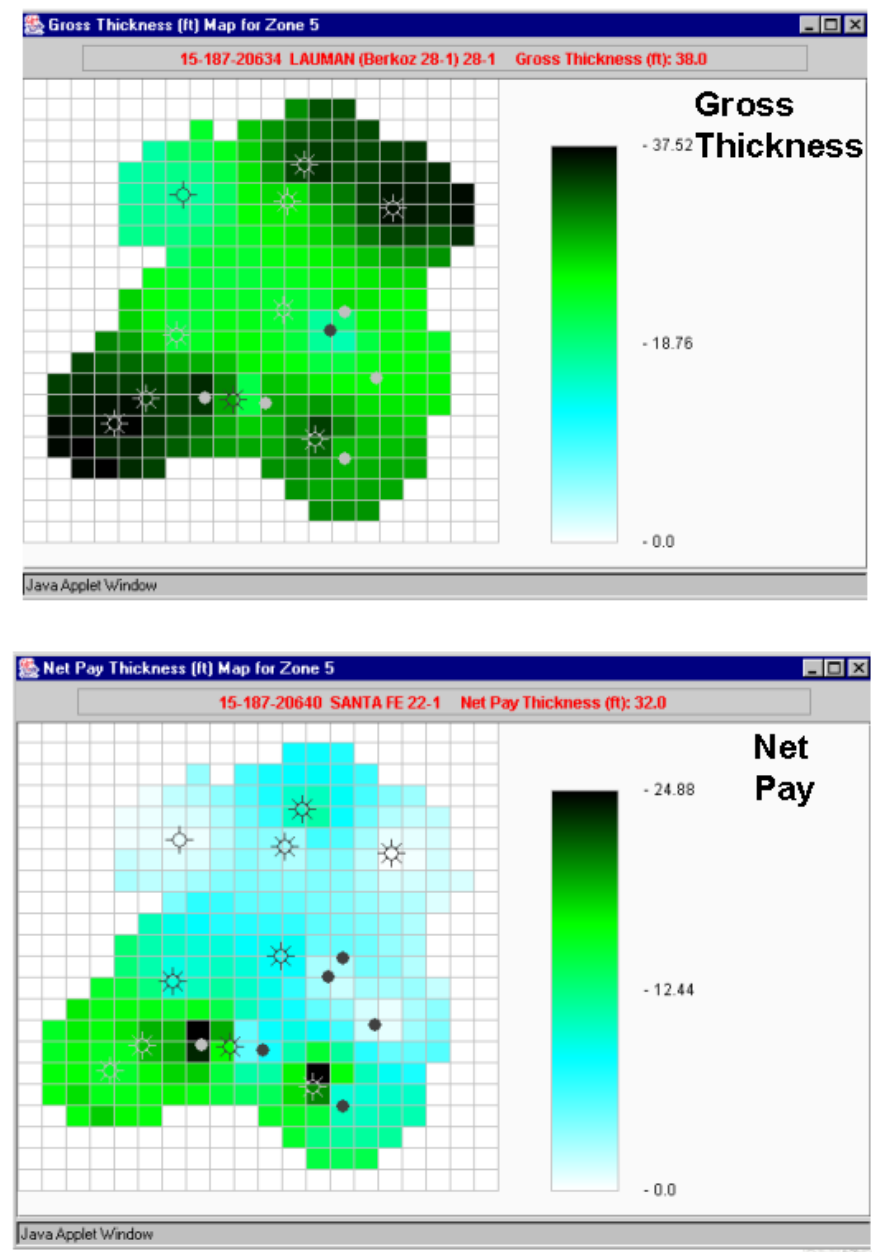
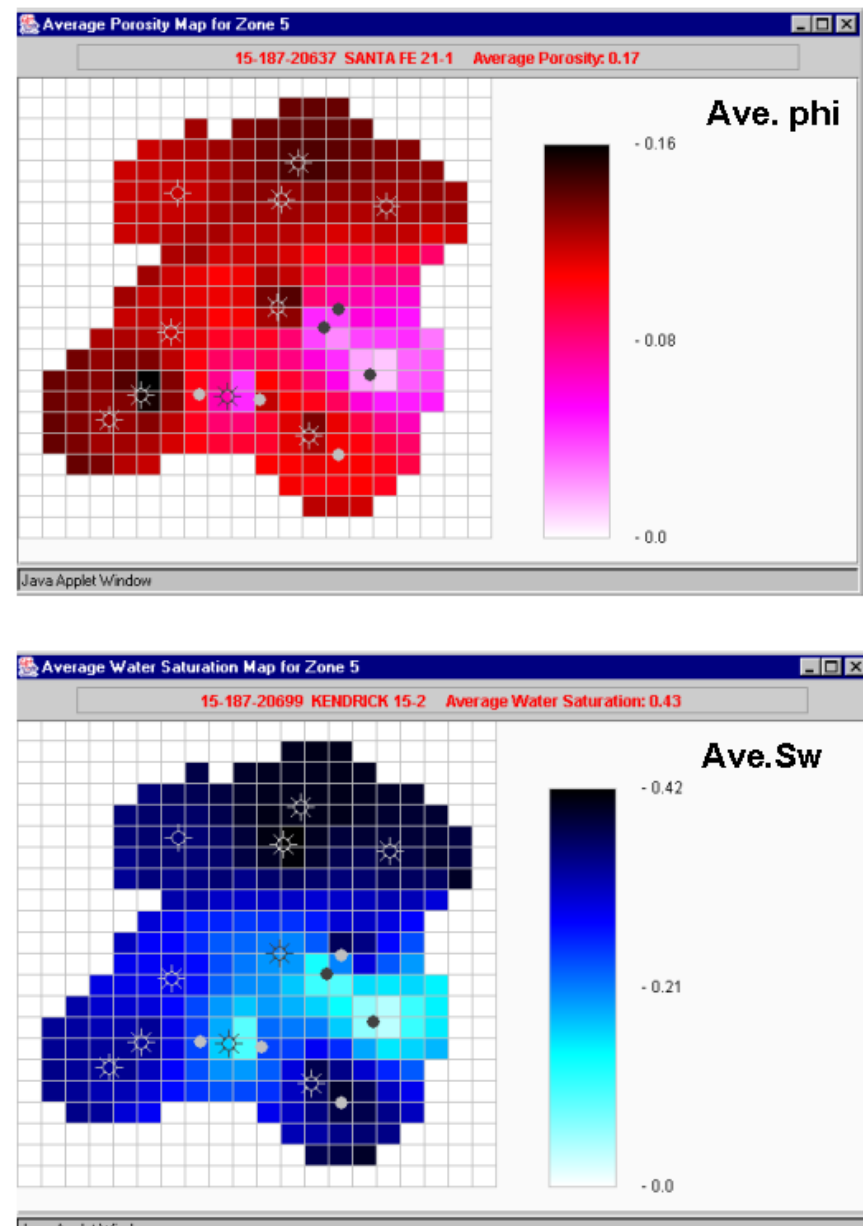

Java Applet Window

\section{Zone 5}

Figure 30. Parameter maps for Zone 5 in the Lower Morrow Sandstone in Arroyo Field, Kansas. Values derived from PfEFFER log analysis. Net pay uses cut-offs for water saturation, porosity, bulk volume water, and shale fraction. Average values of porosity and water saturation are derived from the effective pay. Grid size and interpolation functions are selected by the user. Colors table also selected by the user.

Information used in volumetric analysis can be modified in an iterative manner., changing parameters in log analyses, changing layer definition and correlation, and adding or deleting wells. Results will eventually be compared with production and material balance as further constraints to successful characterization. The net result will be a more robust geo-engineering model of the reservoir suited for simulation. 


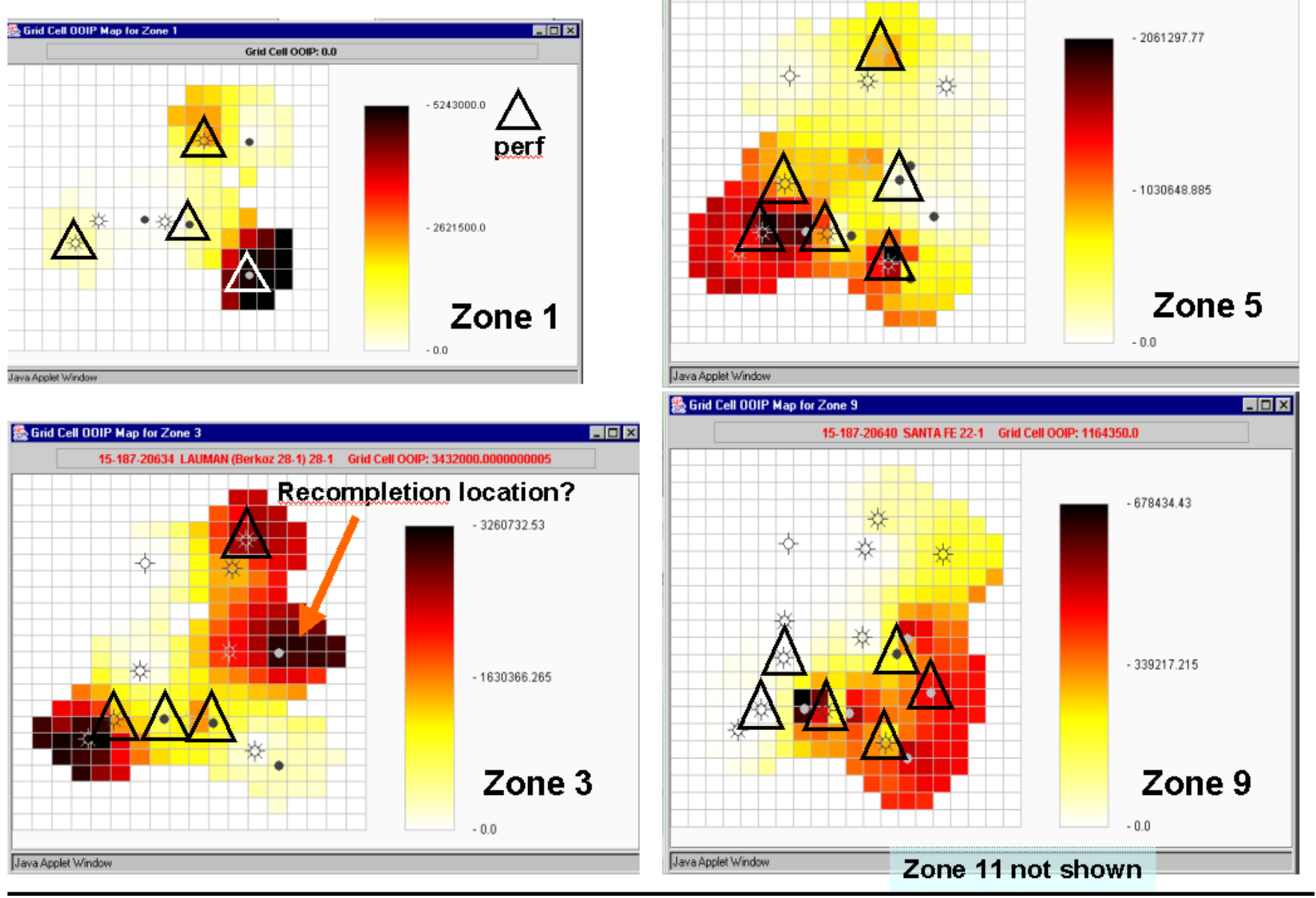

Figure 31. Set of maps from Arroyo Field showing original-oil-in-place (OOIP) for four of five layers. Grid cell size is a consistent 1000 feet. Darker, hotter colors reflect greater oil in place. Triangles indicated wells completed in particular layer/zone. Note well location in zone 3 is an opportunity for recompletion, if it can be further assessed that adjoining layers are not communicating with this interval.

\subsubsection{Production Bubble Maps}

Volumetric analysis provides maps of reservoir parameters and oil and gas in place. Production bubble map movies to be completed in year 3 will allow the user to directly compare lease production with the results from volumetric analysis. Prototype bubble map is shown in Figure 32.

Figure 32. Example of a bubble map of same project area as preceeding maps showing cumulative lease production.

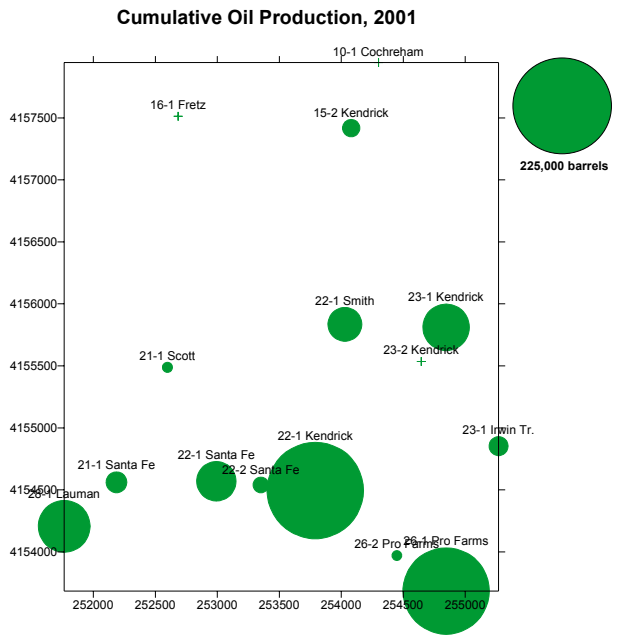




\section{Subtask 3.2. Material Balance Module}

Conceptual background and algorithms were prepared for the Material Balance Module. This module will assist the user in evaluation of drive mechanisms, confirm reservoir volumetrics, and aid in aquifer fitting, all prerequisite to reliable reservoir simulation. Basic concept is that the volume produced equals the expansion of oil \& dissolved gas plus the expansion of gas cap plus water influx plus the expansion of connate water and reduction of pore volume:

$$
\begin{aligned}
\mathrm{F} /\left(\mathrm{E}_{\mathrm{o}}+\mathrm{E}_{\mathrm{fw}}\right)=\mathrm{N}+\mathrm{W}_{\mathrm{e}} \mathrm{B}_{\mathrm{w}} /\left(\mathrm{E}_{\mathrm{o}}+\mathrm{E}_{\mathrm{fw}}\right) \\
\mathrm{F}=\text { vol. produced } \\
\mathrm{E}_{\mathrm{o}}=\text { expansion of oil \& dissolved gas } \\
\mathrm{E}_{\mathrm{fw}}=\text { expansion of formation water and pore volume reduction } \\
\mathrm{W}_{\mathrm{e}}=\text { water influx } \\
\mathrm{N}=\text { OOIP }
\end{aligned}
$$

The importance in reservoir characterization is to identify drive mechanism, confirm reservoir volumetric, and provide aquifer fitting. All of these parameters are ingredients to help insure fluid flow simulation.

For a bottom water drive reservoir that is above bubble point pressure, the material balance equation is:

water influx - Carter Tracy Aquifer model

simplified equation, $\mathrm{F} / \mathrm{E}=\mathrm{N}+\mathrm{W}_{\mathrm{e}} / \mathrm{E}$

$$
\begin{aligned}
& \text { where, } E=E_{o}+E_{f w} \\
& B_{w}=1
\end{aligned}
$$

\section{Subtask 3.3. Parameterization for Reservoir Simulation}

\subsubsection{PVT Calculator}

The PVT calculator estimates formation volume factors, viscosity, and compressibilities sued in the DST, volumetric and material balance modules. PVT can also be used as a stand-alone application (Figure 33).

\section{Provides input parameter(s) to modules}

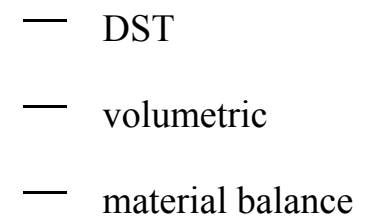




\section{Calculate}

$$
\begin{array}{ll}
\text { - } & \beta \text { - formation volume factors } \\
- & \mu \text { - viscosity } \\
- & \mathrm{c}-\text { compressibilities }
\end{array}
$$
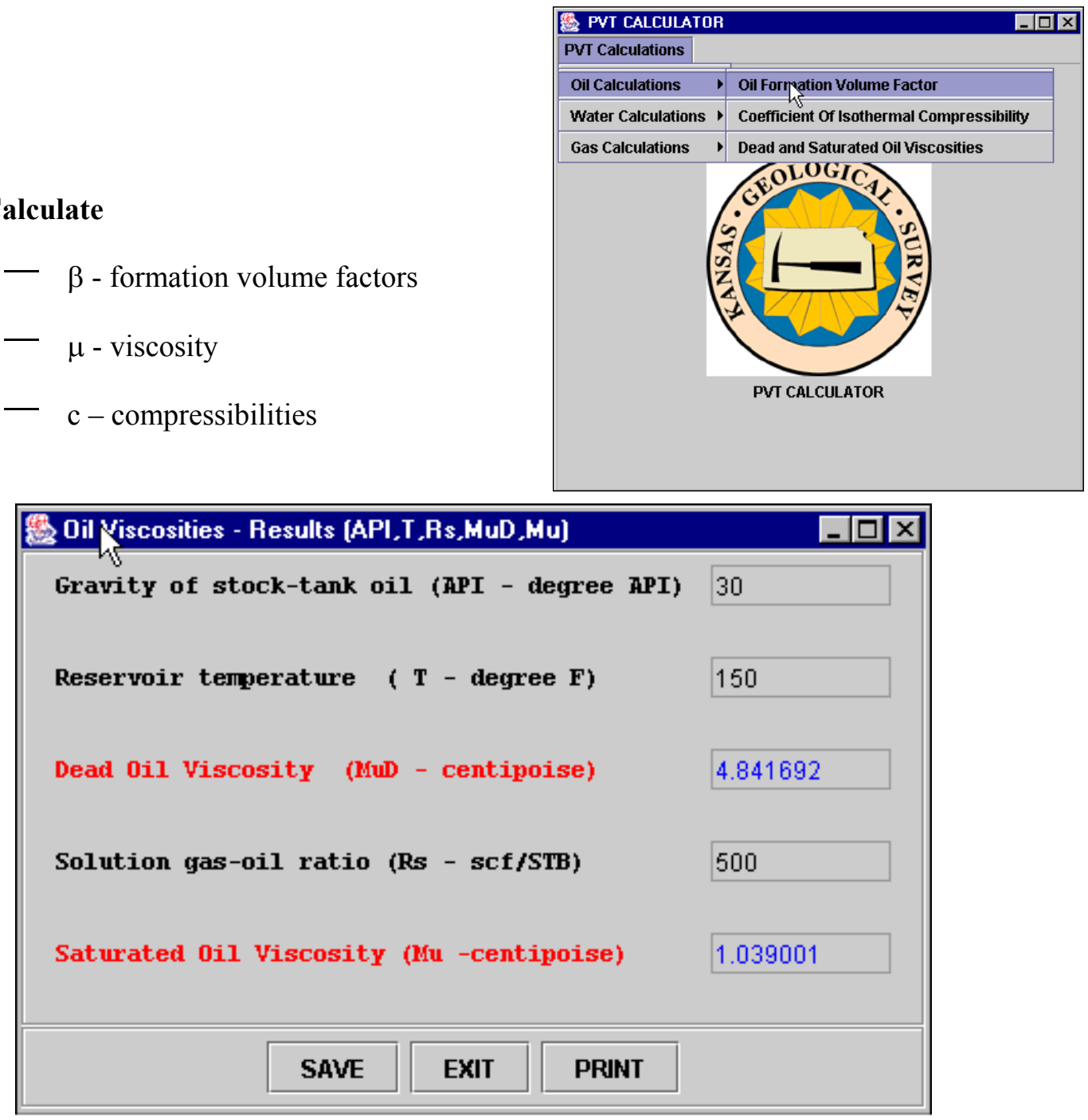

Figure 33. Example dialogs from the PVT Module.

\subsubsection{DST Analyst}

DST Analyst continues to be developed. It will conduct Horner analysis and calculate permeability, skin, and drainage radius from manually entered and digital DST information. Dialogs lead user through the analysis including: search for relevant DST data in KGS inventory, retrieve DST header information from digital file, initiate retrieval of DST data, select particular test data for analysis, display header info from selected test, display test and recovery info, and generate Horner plot. Program allows user to fit a line through the linear portion of the Horner Plot in real time. User is able to obtain a summary of $\mathrm{P}_{\mathrm{i}} \& \mathrm{~m}$ and fluid recovery details, to calculate initial \& final flow rates, and to define DST interval on well log graphic in Well Profile Module. Example applet windows are shown in Figure 34. 
Current development of the DST Module:

1. Input data from manual or digital file

Pressure vs. time data, shut-in \& flow times, test interval

Q

2. Build-up data plot - Pi, m

3. Output
$\mathrm{Pi}, \mathrm{m}, \mathrm{Q}, \beta, \mathrm{h}$ - calculate $\mathrm{K}$
$\phi, \mu, \mathrm{c}$ - calculate skin
$\beta, \mu$ - PVT module

Under construction in DST Module:

- Calculators for oil

- Permeability

- Skin

- $\operatorname{Re}$ (drainage radius)

- DST module for gas wells
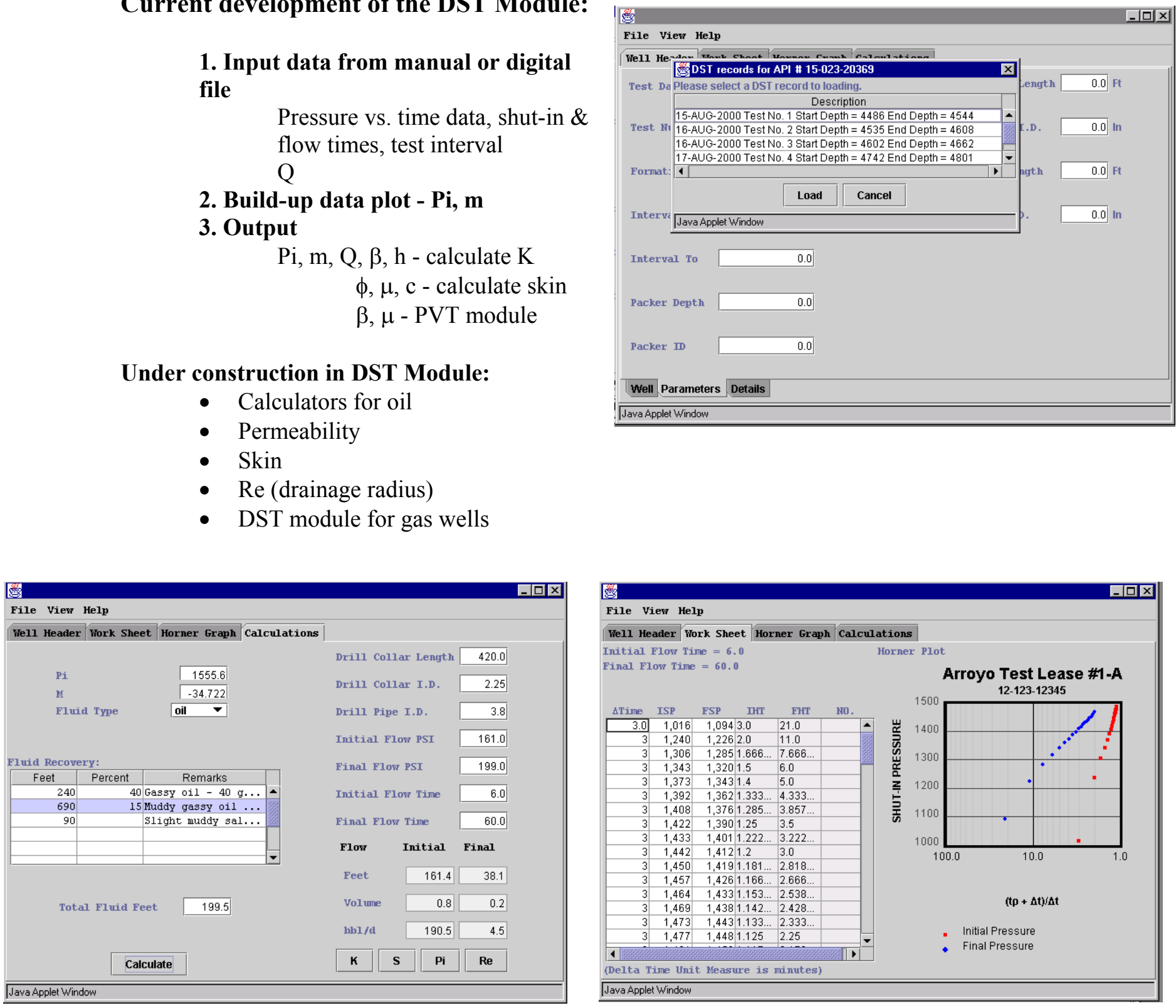

Figure 34. Selected dialogs from prototype DST Module showing those that help the user choose a particular test to analyze, examine table of pressure data and resulting Horner Plot, and obtain calculations of $\mathrm{P}_{\mathrm{i}}, \mathrm{M}$, and flow rate. Time and pressure data can be typed into the spreadsheet by the user, if the DST is not in digital form. 


\section{TASK 4. TECHNOLOGY TRANSFER}

\section{Subtask 4.1. Project Application and Testing}

\subsubsection{Industry partners affiliated with GEMINI}

Well data have been obtained from several partnering companies to test and evaluate the prototype software and to obtain focused feedback from company representatives including affiliates of Anadarko Production Corporation, BP, Lario Petroleum, Mull Drilling Company, Murfin Drilling Company, and Pioneer Resources. Test examples are also being drawn from well and lease databases resident on the Kansas Geological Survey website (http://www.kgs.ukans.edu/) and the Digital Petroleum Atlas (http://www.kgs.ukans.edu/DPA/dpaHome.html). Examples include reservoir characterization and volumetric analysis of 18 wells in the Arroyo Field, Stanton County, Kansas. GEMINI has also been utilized in regional analysis of pay in cyclic carbonates of the Middle and Upper Pennsylvanian Lansing, Kansas City, Marmaton groups involving 100 wells in Haskell County, Kansas. Results from both test cases are summarized in on the GEMINI website: http://www.kgs.ku.edu/Gemini/Presentations/KIOGA2002/index.htm). The Haskell County exploratory study is summaried below.

\subsubsection{Exploration Application of GEMINI}

GEMINI was applied to an exploration example to aid in the technology transfer effort. The example comes from Haskell County, Kansas. The objective is to define hydrocarbon log shows over an 800 feet interval of Middle and Upper Pennsylvanian age predominately carbonate strata (Figure 35). Porosity in these carbonate rocks in this area is predominately oomoldic where effective porosity is associated with touching oomolds and vugs and intercrystalline porosity. The difficulty in evaluating this petrofacies results from the complexity of pore types that creates considerable variation in cutoffs of effective pay. Generally, BVW and Sw are quite low. Possible pay zones can be initially screened through visual examination of well profiles when Sw and BVW are included in the presentation. Intervals of low values of BVW and Sw can be further analyzed using the PfEFFER log analysis module. Pickett crossplots can be depth-filtered to specifically examine patterns of points with low BVW and Sw values. The cross sections can be included to help define the lateral extent of the prospective pay zones.

One hundred LAS logs were used in this case study, with the Middle and Upper Pennsylvanian strata considered as one layer, including the entire 800-foot section of the Lansing, Kansas City, and Marmaton Groups (Figure 36). Intervals were identified and selectively analyzed using Pickett crossplots (Figure 37). The KHAN module will eventually be applied to directly evaluate "raw" LAS files using similar criteria for this pore type, but also for other petrofacies. The automated process to decipher pay from composite profiles in multiple wells will potentially save considerable amounts of time in targeting intervals for further evaluation (Figures 39 and 40). 


\section{Haskell County, Kansas}

- Evaluate potential for bypassed and underproduced pay in oomoldic lithofacies

- Use of PfEFFER, Cross Section, and Volumetrics

(with Rock Catalog, and DST and PVT calculators)

- Lansing, Kansas City, and Marmaton carbonates - project includes over 800 feet of section and 100 wells

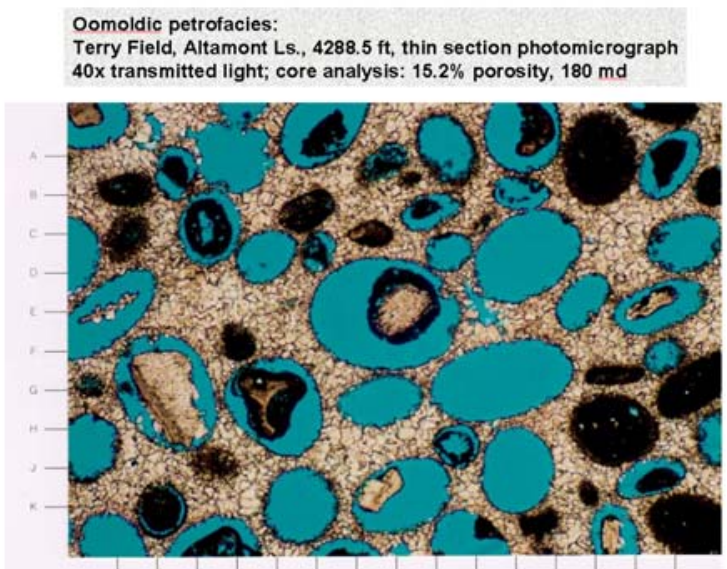

Figure 35. LAS dataset used in Haskell County to test use of GEMINI in an exploratory concept, defining prospective pay over large stratigraphic interval, subregional area, and using moderate sized LAS well database. Bypassed and underproduced pay are believed to be abundant in the stratigraphic interval examined.

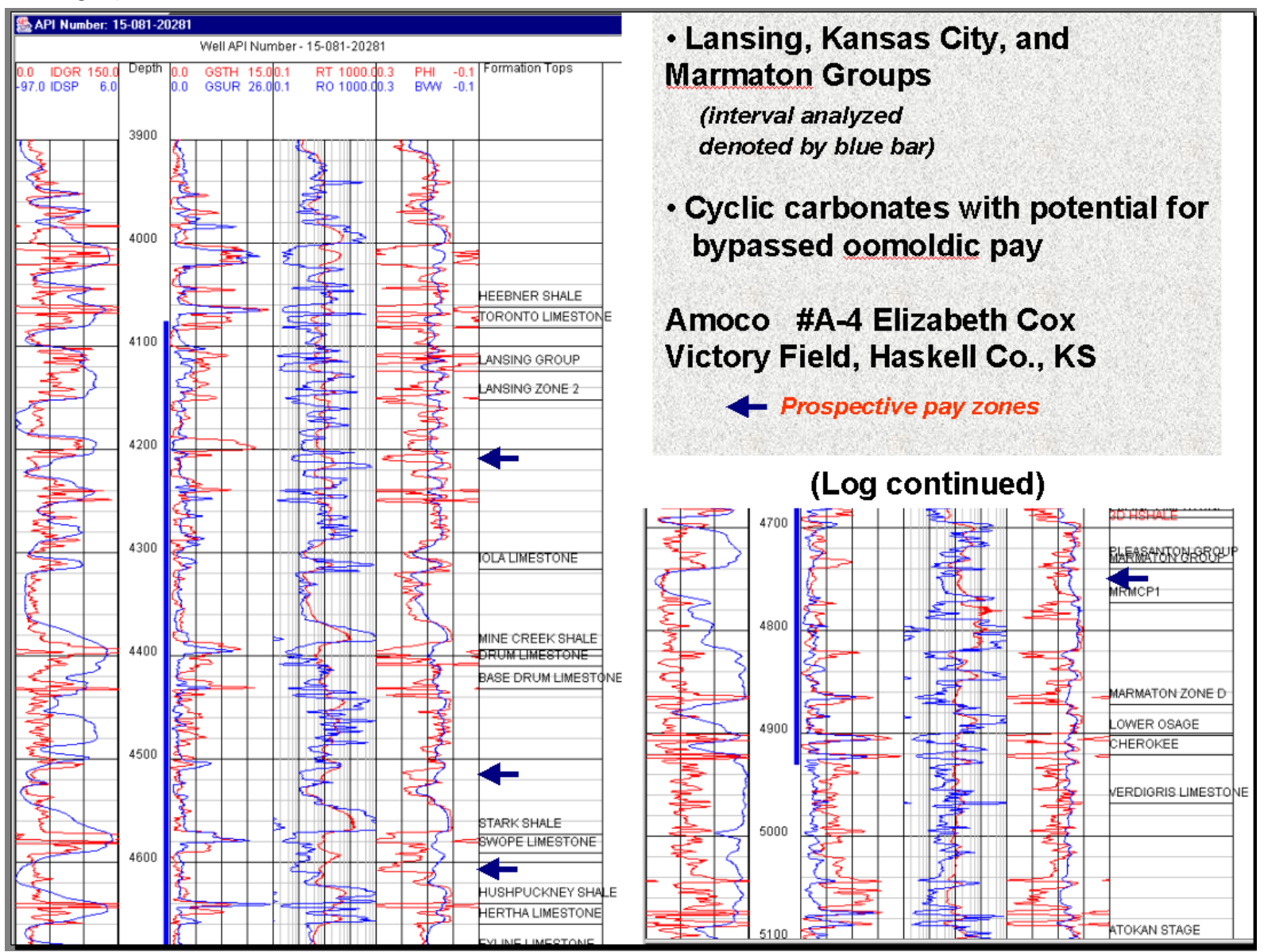

Figure 36. Example log profile of a well from the Haskell County database showing $800 \mathrm{ft}$ stratigraphic interval that is the target of the exploratory example. BVW and porosity are plotted together in tract 4 as a quick look technique to spot log shows. Specifically, low BVW relative to porosity is inferred as a "log show", delimited in this example by the blue arrows. 

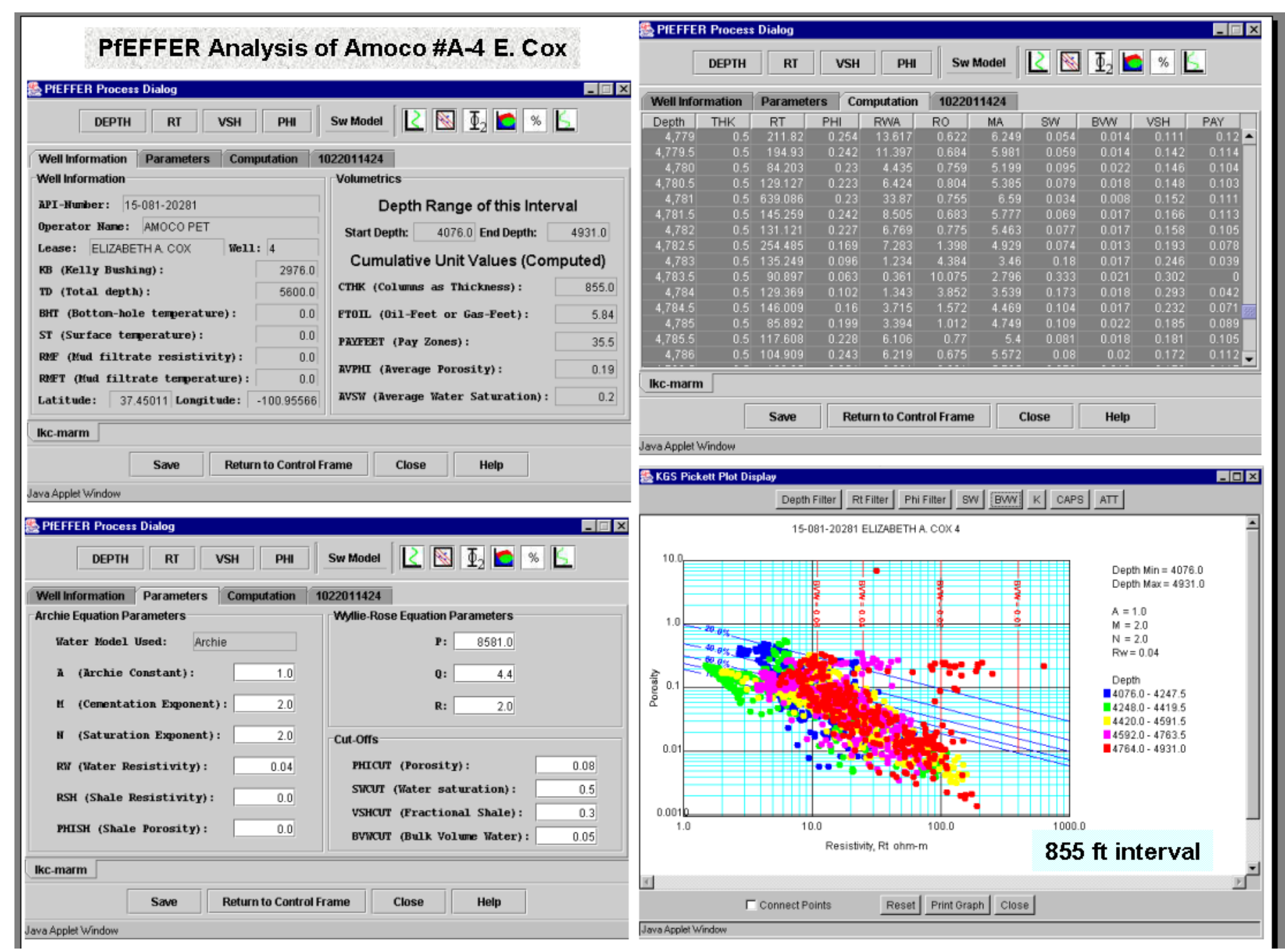

Figure 37. Dialog windows from PfEFFER log analysis showing reservoir cut-off parameters and Pickett crossplot of the total interval covering $855 \mathrm{ft}$ of Middle and Upper Pennsylvanian cyclic carbonates.

The depth-annotated Pickett cross plot of the entire $855 \mathrm{ft}$ interval in Figure 34 reveals several points that have high porosity, low water saturation, and low bulk volume water and appear to be good log shows. This particular well, the Amoco Cox \#A-4 was cored and the primary pore type is oomoldic. Typical cutoffs were applied to the PfEFFER log analysis to define "pay". In this screening exercise for pay, the user can now filter the Pickett crossplot by depth ranges to further isolate the interesting zones and better understand the patterns to determine additional characteristics of the potential reservoirs (Figure 38). 


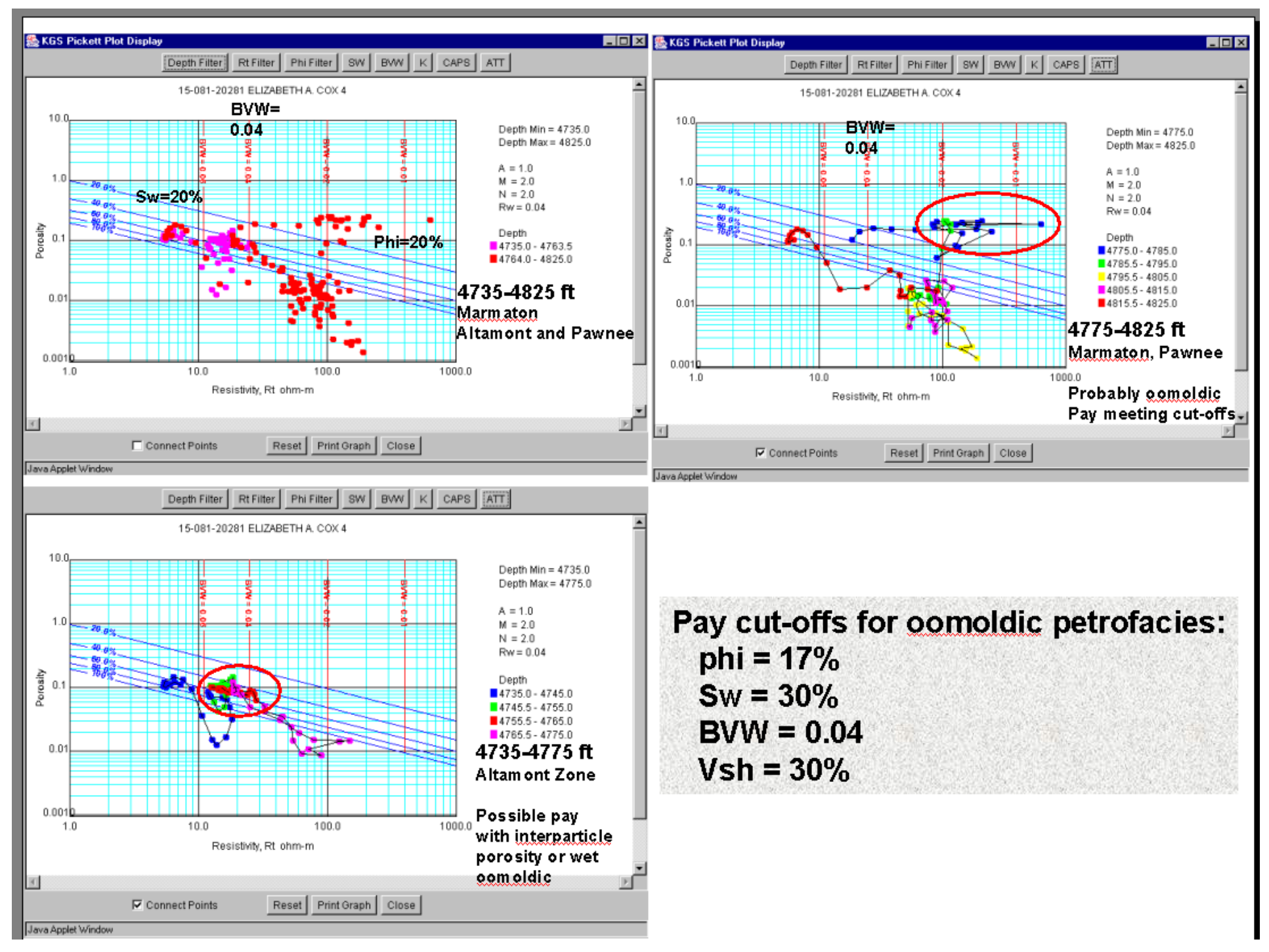

Figure 38. Depth-filtered Pickett crossplots examining potential pay zones.

The depth filtering of the Pickett crossplot was performed in two steps, first isolating two zones, the Altamont and the Pawnee Limestones. The depth plot in Figure 36 helped in delimiting the two cyclic limestone units. The plot in the upper left of Figure 38 shows that the interval contains the potential pay interval. This interval was further subdivided and the lines connecting the succession of points by depth were added for the other plots shown in Figure 38. The Altamont Limestone has points trending along a line parallel to the water saturation line at moderately low water saturations $(50 \%)$ and porosity $(10 \%)$, but higher BVW between 0.04 and 0.05 . This interval may represent interparticle pore type and marginal pay with finer pores higher in the potential reservoir. The most prospective pay is in the Pawnee Limestone interval shown in the upper right plot in Figure 38. The best potential pay is near the top of the reservoir and the BVW and 
Sw are very low while the porosity and resistivity are high. This is very characteristic of an oomoldic reservoir where the oomolds have either been crushed, fractured, or partly dissolved to create a complex network of touching vugs. Also, cements between the oomolds may exhibit intercrystalline porosity and total porosity may reach close to $35 \%$.

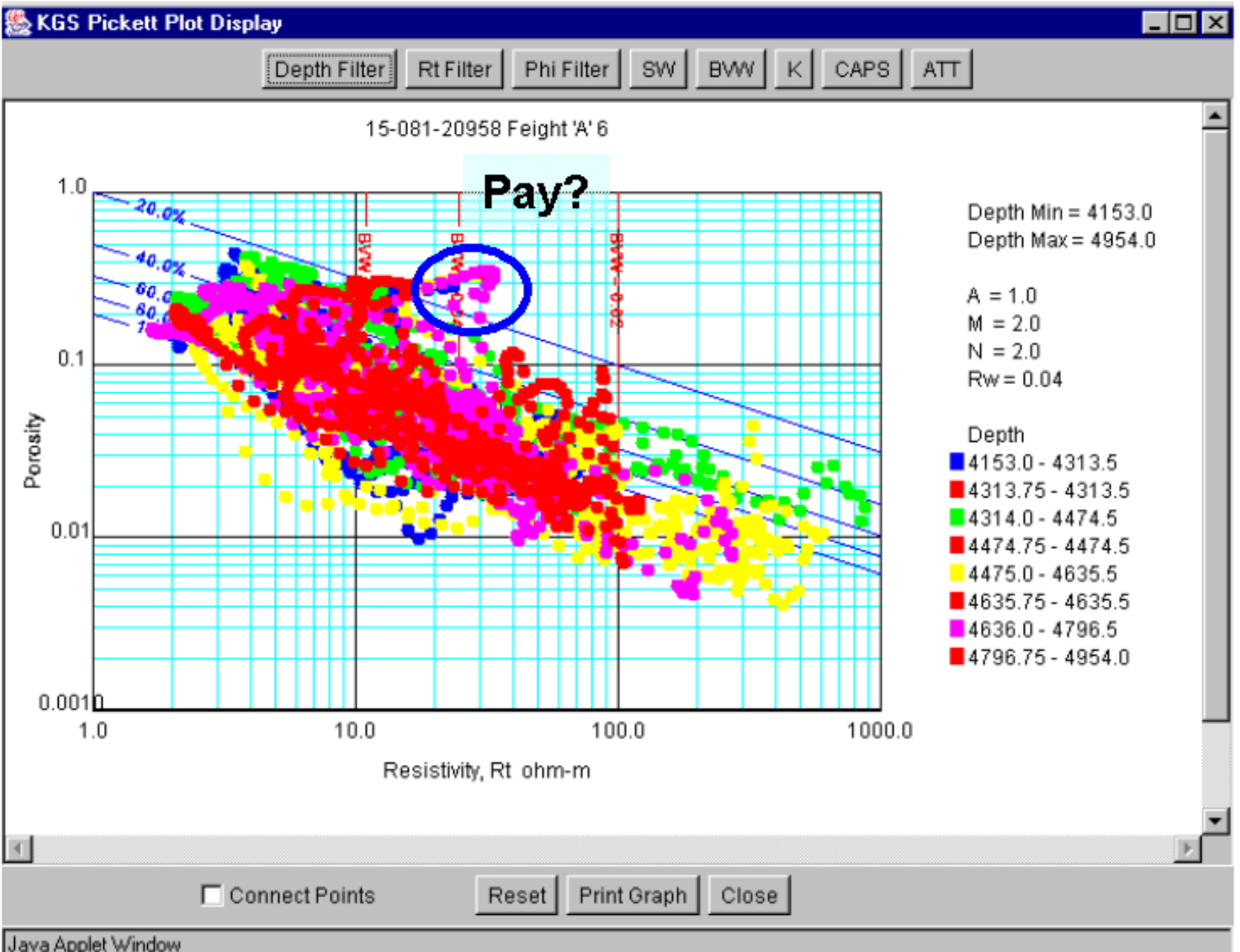

Figure 39. Pickett crossplot for entire 855-foot interval in new well exhibiting points with low Sw, relatively low BVW, and high porosity that may represent hydrocarbon pay. KHAN software would be used to automate the process of isolating these potential pays in this well and the other 100 LAS files in the project. Alternatively, the user can progress through the depth filtering and manually isolate potential pay zones. 

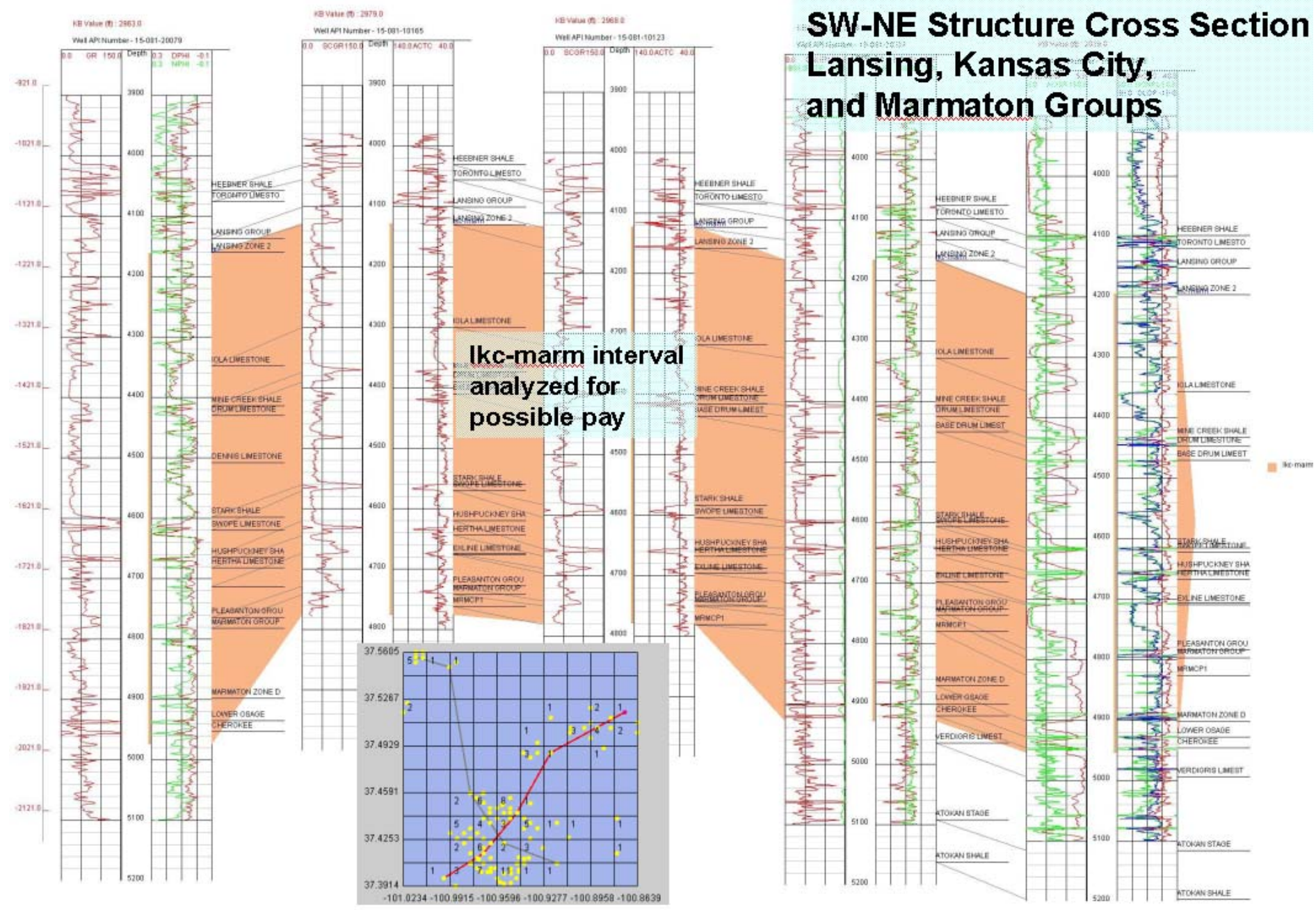

Figure 40. Structural wireline log cross section highighting 800+ $\mathrm{ft}$ thick Middle and Upper Pennsylvanian interval in Haskell County, Kansas. Base map in lower middle showing project area, 100 wells included in the project, and cross section index. Stratigraphic Interval consists of cyclic carbonate-dominated intervals. Plans are to automate pay detection based on KHAN module utilizing LAS files used to construct this or all 100 wells included in this project.

\subsubsection{Technology Transfer Opportunities}

Presentations have been given on GEMINI during second year of development:

Kansas Geological Society, November 15, 2001

Tulsa Geological Society, March 5,2002

AAPG/SEPM Annual Meeting, poster session, Houston, March 12, 2002

BP facilities for GEMINI team, Houston, March 2002

PTTC Reservoir Characterization Workshop, Wichita, April 23, 2002

Panhandle Geological Society, May 22, 2002

Anadarko Production Corporation, June 25, 2002

Kansas Independent Oil and Gas Association, August 19, 2002 
Future Plans:

Mid-Continent AAPG, 1 day workshop on GEMINI, October 2003

\section{Subtask 4.2. Concepts and Tutorial}

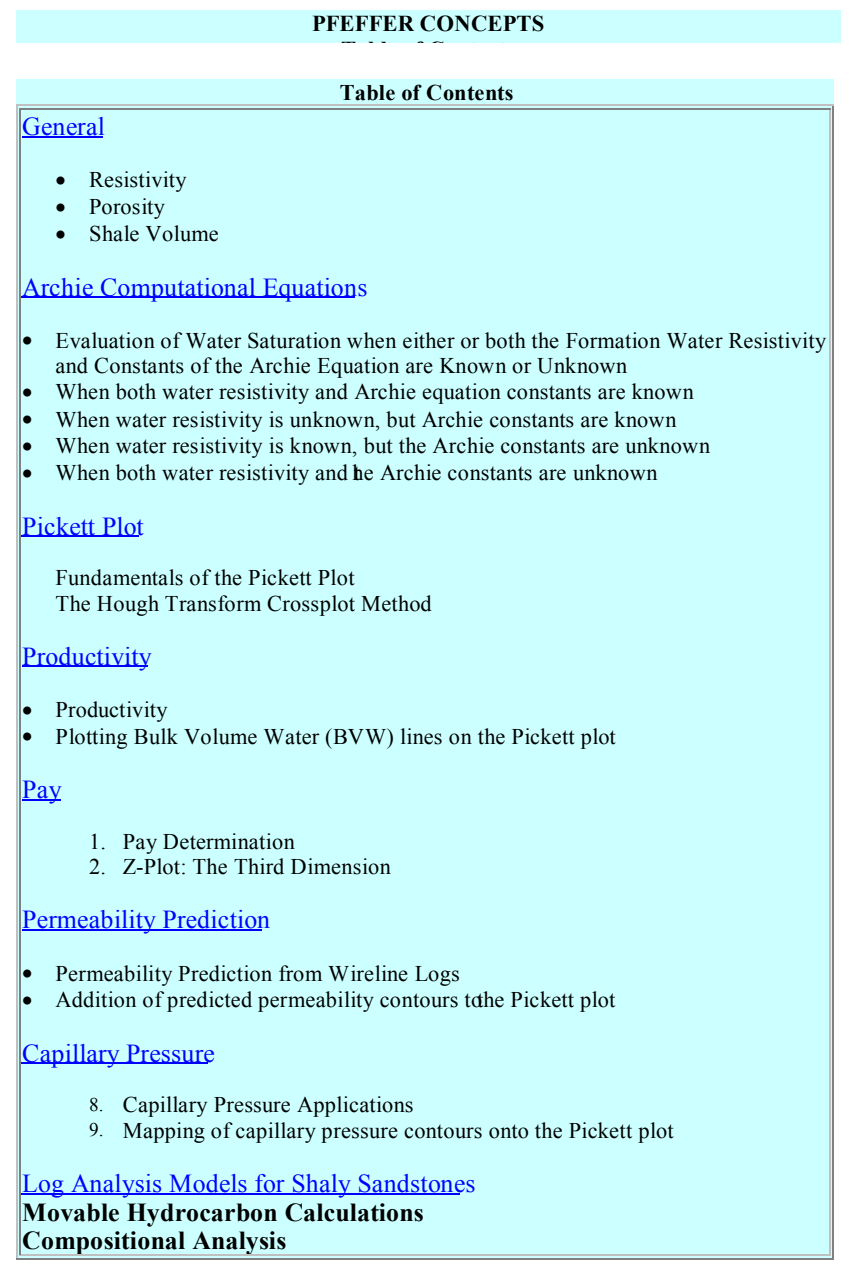

The concepts and tutorial are becoming available in GEMINI Help. Concepts is presented as a set of indexed web pages such as that shown in Figure 41. The concepts are linked to activities in the modules or can be accessed in their entirety as a manual to explain why and how the analysis is performed. Tutorial is a separate web document that provides step-by-step negotiation of GEMINI (Figure 42). With these two features, the user can obtain background on fundamentals behind the modules and learn how to use the program.

In addition to the concepts and tutorial, GEMINI workflow will suggest a path to obtain defined results and will document the path taken as modules accessed and parameters used in the analysis. Workflow will clarify the activities incorporated in the project to both user and his/her collaborating partners.

Figure 41. Example of interactive concepts web page used to understand background of GEMINI Modules. Web pages are indexed and linked back to modules for quick reference by user activating Help while using the program. 


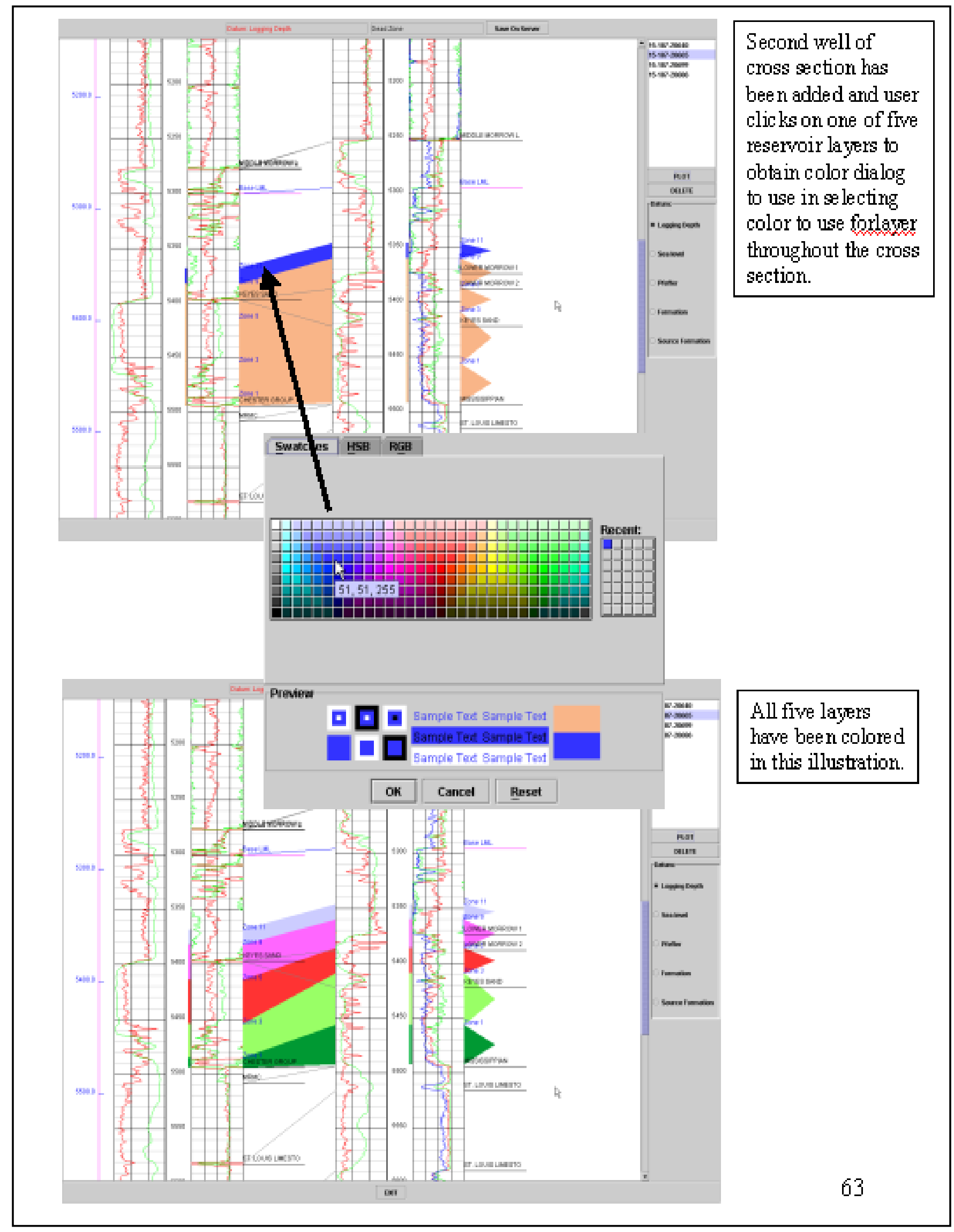

Figure 42. Page from Tutorial/Step-by-Step showing how to add colors to layers in construction of a cross section. 


\section{FUTURE PLANS}

Modules to be completed during 2003 include: KHAN (Kansas Hydrocarbon Association Navigator), Production Mapping corresponding to maps created in volumetrics, DST Analyst, Material Balance, and completion of Help/Tutorials. Additional developments in GEMINI include Workflow, File Output, Synthetic Seismogram, and Error Logging. Status can be reviewed on the GEMINI website: http://www.kgs.ukans.edu/Gemini/gemini-reports.html.

\section{SELECTED REFERENCES}

Bhattacharya, S., Watney, W.L., Doveton, J.H., Guy, W.J., Bohling, G., 1999, From geomodels to engineering models - Opportunities for spreadsheet computing: Gulf Coast Section Society SEPM, Advanced Reservoir Characterization for the Twenty-First Century, Nineteenth Annual Bob F. Perkins Research Conference, Gulf Coast Section, SEMP Foundation, Houston, TX. , p. 179-193.

Bohling, G. C., J. H. Doveton, and W. L. Watney, 1996, Systematic identification of sequence stratigraphic units from wireline logs, in Stratigraphic Analysis Utilizing Advanced Geophysical, Wireline and Borehole Technology For Petroleum Exploration and Production, Papers presented at the Gulf Coast Section SEPM 17th Annual Research Conference, p. 2937.

Bohling, G. C., J. H. Doveton, and P. Hoth, 1997, Probabilistic classification and prediction of facies types in a mid-continent cretaceous deltaic-marine sequence from petrophysical log descriptors using a CMAC procedure, in Proceedings of the Third Annual Conference of the IAMG, CIMNE, Barcelona, p. 242-247.

Doveton, J.H., Watney, W.L., and Guy, W.J., 2000, Integrated analysis of reservoir petrofacies in platform carbonates of Kansas: techniques and case studies, in Johnson, K.S., ed., Platform carbonates in the southern Midcontinent, 1996 symposium: Oklahoma Geological Survey Circular 101, p. 223-225.

Guy, W.J., 2002, A practical Log Analysis Guide to the Oil and Gas Fields of Kansas, PTTC Workshop, October $18^{\text {th }}$, Lawrence, KS.

Hagens, A., and J. H. Doveton, 1991, Application of a simple cerebellar model to geologic surface mapping, Computers \& Geosciences, Vol. 17, No. 4, p. 561-567.

Watney, W.L., W.J. Guy, J.H. Doveton, S. Bhattacharya, P. M. Gerlach, G. C. Bohling, T. R. Carr, 1999, Petrofacies Analysis - A petrophysical tool for geologic/engineering reservoir characterization: Proceedings of the Fourth International Reservoir Characterization Technical Conference, American Association of Petroleum Geologists Memoir 71, p. 73-90.

Watney, W.L., Guy, W.J., and Byrnes, A.P., 2001, Characterization of the Mississippian Osage Chat in South-Central Kansas: American Association of Petroleum Geologists Bulletin, v. 85, p. 85-114. 